\title{
eCommons@AKU
}

Woman and Child Health

Division of Woman and Child Health

November 2010

\section{Community-based intervention packages for reducing maternal and neonatal morbidity and mortality and improving neonatal outcomes}

Zohra S. Lassi

Aga Khan University

Batool A. Haider

Aga Khan University, batool.ali@aku.edu

Zulfiqar Ahmed Bhutta

Aga Khan University, zulfiqar.bhutta@aku.edu

Follow this and additional works at: https://ecommons.aku.edu/

pakistan_fhs_mc_women_childhealth_wc

Part of the Maternal and Child Health Commons

\section{Recommended Citation}

Lassi, Z., Haider, B., Bhutta, Z. A. (2010). Community-based intervention packages for reducing maternal and neonatal morbidity and mortality and improving neonatal outcomes. Cochrane Database of Systematic Reviews(11), 7754-7754.

Available at: https://ecommons.aku.edu/pakistan_fhs_mc_women_childhealth_wc/8 


\title{
Community-based intervention packages for reducing maternal and neonatal morbidity and mortality and improving neonatal outcomes (Review)
}

\author{
Lassi ZS, Haider BA, Bhutta ZA
}

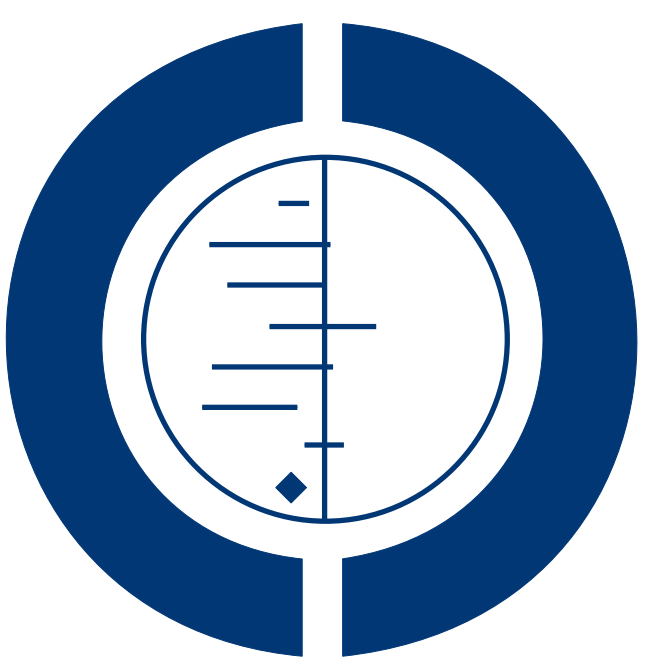

\section{THE COCHRANE COLLABORATION $^{\circledR}$}

This is a reprint of a Cochrane review, prepared and maintained by The Cochrane Collaboration and published in The Cochrane Library 2010, Issue 11

http://www.thecochranelibrary.com

\section{WILEY}

Community-based intervention packages for reducing maternal and neonatal morbidity and mortality and improving neonatal outcomes (Review)

Copyright $\odot 2010$ The Cochrane Collaboration. Published by John Wiley \& Sons, Ltd. 
TABLE OF CONTENTS

HEADER . . . . . . . . . . . . . . . . . . . . . . . . . . . . . . . . . . . . . . . . . . . . . . . .

ABSTRACT . . . . . . . . . . . . . . . . . . . . . . . . . . . . . . . . . . . . . . . . . . . . . . . . 1

PLAIN LANGUAGE SUMMARY . . . . . . . . . . . . . . . . . . . . . . . . . . . . . . . . . . . . . 2

BACKGROUND . . . . . . . . . . . . . . . . . . . . . . . . . . . . . . . . . . . . . . . . . . . .

OBJECTIVES . . . . . . . . . . . . . . . . . . . . . . . . . . . . . . . . . . . . . . . . . . . . . . .

METHODS . . . . . . . . . . . . . . . . . . . . . . . . . . . . . . . . . . . . . . . . .

RESULTS . . . . . . . . . . . . . . . . . . . . . . . . . . . . . . . . . . . . . . . . . . .

Figure 1. . . . . . . . . . . . . . . . . . . . . . . . . . . . . . . . . . . . . . . .

Figure 2. . . . . . . . . . . . . . . . . . . . . . . . . . . . . . . . . . . . . . . . .

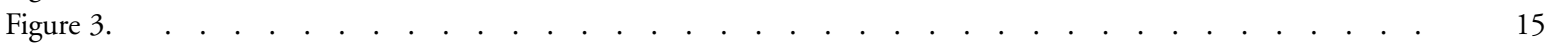

Figure $4 . \quad$. . . . . . . . . . . . . . . . . . . . . . . . . . . . . . . . . . . . . . . .

DISCUSSION . . . . . . . . . . . . . . . . . . . . . . . . . . . . . . . . . . . . . . . . . . . . .

AUTHORS' CONCLUSIONS . . . . . . . . . . . . . . . . . . . . . . . . . . . . . . . . . . . . . .

ACKNOWLEDGEMENTS . . . . . . . . . . . . . . . . . . . . . . . . . . . . . . . . . . . . . . . . . .

REFERENCES . . . . . . . . . . . . . . . . . . . . . . . . . . . . . . . . . . . . . . 20

CHARACTERISTICS OF STUDIES . . . . . . . . . . . . . . . . . . . . . . . . . . . . . . . . . . . . . .

DATA AND ANALYSES . . . . . . . . . . . . . . . . . . . . . . . . . . . . . . . . . . . . . . . . 53

Analysis 1.1. Comparison 1 Community-based intervention versus control, Outcome 1 Maternal mortality. $\quad$. . 56

Analysis 1.2. Comparison 1 Community-based intervention versus control, Outcome 2 Neonatal mortality. $\quad$. . $\quad 57$

Analysis 1.3. Comparison 1 Community-based intervention versus control, Outcome 3 Early neonatal mortality. . . 58

Analysis 1.4. Comparison 1 Community-based intervention versus control, Outcome 4 Late neonatal mortality. . . 60

Analysis 1.5. Comparison 1 Community-based intervention versus control, Outcome 5 Perinatal mortality. . . . . 61

Analysis 1.6. Comparison 1 Community-based intervention versus control, Outcome 6 Stillbirths. . . . . . . . 62

Analysis 1.7. Comparison 1 Community-based intervention versus control, Outcome 7 Mean birthweight. . . . . . 63

Analysis 1.8. Comparison 1 Community-based intervention versus control, Outcome 8 Maternal morbidity. . . . . 64

Analysis 1.9. Comparison 1 Community-based intervention versus control, Outcome 9 Complication of pregnancy: haemorrhage. . . . . . . . . . . . . . . . . . . . . . . . . . . . . . . . . . . .

Analysis 1.10. Comparison 1 Community-based intervention versus control, Outcome 10 Complication of pregnancy: obstructed labour.

Analysis 1.11. Comparison 1 Community-based intervention versus control, Outcome 11 Complication of pregnancy: puerperal sepsis. . . . . . . . . . . . . . . . . . . . . . . . . . . . . . . . . . . . . . . . . .

Analysis 1.12. Comparison 1 Community-based intervention versus control, Outcome 12 Complication of pregnancy: eclampsia.

Analysis 1.13. Comparison 1 Community-based intervention versus control, Outcome 13 Complication of pregnancy: spontaneous abortion.

Analysis 1.14. Comparison 1 Community-based intervention versus control, Outcome 14 Referal to health facility for any complication during pregnancy.

Analysis 1.15. Comparison 1 Community-based intervention versus control, Outcome 15 Institutional deliveries.

Analysis 1.16. Comparison 1 Community-based intervention versus control, Outcome 16 Birth attended by healthcare provider.

Analysis 1.17. Comparison 1 Community-based intervention versus control, Outcome 17 Initiation of breastfeeding within 1 hour of birth.

Analysis 1.18. Comparison 1 Community-based intervention versus control, Outcome 18 Healthcare seeking for maternal morbidities.

Analysis 1.19. Comparison 1 Community-based intervention versus control, Outcome 19 Healthcare seeking for neonatal morbidities.

Analysis 1.20. Comparison 1 Community-based intervention versus control, Outcome 20 Maternal mortality: low risk of bias studies.

Analysis 1.21. Comparison 1 Community-based intervention versus control, Outcome 21 Neonatal mortality: low risk of bias studies.

Community-based intervention packages for reducing maternal and neonatal morbidity and mortality and improving neonatal 
Analysis 1.22. Comparison 1 Community-based intervention versus control, Outcome 22 Perinatal mortality: low risk of bias studies.

Analysis 1.23. Comparison 1 Community-based intervention versus control, Outcome 23 Stillbirths: low risk of bias studies. . . . . . . . . . . . . . . . . . . . . . . . . . . . . . . . . . . . . 74 ADDITIONAL TABLES . . . . . . . . . . . . . . . . . . . . . . . . . . . . . . . . . . . . . . . . APPENDICES . . . . . . . . . . . . . . . . . . . . . . . . . . . . . . . . . . . . . 77 HISTORY . . . . . . . . . . . . . . . . . . . . . . . . . . . . . . . . . . 77 CONTRIBUTIONS OF AUTHORS . . . . . . . . . . . . . . . . . . . . . . . . . . . . . . . . . . . 77

DECLARATIONS OF INTEREST . . . . . . . . . . . . . . . . . . . . . . . . . . . . . . . . . . . . . . . . . . .

SOURCES OF SUPPORT . . . . . . . . . . . . . . . . . . . . . . . . . . . . . . . . . . . . . . . . .

DIFFERENCES BETWEEN PROTOCOL AND REVIEW . . . . . . . . . . . . . . . . . . . . . . . . . 78

INDEX TERMS . . . . . . . . . . . . . . . . . . . . . . . . . . . . . . . . . . . . 78 


\title{
[Intervention Review]
}

\section{Community-based intervention packages for reducing maternal and neonatal morbidity and mortality and improving neonatal outcomes}

\author{
Zohra S Lassi ${ }^{1}$, Batool A Haider ${ }^{1}$, Zulfiqar A Bhutta ${ }^{1}$ \\ ${ }^{1}$ Division of Women and Child Health, Aga Khan University Hospital, Karachi, Pakistan \\ Contact address: Zulfiqar A Bhutta, Division of Women and Child Health, Aga Khan University Hospital, Stadium Road, PO Box \\ 3500, Karachi, 74800, Pakistan. zulfiqar.bhutta@aku.edu.
}

Editorial group: Cochrane Pregnancy and Childbirth Group.

Publication status and date: New, published in Issue 11, 2010.

Review content assessed as up-to-date: 11 July 2010.

Citation: Lassi ZS, Haider BA, Bhutta ZA. Community-based intervention packages for reducing maternal and neonatal morbidity and mortality and improving neonatal outcomes. Cochrane Database of Systematic Reviews 2010, Issue 11. Art. No.: CD007754. DOI: 10.1002/14651858.CD007754.pub2.

Copyright (C) 2010 The Cochrane Collaboration. Published by John Wiley \& Sons, Ltd.

\begin{abstract}
A B S T R A C T
Background

While maternal, infant and under-five child mortality rates in developing countries have declined significantly in the past two to three decades, newborn mortality rates have reduced much more slowly. While it is recognised that almost half of the newborn deaths can be prevented by scaling up evidence-based available interventions such as tetanus toxoid immunisation to mothers; clean and skilled care at delivery; newborn resuscitation; exclusive breastfeeding; clean umbilical cord care; management of infections in newborns, many require facility based and outreach services. It has also been stated that a significant proportion of these mortalities and morbidities could also be potentially addressed by developing community-based packages interventions which should also be supplemented by developing and strengthening linkages with the local health systems. Some of the recent community-based studies of interventions targeting women of reproductive age have shown variable impacts on maternal outcomes and hence it is uncertain if these strategies have consistent benefit across the continuum of maternal and newborn care.
\end{abstract}

\section{Objectives}

To assess the effectiveness of community-based intervention packages in reducing maternal and neonatal morbidity and mortality; and improving neonatal outcomes.

\section{Search methods}

We searched The Cochrane Pregnancy and Childbirth Group's Trials Register (January 2010), World Bank's JOLIS (12 January 2010), BLDS at IDS and IDEAS database of unpublished working papers (12 January 2010), Google and Google Scholar (12 January 2010).

\section{Selection criteria}

All prospective randomised and quasi-experimental trials evaluating the effectiveness of community-based intervention packages in reducing maternal and neonatal mortality and morbidities; and improving neonatal outcomes.

\section{Data collection and analysis}

Two review authors independently assessed trial quality and extracted the data.

Community-based intervention packages for reducing maternal and neonatal morbidity and mortality and improving neonatal 


\section{Main results}

The review included 18 cluster-randomised/quasi-randomised trials, covering a wide range of interventional packages, including two subsets from one trial. We incorporated data from these trials using generic inverse variance method in which logarithms of risk ratio estimates were used along with the standard error of the logarithms of risk ratio estimates. Our review did not show any reduction in maternal mortality (risk ratio (RR) 0.77; 95\% confidence interval (CI) 0.59 to 1.02, random-effects (10 studies, $\mathrm{n}=144,956$ ), $\mathrm{I}^{2} 39 \%$, $\mathrm{P}$ value 0.10 . However, significant reduction was observed in maternal morbidity (RR $0.75 ; 95 \%$ CI 0.61 to 0.92 , random-effects (four studies, $\mathrm{n}=138,290$ ), I² 28\%; neonatal mortality (RR 0.76; 95\% CI 0.68 to 0.84 , random-effects (12 studies, $\mathrm{n}=136,425$ ), $\mathrm{I}^{2}$ $69 \%$, P value < 0.001), stillbirths (RR 0.84; 95\% CI 0.74 to 0.97 , random-effects ( 11 studies, $\mathrm{n}=113,821$ ), I2 66\%, P value 0.001 ) and perinatal mortality (RR 0.80; $95 \%$ CI 0.71 to 0.91 , random-effects (10 studies, $\mathrm{n}=110,291), \mathrm{I}^{2} 82 \%, \mathrm{P}$ value $\left.<0.001\right)$ as a consequence of implementation of community-based interventional care packages. It also increased the referrals to health facility for pregnancy related complication by $40 \%$ (RR 1.40; 95\% CI 1.19 to 1.65 , fixed-effect (two studies, $\mathrm{n}=22,800$ ), I2 $0 \%$, P value 0.76 ), and improved the rates of early breastfeeding by $94 \%$ (RR 1.94; 95\% CI 1.56 to 2.42, random-effects (six studies, $\mathrm{n}=20,627$ ), $\mathrm{I}^{2}$ $97 \%$, P value $<0.001)$. We assessed our primary outcomes for publication bias, but observed no such asymmetry on the funnel plot.

\section{Authors' conclusions}

Our review offers encouraging evidence of the value of integrating maternal and newborn care in community settings through a range of interventions which can be packaged effectively for delivery through a range of community health workers and health promotion groups. While the importance of skilled delivery and facility-based services for maternal and newborn care cannot be denied, there is sufficient evidence to scale up community-based care through packages which can be delivered by a range of community-based workers.

\section{PLAIN LANGUAGESUMMARY}

\section{Community-based intervention packages for preventing maternal and newborn illness and death and improving neonatal outcomes}

While women, newborn and under-five child death rates in developing countries have declined significantly in the past two to three decades, newborn mortalities have hardly changed. It is now been recognised that almost half of newborn deaths can be prevented by tetanus toxoid immunisation of the mothers; clean and skilled care at the birth; newborn resuscitation; exclusive breastfeeding; clean umbilical cord care; and management of infections in the newborns. In developing countries, almost two-thirds of births occur at home and only half are attended by a trained birth attendant. It has also been known that a large proportion of these deaths and diseases can be potentially addressed by developing community-based packaged interventions that should be integrated with local health systems.

The review authors found 18 randomised and quasi-randomised controlled studies evaluating the impact of community-based intervention packages for the prevention of maternal illness and death in improving newborn health outcomes. These studies were mostly conducted in developing countries (India, Bangladesh, Pakistan, Gambia, Nepal, Indonesia) with one additional study in Greece. Women in areas assigned to receive a community-based intervention package with health workers receiving additional training had decreased illnesses and complications during pregnancy and birth associated with decreased stillbirths, perinatal and neonatal deaths. Referrals rates to health facilities for pregnancy related complications, and initiation of breastfeeding within an hour of birth were also improved. This review offers encouraging evidence of the value of integrating maternal and newborn care in community settings through a range of strategies, many of which can be packaged effectively for delivery through a range of community health workers.

\section{B A C K G R O U N D}

The Millennium Development Goal for maternal health (MDG5) calls for a reduction in maternal mortality by two-thirds by the year 2015 (Sachs 2005). The estimates of maternal mortal- ity suggest that 342,900 (uncertainty interval 302,100-394,300) maternal deaths occurred worldwide in 2008 , and that more than $50 \%$ of these deaths occurred in six countries (India, Nigeria, Pakistan, Afghanistan, Ethiopia, and the Democratic Republic of 
the Congo) (Bhutta 2010). The maternal mortality ratio for subSaharan Africa was estimated to be nearly 600 per 100,000 live births: almost twice that of South Asia, four times as high as in Latin America and the Caribbean, and nearly 50 times higher than in industrialised countries (Hogan 2010). Most of these maternal deaths seem to occur between the third trimester and the first week after the end of pregnancy (Ronsmans 2006). Mortality has also been found to be extremely high on the first and second days after birth (Hurt 2002).

Almost $80 \%$ of maternal deaths are due to direct obstetric causes including severe bleeding (haemorrhage), infection, complications of unsafe abortion, eclampsia, and obstructed labour; with other causes being related to the unfavourable conditions created by lack of access to health care, illiteracy and factors related to poverty (Hoj 2003). Many women are estimated to suffer pregnancy-related illnesses (9.5 million), near-miss events which are the lifethreatening complications that women survive ( 1.4 million), and other potentially devastating consequences after birth (Ashford 2002; Say 2004; WHO 2000). The consequences of near-miss events on women themselves and their families can be substantial, and recovery can be slow, with lasting sequelae. An estimated 10 to 20 million women develop physical or mental disabilities every year as a result of complications or poor management (Ashford 2002; Murray 1998). The long-term consequences are not only physical, but are also psychological, social, and economic (Filippi 2006).

Pregnancy-related illnesses and complications during pregnancy and delivery are associated with a significant impact on the fetus, resulting in poor pregnancy outcomes (Walsh 1994). In developing countries, almost two-thirds of births occur at home and only half are attended by a trained birth attendant (WHO 1996). In the 1970 s the World Health Organization promoted training of traditional birth attendants (TBAs) as a major public health strategy to reduce the burden of mortality and morbidities related to pregnancy and childbirth. However, the evidence of the impact of this strategy on maternal and neonatal outcomes is still limited (Sibley 2007). Deaths occurring in the neonatal period (aged 0-27 days) account for $41 \%$ (3575 million) of all deaths in children younger than five years (Black 2010). In developing countries, most of the maternal, perinatal and neonatal deaths and morbidities occur at home. The reasons are multi-factorial, including poverty; poor health status of women; illiteracy; lack of information regarding the availability of health services/providers; lack of control on household resources and decision making authority; poor antenatal and obstetric care, both within the community and health facilities; absence of a trained attendant at delivery; inadequate referral system for emergency obstetric care; inadequate or lack of transportation facilities; and absence of/poor linkages of health centres with the communities (Ensor 2004). The majority of maternal and neonatal deaths could be prevented with early recogni- tion and proper implementation of required skills and knowledge (Ray 2004).

Soon after the Alma-Ata Declaration, arguments for selective rather than comprehensive primary health care dominated and it was then recognised that community participation was important in supporting the provision of local health services and in delivering interventions at the community level (Rosato 2008). Community participation has long been advocated to build links with improving maternal and child health and there are several trials from south Asia which have evaluated the role of women's groups on maternal and neonatal health. The Makwanpur trial, Nepal implemented a participatory learning cycle (in which they identify, prioritise a problem, select and implement relevant interventions and evaluate the results) through developing women's groups and found a reduction in maternal mortality by $88 \%$ and neonatal mortality by $30 \%$ but the same strategy in other trials have shown variable non significant impacts on maternal and neonatal outcomes (Azad 2010; Tripathy 2010). Another set of studies in which services were provided to women and children in the community indicated that, at full coverage, $41 \%$ to $72 \%$ of newborn deaths could be prevented by available interventions like tetanus toxoid immunisation to mothers; clean and skilled care at delivery; newborn resuscitation; prevention of hypothermia; exclusive breastfeeding; clean umbilical cord care; management of pneumonia and sepsis. Around half of this reduction is possible with communitybased Interventions (Darmstadt 2005). It has also been stated that a significant proportion of these mortalities and morbidities could also be potentially addressed by developing community-based intervention packages (package is defined as delivering more than one intervention via different set of strategies) which should also be supplemented by developing and strengthening linkages with the local health systems.

Some prior reviews have also generated evidences from reviewing community-based maternal and neonatal interventions trials (Bhutta 2005; Haws 2007) but those were not subjected to metaanalyses. Therefore, in this review we will not only assess the effectiveness of community-based intervention packages in reducing maternal and neonatal morbidities and mortality and improving neonatal outcomes but also the impact of different strategies (home visitation, home-based care, community support groups/ women's groups etc.) on the reported outcomes. This review will not evaluate the impact of training TBAs alone (Sibley 2007), or effectiveness of a health education strategy designed for mothers and other family members on newborn survival (Thaver 2009), as these are being evaluated in other reviews.

\section{O B J E C T I VES}

To assess the effectiveness of community-based intervention packages in reducing maternal and neonatal morbidity and mortality and improving neonatal outcomes. 


\section{METHODS}

\section{Criteria for considering studies for this review}

\section{Types of studies}

We included community-based, randomised or quasi-randomised controlled trials, irrespective of language or publication status in this review. We included both individual and cluster-randomised designs.

\section{Types of participants}

Women of reproductive age group, particularly pregnant women at any period of gestation.

\section{Types of interventions}

Intervention packages that included additional training of outreach workers (residents from community who are trained and supervised to deliver maternal and newborn care interventions to her target population) namely, lady health workers/visitors, community midwives, community/village health workers, facilitators or TBAs in maternal care during pregnancy, delivery and in the postpartum period; and routine newborn care.

Additional training was defined as training other than the usual training that health workers received from their governmental or non-governmental organisation and could include a combination of training in providing basic antenatal, natal and postnatal care; preventive essential newborn care, breastfeeding counselling; management and referral of sick newborns; skills development in behaviour change communication and community mobilisation strategies to promote birth and newborn care preparedness. The training sessions have been lectures, supervised hands-on training in a healthcare facility and/or within the community.

The control group in these studies was the one that received their usual maternal and newborn care services from local government and non-government facilities.

\section{Types of outcome measures}

We included studies if they assessed any of the following primary and secondary outcomes.

\section{Primary outcomes}

1. Maternal mortality was defined as number of maternal deaths per live births. Maternal death is defined as the death of a woman while pregnant or within 42 days of termination of pregnancy, irrespective of the duration and site of the pregnancy, from any cause related to or aggravated by the pregnancy or its management

2. Neonatal mortality was defined as the number of neonatal deaths from any cause among total live births:

- early neonatal mortality: neonatal deaths in the first week of life;

- late neonatal mortality: neonatal deaths from seven to 28 days of life.

\section{Secondary outcomes}

1. Perinatal mortality was defined as stillbirths and early neonatal deaths; that is, neonatal deaths in the first week of life among all stillbirths and live births.

2. Stillbirth was defined as fetal death after 28 weeks of gestation but before delivery of the baby's head per all births.

3. Low birthweight was defined as birth weight less than 2500 g.

4. Complications of pregnancy, including prolonged or obstructed labour, eclampsia, postpartum haemorrhage, postpartum depression (as defined by the authors).

5. Referral to a health facility for any complication during pregnancy, delivery, or the postpartum period.

6. Institutional delivery/delivery at a health facility.

7. Birth attended by a health provider (doctor, nurse, midwife or a trained health worker).

8. 1Initiation of breastfeeding within one hour of birth.

9. Exclusive breastfeeding at six months of age.

10. Health care seeking for maternal and/or neonatal morbidities.

11. Infant's weight for age and height for age $Z$ scores at six months of age.

\section{Search methods for identification of studies}

\section{Electronic searches}

We contacted the Trials Search Co-ordinator to search the Cochrane Pregnancy and Childbirth Group's Trials Register (January 2010)

The Cochrane Pregnancy and Childbirth Group's Trials Register is maintained by the Trials Search Co-ordinator and contains trials identified from:

1. quarterly searches of the Cochrane Central Register of Controlled Trials (CENTRAL);

2. weekly searches of MEDLINE;

3. handsearches of 30 journals and the proceedings of major conferences;

4. weekly current awareness alerts for a further 44 journals plus monthly BioMed Central email alerts. 
Details of the search strategies for CENTRAL and MEDLINE, the list of handsearched journals and conference proceedings, and the list of journals reviewed via the current awareness service can be found in the 'Specialized Register' section within the editorial information about the Cochrane Pregnancy and Childbirth Group.

Trials identified through the searching activities described above were each assigned to a review topic (or topics). The Trials Search Co-ordinator searches the register for each review using the topic list rather than keywords.

In addition, we searched the World Bank's JOLIS, British Library for Development Studies BLDS at IDS and IDEAS database of unpublished working papers, Google and Google Scholar. We carried out our search on January 12, 2010. See: Appendix 1 for search strategy.

We did not apply any language restrictions.

\section{Data collection and analysis}

\section{Selection of studies}

Two review authors, Zohra Lassi (ZSL) and Batool Haider (BAH), independently assessed for inclusion of all the potential studies we identified as a result of the search strategy. We resolved disagreement through discussion and, if required, we consulted a senior review author, Zulfiqar Bhutta (ZAB).

\section{Data extraction and management}

We designed a form to extract data. For eligible studies, two review authors (ZSL and BAH) independently extracted the data using the agreed form. We resolved discrepancies through discussion or, if required, we consulted a third review author. We entered data into Review Manager software (RevMan 2008) and checked for accuracy. When information regarding any of the above was unclear, we attempted to contact authors of the original reports to provide further details.

\section{Assessment of risk of bias in included studies}

Two review authors (ZSL and BAH) independently assessed risk of bias for each study using the criteria outlined in the Cochrane Handbook for Systematic Reviews of Interventions (Higgins 2009). We resolved any disagreement by discussion.

\section{I) Sequence generation (checking for possible selection bias)}

We described for each included study the method used to generate the allocation sequence in sufficient detail to allow an assessment of whether it should produce comparable groups. We assessed the method as:
- adequate (any truly random process, e.g. random number table; computer random number generator);

- inadequate (any non-random process, e.g. odd or even date of birth; hospital or clinic record number); or

- unclear.

\section{(2) Allocation concealment (checking for possible selection bias)}

We described for each included study the method used to conceal the allocation sequence in sufficient detail and determine whether intervention allocation could have been foreseen in advance of, or during recruitment, or changed after assignment. We assessed the methods as:

- adequate (e.g. telephone or central randomisation; consecutively numbered sealed opaque envelopes);

- inadequate (open random allocation; unsealed or nonopaque envelopes, alternation; date of birth);

- unclear.

\section{(3) Blinding (checking for possible performance bias)}

We described for each included study the methods used, if any, to blind study participants and personnel from knowledge of which intervention a participant received. We judged studies at low risk of bias if they were blinded, or if we judge that the lack of blinding could not have affected the results. We assessed blinding separately for different outcomes or classes of outcomes. We assessed the methods as:

- adequate, inadequate or unclear for participants;

- adequate, inadequate or unclear for personnel;

- adequate, inadequate or unclear for outcome assessors.

(4) Incomplete outcome data (checking for possible attrition bias through withdrawals, dropouts, protocol deviations)

We described for each included study, and for each outcome or class of outcomes, the completeness of data including attrition and exclusions from the analysis. We stated whether attrition and exclusions were reported, the numbers included in the analysis at each stage (compared with the total randomised participants), and if reasons for attrition or exclusion were reported. We assessed methods as:

- adequate;

- inadequate;

- unclear.

\section{(5) Selective reporting bias}

We described for each included study how we investigated the possibility of selective outcome reporting bias and what we found. We assessed the methods as: 
- adequate (where it is clear that all of the study's prespecified outcomes and all expected outcomes of interest to the review have been reported);

- inadequate (where not all the study's pre-specified outcomes have been reported; one or more reported primary outcomes were not pre-specified; outcomes of interest were reported incompletely and so cannot be used; study fails to include results of a key outcome that would have been expected to have been reported);

- unclear.

\section{(6) Other sources of bias}

We described for each included study any important concerns we have about other possible sources of bias. We assessed whether each study was free of other problems that could put it at risk of bias:

- yes;

- no;

- unclear.

\section{(7) Overall risk of bias}

We made explicit judgement about whether studies were at high risk of bias, according to the criteria given in the Handbook ( Higgins 2009). With reference to (1) to (6) above, we assessed the likely magnitude and direction of the bias. We explored the impact of the level of bias through undertaking sensitivity analyses for primary and some secondary mortality outcomes.

\section{Measures of treatment effect}

We carried out statistical analysis using the Review Manager software (RevMan 2008).

\section{Dichotomous data}

For dichotomous data, we presented results as summary risk ratio with $95 \%$ confidence intervals.

\section{Continuous data}

For continuous data, we used the mean difference if outcomes were measured in the same way between trials. We used the standardised mean difference to combine trials that measure the same outcome, but use different methods.

\section{Unit of analysis issues}

\section{Cluster-randomised trials}

We included cluster-randomised/quasi-randomised trials in the analyses along with individually randomised trials. We incorporated the data of cluster-randomised/ quasi-randomised trials using generic inverse variance method in which logarithms of risk ratio estimates were used along with the standard error of the logarithms of risk ratio estimates.

\section{Dealing with missing data}

For included studies, we noted levels of attrition. For all outcomes we carried out analyses, as far as possible, on an intention-to-treat basis; i.e. we attempted to include all participants randomised to each group in the analyses. The denominator for each outcome in each trial was the number randomised minus any participants whose outcomes were known to be missing.

\section{Assessment of heterogeneity}

We assessed statistical heterogeneity in each meta-analysis using the $\mathrm{T}^{2}, \mathrm{I}^{2}$ and $\mathrm{Chi}^{2}$ statistics. We regarded heterogeneity as substantial if $\mathrm{T}^{2}$ was greater than zero and either $\mathrm{I}^{2}$ was greater than $30 \%$ or there was a low $\mathrm{P}$ value $(<0.10)$ in the $\mathrm{Chi}^{2}$ test for heterogeneity. We also undertook exploratory subgroup analyses (described under the heading of subgroup analysis) of subsets of studies to generate hypotheses regarding the reasons for high levels of statistical heterogeneity where applicable.

\section{Assessment of reporting biases}

Where there are 10 or more studies in the meta-analysis we investigated reporting biases (such as publication bias) using funnel plots. We assessed funnel plot asymmetry visually. If asymmetry is suggested by a visual assessment, we performed exploratory analyses to investigate it.

\section{Data synthesis}

We carried out statistical analysis using the Review Manager software (RevMan 2008). We used fixed-effect meta-analysis for combining data where trials were examining the same intervention, and the trials' populations and methods were judged sufficiently similar or when heterogeneity was not sufficient on statistical grounds. On occasions where we suspected clinical or methodological heterogeneity between studies sufficient to suggest that treatment effects may differ between trials or when tests for heterogeneity found heterogeneity, we used random-effects meta-analysis. If we identified substantial heterogeneity in a fixed-effect meta-analysis, we noted this and repeat the analysis using a random-effects method (Deeks 2001). 


\section{Subgroup analysis and investigation of heterogeneity}

We pre-specified the following subgroup analysis to investigate heterogeneity.

- Content of intervention.

- Duration of training.

- Continued education after initial training.

- Baseline mortality (maternal, perinatal and neonatal).

- Presence/absence of community mobilisers, advocacy or support groups.

- Involvement of other family members through community mobilisation (husband, mother-in-law).

- Linkages to healthcare system.

\section{Sensitivity analysis}

We performed sensitivity analyses based on the randomisation process, with quasi-randomised studies being excluded. We performed sensitivity analyses assessing the presence of adequate sequence generation and allocation concealment in the primary outcomes.

\section{RE S U L T S}

\section{Description of studies}

See: Characteristics of included studies; Characteristics of excluded studies.

See Characteristics of included studies; Characteristics of excluded studies; Table 1.

\section{Results of the search}

We identified a total of 30,183 (after removing duplicates) titles and abstracts, written in English and other languages. We considered 84 (42 original) full-text papers for inclusion in this review, and eventually determined that 27 (18 original projects) were eligible for inclusion. All, except one study (Bhutta 2010), were published journal articles. We included results from two intervention arms (two sub sets) of Baqui 2008 and reported them as Baqui -home care (a) 2008; Baqui-com care (a) 2008.

\section{Setting}

Five studies were conducted in India (Bang 1999; Baqui-CARE INDIA 2008; Kumar 2008; Srinivasan 1995; Tripathy 2010), five in Bangladesh (Azad 2010; Bari 2006; Baqui -home care (a) 2008; Baqui-com care (a) 2008; Ronsmans 1997; Syed 2006) three in Pakistan (Bhutta 2008; Bhutta 2010; Jokhio 2005), two in Gambia (Foord 1995; Greenwood 1990), one in Nepal (Manandhar
2004), one in Indonesia (Alisjahbana 1995), and one in Greece (Kafatos 1991).

\section{Outcomes}

These studies reported multiple effect measures and many did not specify a primary outcome. We extracted relevant outcomes (reported as events and population size along with RR and OR) and categorised them for the analysis according to the results detailed below and in Table 1; Characteristics of included studies.

\section{Included studies}

We have provided a comparison of the characteristics of the included studies in Table 1. Also see the Characteristics of included studies.

The study from Gambia by Greenwood 1990 was conducted for a period of five years. The study was conducted on 1913 women aged 15 to 44 years with intervention and control arms. In August 1983, the Gambian government introduced a PHC program in the Ferafenni district. Traditional birth attendants (TBAs), who were generally elderly and illiterate, from that area were selected and trained for 10 weeks on advising women on antenatal and postnatal care and delivering women at home. Afterwards, PHC areas were compared with non-PHC areas. In non-PHC areas, health services were provided by government health staff. On initial survey, none of the TBAs were found to be trained in intervention and control arms, and hospital trained midwives in PHC areas were $15 \%$ as compared to $16 \%$ in non-PHC areas.

Another included study from Florina, Greece (Kafatos 1991) was a randomised controlled trial. Clinics were randomised to minimise contamination. Florina's 20 clinics were randomly divided into intervention and control arms, and 300 women from intervention clinics and 268 from control clinics were selected. Nurses were intensively trained for health and nutrition counselling. Women and newborns were targeted at homes because of non-attendance and infrequent attendance. During home visits, emphasis was given on nutrition counselling along with general hygiene, preparation of pregnancy. They also covered topics like appropriate feeding, breastfeeding, infant hygiene, clothing, immunisation, and stimulation exercises to improve psychomotor development in infants. Furthermore, each mother was given picture booklets which provided above mentioned information in a simplified manner. On the other hand, women from control clinics received care from government health services. The characteristics of women in term of age, parity, socioeconomic status was similar in intervention and control arms.

In Foord 1995, TBAs were trained in the intervention areas for early identification and registration of pregnant women in an antenatal care program. Control areas received standard care from their local health facilities. A total of 1516 women were selected from both intervention and control villages. Before the project 
began villages were served by an $\mathrm{MCH}$ teams and primary health workers consisting of community heath nurses and trained TBAs and village health workers. Community health nurses from the local health centre provided supervision.

The study conducted in Bangladesh (Alisjahbana 1995) was a longitudinal study which followed pregnant women over a 15-month period in an implementation and control area. These areas were located in West Java, Indonesia. In this study, TBAs were given training in detection or pregnancy complication and taking appropriate action in terms of referrals. Control areas received routine services from government healthcare facilities and hospitals. The women in the intervention and control arms were similar in all traits except parity, occupation, father's occupation, house ownership, unsafe water supply and poor sanitation, and previous abortion history. Data were gathered on 3275 women from the intervention and control arms.

The trial conducted in India (Srinivasan 1995) was a randomised controlled trial from Tamil Nadu, India. Three sub-centres were selected at random from among those beyond $10 \mathrm{~km}$ pf PHC. One each was randomly allocated to high-risk package, Tamil Nadu Government (TNG) package and control. All packages were implemented by trained female ancillary nurse midwives (ANMs), who were trained for six weeks on a general training programme, and for six weeks on a special training programme to detect and treat maternal and neonatal infections. In the high-risk package, ANMs detected pregnancies, registered them, and measured height, weight, haemoglobin; testing urine, etc. They also distributed folic acid tablets, and administered two doses of tetanus toxoid as recommended under the universal immunisation programme. On the screening as high-risk mothers, mothers were advised to have delivery at hospitals, and three postnatal visits were made by ANMs to detect and treat infections in mothers and neonates. In the TNG package, a set of routine antenatal care services recommended by local provincial government was implemented. The characteristics of the study population at registration were broadly similar in the three groups. Total of 45,154 participants was covered in these packages; however, analysis was performed on only 1623 women.

Ronsmans 1997 was conducted in Matlab, Dhaka, Bangladesh. In 1977, the government of Bangladesh trained TBAs who were already working in the community. Those areas then delivered extensive services in health and family planning and were called as MCH-FP areas. In 1987, a programme incorporating outreach services by trained midwives with an active referral system was implemented in Matlab, Bangladesh. In total, they trained 80 female community health workers who delivered services during twice-monthly home visits. Control areas were not intervened with such intensive health inputs. A total of 44,916 livebirths from intervention and comparison areas were covered.

Bang 1999 was conducted in Gadchiroli district of India (Maharashtra state) with the aim that the home-based neonatal care package for the management of sepsis would reduce the neonatal mortality rate. They trained female village health workers to take histories of pregnant women, observe the process of labour, examine neonates, and record finding. Furthermore, they were given colour photographs of various neonatal signs for visual reference. In the first year of intervention they listened to pregnant women in the village, collected their data by home visits, observed labour and neonates. In the second year, female village health workers were trained in home-based management of neonatal illnesses, and in the last year, health education of mothers and grandmothers about care of pregnant women and of neonates were added to the programme. Training of TBAs and management of pneumonia in children was not given by the project team in the control area, where these tasks were done by the government health services and the Integrated Child Development Service (ICDS) workers. The crude birth rate in the last year was $24.4 / 1000$ population in the intervention cluster and 23.7/1000 population in the control clusters. The total livebirths in intervention and control clusters were 1108 and 979 respectively. Baseline characteristics of intervention and control arm were similar at statistical grounds. The neonatal mortality rates at the baseline in the intervention arm were 62/ 1000 live births and among the control group was 57.7/1000 live births. On the other hand, perinatal mortality rates among the intervention and control arms were 68.3/1000 births and 64.9/ 1000 births respectively.

The study conducted by Manandhar 2004 in Makwanpur district of Nepal was a cluster-randomised controlled trial. The study was conducted with the aim of reducing neonatal deaths with community-based participatory interventions. As the first step of intervention they discussed issues around childbirth and care behaviours in the community. On the basis of a baseline service audit, they equipped primary health centres in the study areas with resuscitators, phototherapy units, warm cots and neonatal resuscitation equipment and essential neonatal drugs. Furthermore, they trained all cadres of government health staff and for CHWs and TBA on essential newborn care. CHWs also received a basic newborn care kit. Equipment in health centres and training to government staff were also provided in control areas. Baseline characteristics in the intervention and control arms were similar except the median number of household per cluster was lower in the control arm. The total numbers of pregnancies, deliveries, live births and breastfed infants in the intervention clusters were 3190, 2945, 2899 , and 2864 respectively, while those in control clusters were 3524, 3270, 3226, and 3181 .

The study conducted in Pakistan (Jokhio 2005) was a clusterrandomised, controlled trial involved seven sub-districts of rural district of Larkana, Sind, Pakistan. The intervention designed for the study was to facilitate care based in the available infrastructure and to be low cost and substantial. TBAs in the intervention arm were trained by obstetricians and female paramedics. TBAs were trained for three days; training involved the use of pictorial cards containing advice on antepartum, intrapartum and postpartum care, how to conduct clean delivery, use of disposable delivery kits, 
when to refer women for emergency obstetric care, and care of the newborn. They also visited women in the antenatal and postnatal periods to check for danger signs and to encourage women with such signs to seek emergency obstetrical care. TBAs were instructed to register all pregnant women in their catchment areas and to inform the Lady Health Workers (LHW) about the pregnant women under their care. In the control arm, LHWs followed up all pregnant women in their catchment area in their course of their monthly home visits to women and children. A total of 19,525 women completed follow-up, while the total number of singleton births during the trial period was 18,699 . Baseline maternal characteristics were similar for the study groups across the clusters except for the years of education, which was slightly greater among women in the control group.

Syed 2006 was a quasi-randomised controlled study which evaluated the impact of essential newborn-care interventions in Saving Newborn Lives project areas of Dhaka, Bangladesh. The projects targeted primarily pregnant mothers and family decision-makers, such as husbands, mothers-in-law, caregivers (both formal and informal), and village leaders, The study gathered data from 6435 women. The primary activities for the programme included: training, service-delivery behaviour change communication, advocacy to improve care during delivery, postnatal and neonatal periods, and referral of sick newborns. The frontline health workers, paramedics, and local TBAs were trained on newborn care following the cadre-specific training modules. A behaviour change-communication strategy was developed based on findings of formative research and interventions-targeted messages on key healthful behaviours, such as birth-preparedness, clean delivery, early and exclusive breastfeeding, immediate drying and warming, and major danger signs. The postnatal visit strategy included two or more contacts with the mother and newborn by the health workers at home within the first week of delivery, with the first visit within three days. Programme planning, development of materials, implementation, and routine monitoring were carried out jointly by Save the Children-USA, partner NGOs, and professional bodies to ensure adequate support and sustainability. On the other hand, no such interventions were delivered in control clusters. The baseline characteristics of women and newborn in the project implemented areas were similar to control areas, except of mothers' education.

The study from Bangladesh (Bari 2006) was a cluster-randomised trial with two arms: an intervention arm with $\mathrm{CHW}$ delivering a package of maternal and newborn-care interventions in the home, and a comparison arm. For this study $36 \mathrm{CHWs}$ were recruited and provided with one month of training to equip them to provide a package of maternal and newborn care. These CHWs had education equivalent to grade 10 and were residing in the population they would serve. Each CHW was responsible for a population of 4000, and they assessed 794 sick children during this period. In the control arm, interventions by $\mathrm{CHW}$ were not delivered while they were served by the same hospital.
Another study in India (Baqui-CARE INDIA 2008) was a quasiexperimental design which covered 13,826 women from intervention and comparison clusters. This study evaluated the effect of a community-based package for maternal and newborn interventions that was implemented using existing government infrastructure through an Integrated Nutrition and Health Programme (INHP) in partnership with NGO, CARE-India in eight states of India. This study evaluated the outcomes in two rural districts of Uttar Pradesh, India. In both the INHP and standard government health services, health education was provided by two groups of government functionaries: auxiliary nurse-midwives (ANM), and maternal and child health promotion (anganwadi) workers. ANMs made home visits to promote home care and care seeking, attend deliveries, provide immunisation and encourage of family planning methods. Anganwadi workers served one village and operated a facility called an anganwadi centre. They promoted maternal, newborn, and child health services from fixed sites and through home visits; distributed supplementary food to poor families; and provided preschool education. They were also encouraged to recruit community volunteers to further improve the reach of the programme. These three kind of workers received six days of training on the care of mothers and newborn babies. No interventions were provided to the control arm. Baseline characteristics of intervention and comparison at baseline and end line were all significant. The neonatal mortality rate at baseline in the control arm was 47.8/1000 live births and in the intervention arm was 49.2/1000 live births.

Kumar 2008, conducted in Shivgarh, Uttar Pradesh, India was a clustered-randomised controlled trial. This study was conducted with the aim that an intervention based in a socioculturally contextualised approach of behavior management with an emphasis of hypothermia, within a community with a high neonatal mortality rate, could lead to improved care practices and reduced mortality. The intervention package of essential newborn care broadly categorised into birth preparedness, hygienic delivery, and immediate newborn care including skin-to-skin care, breastfeeding and care seeking from trained providers. They hired community-based health workers, the Saksham Sahayak for behaviour change and were given a combination of classroom and apprenticeship-based field training over seven days related to essential newborn care. They also targeted community stakeholders (community leaders, priests, and teachers), newborn stakeholders (birth attendants, unqualified medical care providers, and healthcare workers) and household target groups (father-in-law, husbands, mother-in-law, pregnant women or mother, neighbours, and relatives). On the other hand, control clusters received the usual services of governmental and non-governmental organisations working their areas. The key baseline characteristics for the three study arms were similar. Total number of deliveries analysed at the end were 3837 , and the total of 3859 births and 3688 live births in intervention and control clusters were reported during the study period. At baseline stillbirth per 1000 births in control arm was 27.2 and in interven- 
tion arm was 24.4. The neonatal deaths in the control arm were $54.2 / 1000$ live births and 64.1/1000 live births in the intervention arm. Perinatal deaths among the control arm were $60 / 1000$ births and in the intervention arm 68.4/1000 births.

Another study from Pakistan (Bhutta 2008) was a pilot phase of a cluster-randomised controlled trial (eight clusters). The study was conducted in Hala and Matiari sub-districts located $250 \mathrm{~km}$ from Karachi. They developed an intervention package that involved the community and the two main providers of primary care: LHWs and Dais (local name for TBAs). LHWs in addition to the standard LHW training programme were given six days' training on antenatal care and to work with Dais to identify births and visit mothers twice during pregnancy, within 24 hours of birth and on days three, seven, 14, and 28 after delivery. Dais were given three days' voluntary training programme in basic newborn care which included basic resuscitation and immediate newborn care. They also identified community volunteers who helped to develop committees for maternal and newborn care in their villages, which conducted three-monthly group education sessions in the intervention villages and helped to establish an emergency transport fund for mothers and newborns. In the communities where the intervention package was not implemented, the LHW training programme continued as usual, but no attempt to make a link Dais with LHWs. Special training in basic and intermediate newborn care was offered to all public-sector rural health centre and hospital-based medical and nursing staff. Baseline characteristics of intervention and control clusters on perinatal, neonatal and stillbirths were similar. Groups were different on provision of electricity and hand pumps, and a higher number of households in the intervention arm had those facilities as compared to control. A total of 5134 total births and 4815 livebirths were identified in the intervention and control clusters during the pilot period. The baseline neonatal mortality rates among the intervention cluster was 57.3/1000 live births, and in control clusters was 52.2/1000 live births. Perinatal mortality rate per 1000 births in the intervention arm was 110.8 and in the control was 94.6, while stillbirth rates per 1000 birth were 65.9 and 58.1 in the intervention and control arms respectively.

The study (Projahnmo-I) conducted in Sylhet district, Bangladesh (Baqui -home care (a) 2008; Baqui-com care (a) 2008) was a cluster-randomised controlled trial. They basically developed an intervention package to promote birth and newborn-care preparedness, including pregnancy care, birth planning, essential newborn care, and awareness of when to seek emergency care for maternal and newborn illnesses. The group had two intervention arms: a homecare study arm and a community care arm. In the home-care arm, they recruited female community health workers, who received six weeks of hands-on supervised training in a tertiary care hospital and in households. The intervention in this arm included skills development for behaviour change, communication, provision of essential newborn care, clinical assessment of neonates and management of sick neonates with an algorithm adopted from the in- tegrated management of childhood illness. They treated newborns with injectable procaine benzylpenicillin and gentamicin, when families were unable to go to health facilities. In the communitycare study arm, families received the usual health services provided by the government, NGOs and private providers. In both these arms male and female community mobilisers held group meetings for the dissemination of birth and newborn care preparedness messages. Families in the comparison arm received the usual health services provided by the government, non-government organisations, and private providers. Refresher training sessions for management of maternal and newborn complications were provided for government health workers in all three study arms. Projahnmo staff ensured adequate supplies of antibiotics for treatment of newborn infections at government sub-district hospitals, which served residents in all three study arms. The end line survey identified 47,158 women with 58,588 pregnancies, 7160 (15\%) of whom declined to participate or were absent during data collection. Survey participants reported a total of 46,444 livebirths, of which 44,380 survived the neonatal period. Outcomes were reported from 1760, 1661 and 1689 births from the home care, community care and control arms respectively. Baseline characteristics across all study arms were similar. In the analysis we treated them as two subsets.

We also included the unpublished work which is under progress by Bhutta 2010 in Hala, Pakistan. The data included in this review were from their eighth surveillance of the intervention and control arms. In this study LHWs and TBAs were trained to deliver Intervention packages and community mobilisation services to women and others members of community. In control clusters, the LHW training programme continued as usual, with regular refresher sessions, but no attempt was made to link LHWs with the Dais. Baseline characteristics among intervention and control arm were similar on statistical grounds. Total number of births in intervention and control clusters were 24,085, and the livebirths were 23,033 . The rate of stillbirths in the intervention arm was $36.57 / 1000$ compare to $47.81 / 1000$ in the control arm. Neonatal mortality in the intervention arm was 47.99 compare to 51.25 /live births in the control arm. Perinatal mortality in the intervention arm was 67.79 compared to $72.06 /$ births in the control arm.

We included a published work by Tripathy 2010 which is from their cluster-randomised controlled trial conducted in Orissa and Jharkhand, India. From 36 clusters in Jharkhand and Orissa (mean cluster population: 6338), 18 clusters were randomly assigned to either intervention or control using stratified allocation. In intervention clusters a woman facilitator convened 13 groups every month to support participatory action and learning for women, and facilitated the development and implementation of strategies to address maternal and newborn health problems. No participatory intervention activities was conducted in control areas. A total of 19,030 births in intervention and control clusters were reported during the trial period, among which 18,449 were live births. Basline characteristics of identified pregnancies in the in- 
tervention and control clusters were similar; however, differences were found in household assets, maternal education, literacy and trial membership, with a women in the intervention clusters tending to be poorer and more disadvantaged.

The study by Azad 2010 was conducted in Bangladesh. They carried out two trials in the same study area using a factorial design: first, a community-based intervention involving participatory women's groups and health services strengthening to improve maternal and newborn health outcomes; second, an intervention involving training TBAs in bag-valve-mask resuscitation of newborns with symptoms of birth asphyxia. Women's groups were facilitated by a local female peer facilitator who acted as a catalyst for community mobilisation. Each facilitator was responsible for a total of 18 groups. Facilitators received five training sessions covering participatory modes of communication and maternal and newborn health issues. The role of the facilitator was to activate and strengthen groups, to support them in identifying and prioritising maternal and newborn problems, to help to identify possible strategies, and to support the planning, implementation and monitoring of strategies in the community. Locally recruited supervisors supported facilitators in preparing for meetings and liaising with community leaders. The control group was not provided with participatory learning groups. A total of 30,952 births and 29,889 live births were reported during the trial period in the intervention and control clusters. The intervention and control clusters were similar in terms of their baseline characteristics. However, stillbirths and neonatal deaths (in numbers) were higher in the control clusters as compare to those in the intervention clusters.

Please refer to the Characteristics of included studies table for more details.

\section{Excluded studies}

We excluded 42 studies as they did not satisfy our inclusion criteria. Eight studies (Dongre 2009; Kawuwa 2007; Le 2009; Moran 2006; McPherson 2006; McPherson 2007; O’Rourke 1998; Xu 1995) were neither randomised nor quasi-randomised controlled trials. We excluded 25 studies (Baqui 2009; Bashour 2008; Bolam 1998; Cooper 2002; El-Mohandes 2003; El-Mohandes 2005; El-Mohandes 2008; Gokcay 1993; Johnson 1993 Joseph 2005; Joseph 2006; Joseph 2009; Katz 2001; Kiely 2007; Koniak-Griffin 1991; Koniak-Griffin 2000; Lumley 2006; MacArthur 2003; Mannan 2008; Mullany 2007; Omer 2008; Rahman 2008; Subramanian 2005; Wiggins 2004; Turan 2003) because the interventions were not related to scope of this review. Purdin 2009 focused on intervention in healthcare facility settings. Shaheen 2003 measured the effectiveness of community health workers' second visit at home for postpartum women. Borghi 2005 and Morrell 2000 measured the cost-effectiveness analysis of participatory interventions with women's groups to improve birth outcomes. There were studies that delivered single interventions only, for example to improve exclusive breastfeeding among expectant mothers (Bhandari 2004; Bhandari 2003; Haider 2000; Mclnnes 2000). More 2008 has published their trial protocol but it does not contain study results.

Please refer to the Characteristics of excluded studies table for more details.

\section{Risk of bias in included studies}

Of these 18 included studies, 11 were randomised controlled trials, while seven were quasi-experimental studies (a research design in which subjects are assigned to treatment (i.e., they receive the intervention being studied) and comparison groups through a process that is not random).

Please refer to Figure 1 and Figure 2 for more details. 
Figure I. Methodological quality graph: review authors' judgements about each methodological quality item presented as percentages across all included studies.

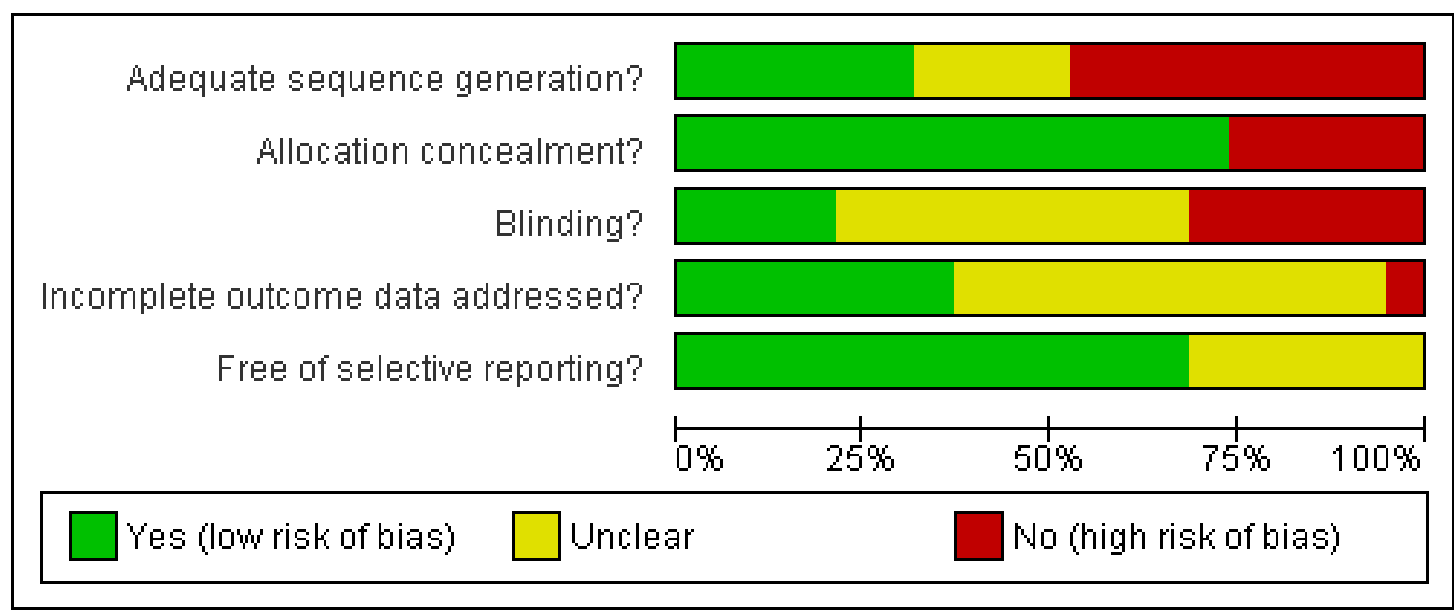


Figure 2. Methodological quality summary: review authors' judgements about each methodological quality item for each included study.

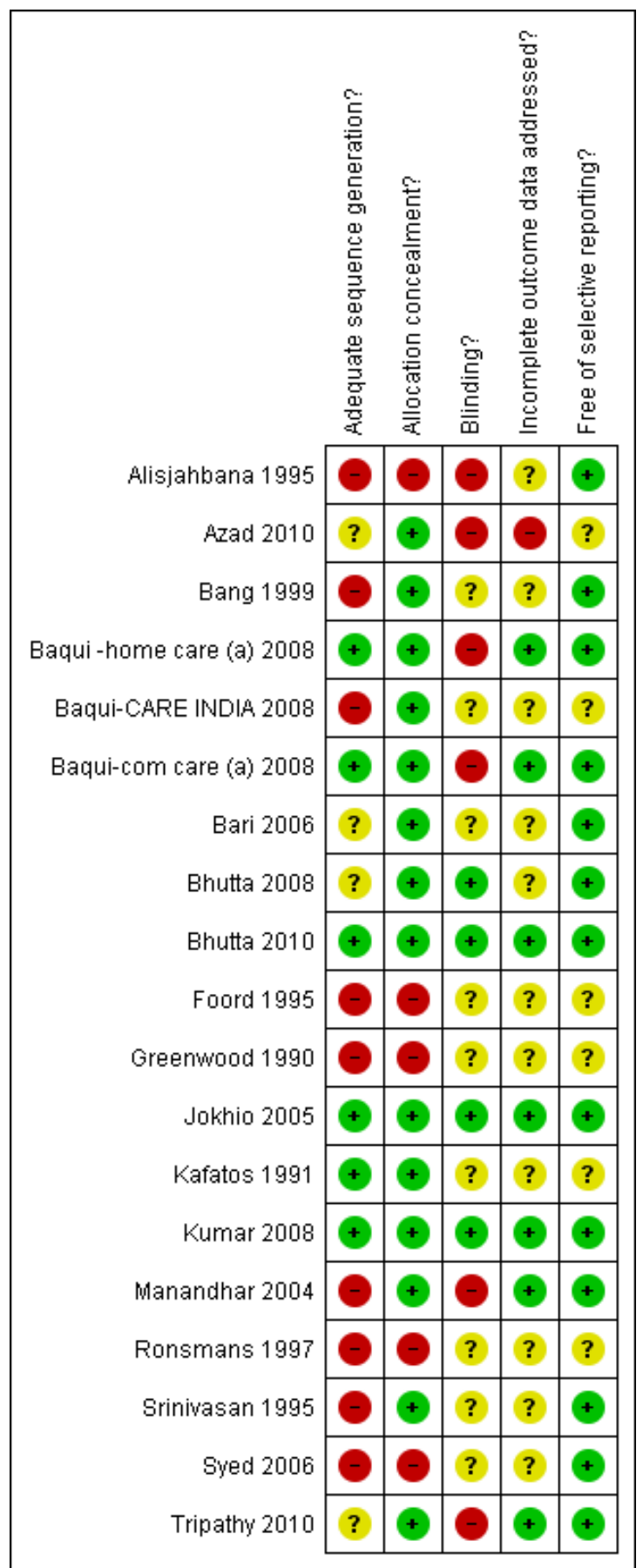

Community-based intervention packages for reducing maternal and neonatal morbidity and mortality and improving neonatal 


\section{Allocation}

In this review, out of 11 studies which were cluster-randomised trials, five (Baqui -home care (a) 2008; Baqui-com care (a) 2008; Bhutta 2010; Jokhio 2005; Kumar 2008) had no issues with sequence generation while allocation concealment was not an issue as all clusters were randomised at once.

\section{Blinding}

Among these 11 studies, three clearly mentioned that masking was unachievable because of the nature of study (Baqui -home care (a) 2008; Baqui-com care (a) 2008; Manandhar 2004), while one study (Jokhio 2005) mentioned that CHWs who recorded outcomes could not be blinded to the intervention status of the women but were not made aware of the main study objective or the outcome measured for the planned comparison. In Bhutta 2008 and Bhutta 2010, data collectors were independent of implementers.

\section{Incomplete outcome data}

Attrition and exclusion were clearly mentioned in one study (Baqui -home care (a) 2008; Bhutta 2010) where incomplete outcome data were approximately $15 \%$ and $12 \%$ respectively.

\section{Selective reporting}

We found 12 of the included studies (Azad 2010; Alisjahbana 1995; Bang 1999; Bhutta 2008; Bhutta 2010; Baqui -home care (a) 2008; Baqui-com care (a) 2008; Kafatos 1991; Kumar 2008; Manandhar 2004; Srinivasan 1995; Syed 2006; Tripathy 2010) to be free from selective reporting. Several others had insufficient information available to permit any judgement.

\section{Effects of interventions}

\section{Primary outcomes}

\section{Maternal mortality}

Overall, the community-based intervention packages showed no significant impact on reducing maternal mortality (average risk ratio (RR) $0.77 ; 95 \%$ confidence interval (CI) 0.59 to 1.02 , randomeffects (10 studies, $\mathrm{n}=144,956)$ ), and the results were heterogeneous $\left(\mathrm{T}^{2}=0.07, \mathrm{I}^{2}=39 \%\right.$ and $\mathrm{Chi}^{2} \mathrm{P}$ value 0.10 ) (Analysis 1.1 ). We therefore attempted to look for the effect of different modalities and interventions delivered at varying time periods on reducing maternal mortalities. We found that intervention packages that consisted of building support groups (average RR 0.84; 95\% CI 0.36 to 1.95 , random-effects (three studies, $\mathrm{n}=54,789)$ ), ( $\mathrm{T}^{2}$ $=0.38, \mathrm{I}^{2}=76 \%$ and $\mathrm{Chi}^{2} \mathrm{P}$ value 0.02 ), and those that mobilised community and made home visits during antenatal and postnatal periods (average RR 0.72 ; $95 \%$ CI 0.49 to 1.05 , random-effects (three studies, $\mathrm{n}=43,233)$ ), $\left(\mathrm{T}^{2}=0.0, \mathrm{I}^{2}=0 \%\right.$ and $\mathrm{Chi}^{2} \mathrm{P}$ value 0.48 ) had non-significant impact on maternal mortality. However, packages that provided training to TBAs, who then made home visits during the antenatal period and during delivery, had a significant impact on reducing maternal deaths (RR 0.70; 95\% CI 0.51 to 0.96 , random-effects (average four studies, $\mathrm{n}=46,934)$ ), $\mathrm{T}^{2}=0.0, \mathrm{I}^{2}=0 \%$ and $\mathrm{Chi}^{2} \mathrm{P}$ value 0.47 )

We also performed a sensitivity analysis of low risk of bias studies (which had used adequate sequence generation and allocation concealment methods) and found a non-significant impact of community-based intervention package on maternal mortality (RR 0.76 ; $95 \%$ CI 0.53 to 1.09 , fixed-effect (three studies, $\mathrm{n}=57,216$ ) $\left(\mathrm{I}^{2}=0 \%\right.$ and $\mathrm{Chi}^{2} \mathrm{P}$ value 0.53 ) (Analysis 1.20 ).

We found few studies that reported maternal mortality, so we assessed it for small study effect (publication bias). There are several methods of assessing the occurrence of publication bias. A common approach is based on scatter plots of the treatment effect estimated by individual studies versus a measure of study size or precision (the "funnel plot"). In this graphical representation, larger and more precise studies are plotted at the top, near the combined effect size, while smaller and less precise studies will show a wider distribution below. If there is no publication bias, the studies would be expected to be symmetrically distributed on both sides of the combined effect size line. In case of publication bias, the funnel plot may be asymmetrical, since the absence of studies would distort the distribution on the scatter plot. For maternal mortality, we observed that the majority of studies fell at the top and at both sides of the vertical line; this indicated no obvious asymmetry and thus no publication bias. (Figure 3). 
Figure 3. Funnel plot of comparison: I Community-based intervention versus control, outcome: I.I Maternal mortality.

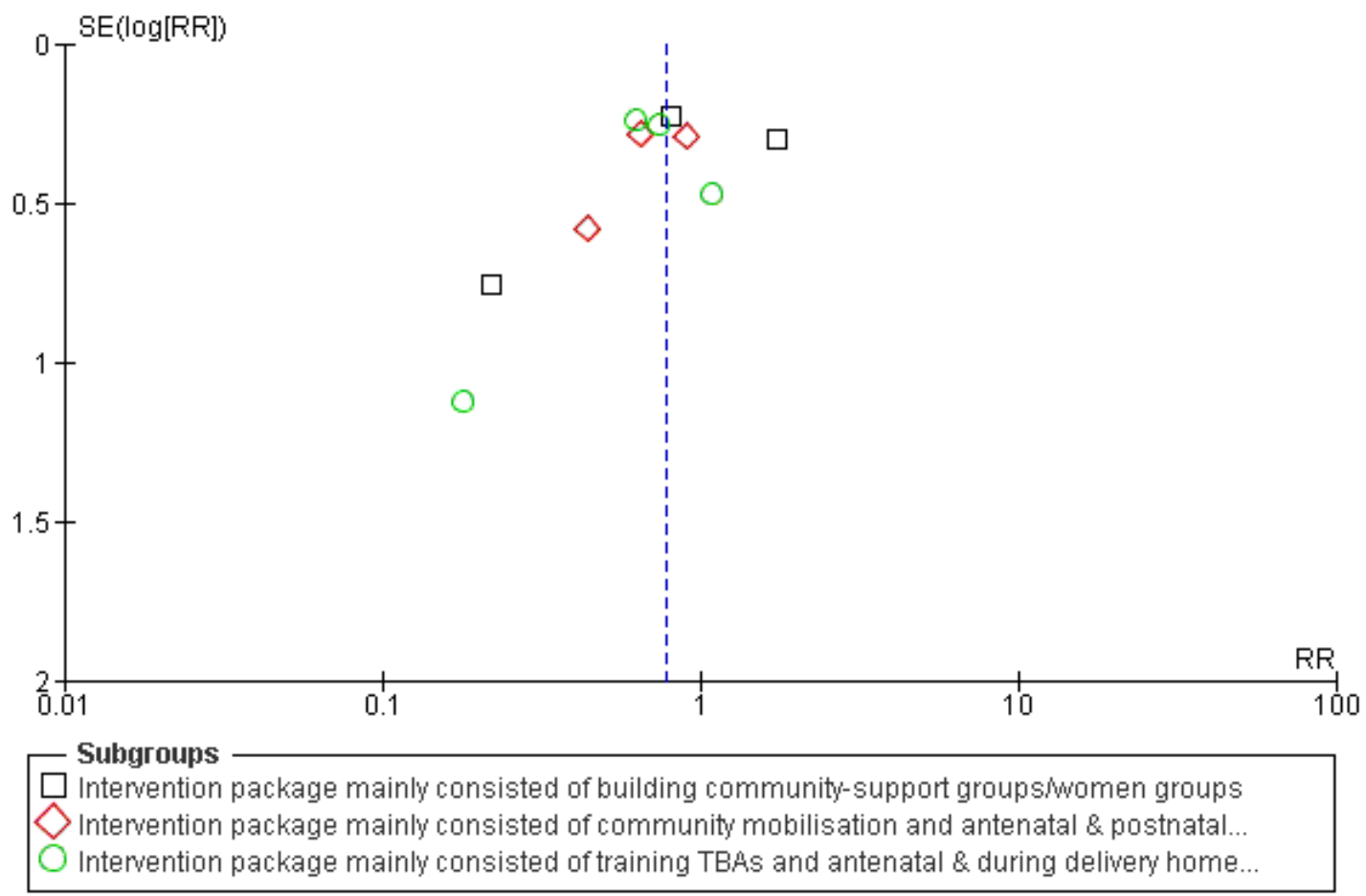

\section{Neonatal mortality}

Community-based intervention packages were associated with a significant reduction in neonatal mortality by $24 \%$ (average RR 0.76 ; $95 \%$ CI 0.68 to 0.84 , random-effects (12 studies, $\mathrm{n}=$ $136,425)$ ), and the results were heterogenous $\left(\mathrm{T}^{2}=0.02, \mathrm{I}^{2}=69 \%\right.$ and $\mathrm{Chi}^{2} \mathrm{P}$ value $<0.001$ ) (Analysis 1.2). When the impact was evaluated separately for packages that built support and advocacy groups, those that provided home visitation along with community mobilisation, had a significant impact on reducing average neonatal mortality by $21 \%$ (average RR $0.79 ; 95 \%$ CI 0.68 to 0.92 , random-effects (four studies, $\mathrm{n}=59,984),\left(\mathrm{T}^{2}=0.01, \mathrm{I}^{2}=\right.$ $44 \%$ and $\mathrm{Chi}^{2} \mathrm{P}$ value 0.15 )) and 23\% (average RR 0.77; 95\% CI 0.61 to 0.96 , random-effects (four studies, $\mathrm{n}=44,520)$, $\left(\mathrm{T}^{2}=\right.$ $0.04, \mathrm{I}^{2}=84 \%$ and $\mathrm{Chi}^{2} \mathrm{P}$ value 0.00004$)$ ). We also found significant evidence of reduced neonatal mortality when home-based neonatal care and sepsis management were delivered as a part of package (average RR 0.43 ; $95 \%$ CI 0.27 to 0.69 , random-effects (one study, $\mathrm{n}=2089)$ ); when mothers were given health education at home (average RR 0.67, 95\% CI: 0.46 to 0.98 , randomeffects (one study, $\mathrm{n}=519)$ ). and when packages provided community mobilisation along with home-based neonatal treatment (RR 0.66; 95\% CI 0.47 to 0.93 (one study, $\mathrm{n}=4248$ ). On the other hand, we found non-significant impact when TBAs were trained and asked to make home visits (average RR 0.79; 95\% CI 0.63 to 1.01 , random-effects (two studies, $\mathrm{n}=25,067))\left(\mathrm{T}^{2}=\right.$ $0.02, \mathrm{I}^{2}=71 \%$ and $\mathrm{Chi}^{2} \mathrm{P}$ value 0.06 ).

We also performed a sensitivity analysis of low risk of bias studies (which had used adequate sequence generation and allocation concealment methods) and found a significant $22 \%$ reduction in neonatal mortality (RR $0.78 ; 95 \%$ CI 0.67 to 0.92 , random-effects (five studies, $\mathrm{n}=56,878)\left(\mathrm{T}^{2}=0.02, \mathrm{I}^{2}=68 \%\right.$ and $\mathrm{Chi}^{2} \mathrm{P}$ value 0.01). (Analysis 1.21).

We did not find any obvious asymmetry in the funnel plot for total neonatal mortality (Figure 4). 
Figure 4. Funnel plot of comparison: I Community-based intervention versus control, outcome: I.2 Neonatal mortality.

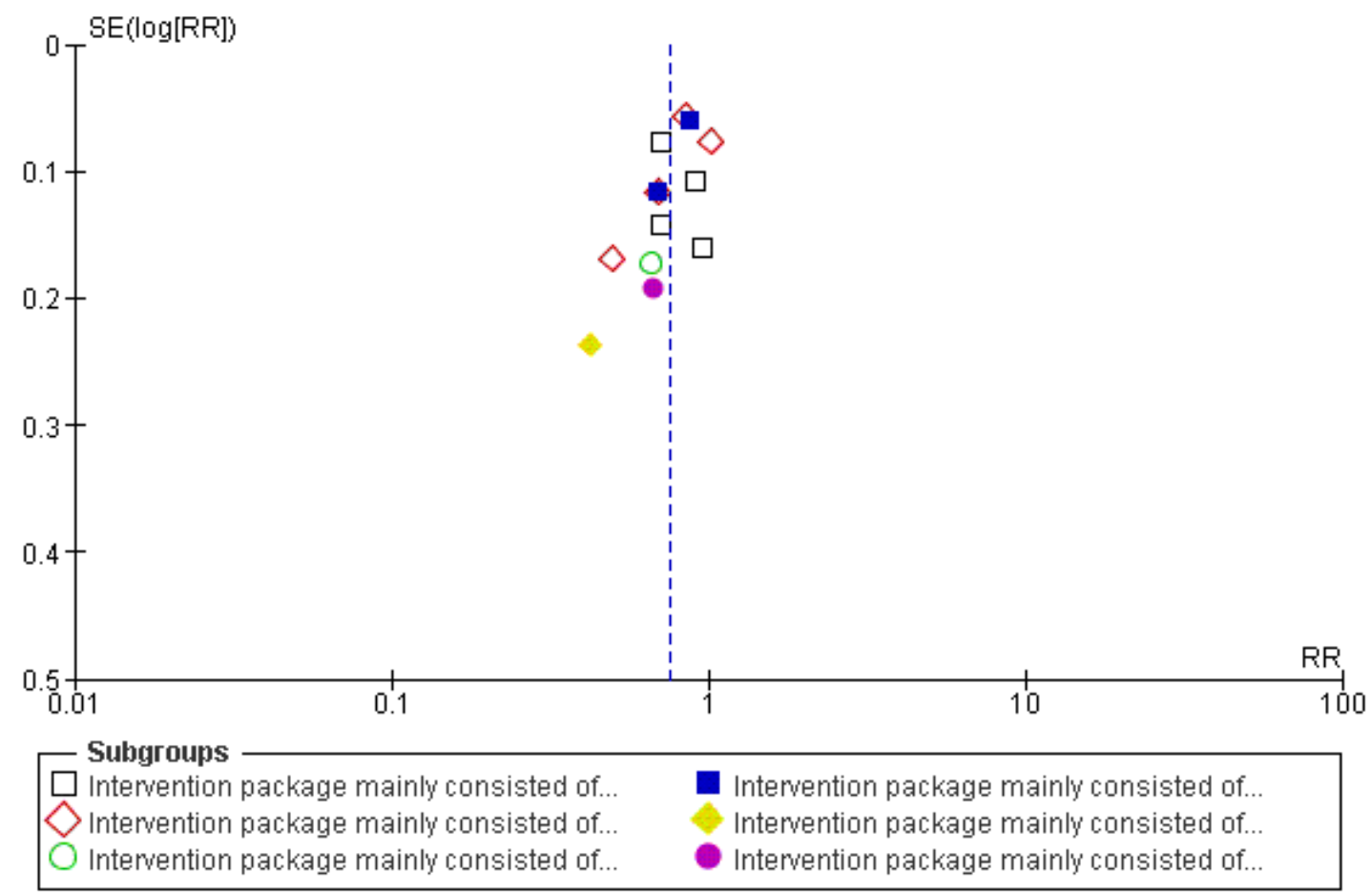

\section{Early neonatal mortality}

Results were also significant when impact was estimated for early neonatal mortality (average RR $0.74 ; 95 \%$ CI 0.64 to 0.86 , random-effects (eight studies, $\mathrm{n}=88,836)$ ), and the results were heterogenous $\left(\mathrm{T}^{2}=0.02, \mathrm{I}^{2}=59 \%\right.$ and $\mathrm{Chi}^{2} \mathrm{P}$ value 0.02 ) (Analysis 1.3). On subgroup analysis, early neonatal deaths had no association with packages that consisted of training TBAs who made home visits during antenatal and intrapartum period (average RR 0.85 ; $95 \%$ CI 0.52 to 1.39 , random-effects (one study, $\mathrm{n}=1834$ )). Whereas, community support groups/women's groups (average RR 0.76 ; $95 \%$ CI 0.58 to 0.98 , random-effects (three studies, $\mathrm{n}$ $=54,221)),\left(\mathrm{T}^{2}=0.04, \mathrm{I}^{2}=73 \%\right.$ and $\mathrm{Chi}^{2} \mathrm{P}$ value 0.02$)$; community mobilisation along with antenatal $\&$ postnatal home visitation (average RR $0.81 ; 95 \%$ CI 0.69 to 0.94 , random-effects (three studies, $\mathrm{n}=30,694)),\left(\mathrm{T}^{2}=0.00, \mathrm{I}^{2}=15 \%\right.$ and $\mathrm{Chi}^{2} \mathrm{P}$ value 0.31 ); and home-based neonatal care (average RR 0.45; 95\% CI 0.28 to 0.72 , random-effects (one study, $\mathrm{n}=2089$ )) had significant association with early neonatal mortality.

\section{Late neonatal mortality}

Results were significant when impact was estimated for late neonatal mortality (RR $0.72 ; 95 \%$ CI 0.65 to 0.830 , fixed-effects (nine studies, $\mathrm{n}=107,535)),\left(\mathrm{I}^{2}=31 \%\right.$ and $\mathrm{Chi}^{2} \mathrm{P}$ value 0.17$)$ (Analysis 1.4). On subgroup analysis, we found a significant impact of packages that consisted of training TBAs who made home visits during the antenatal and intrapartum period on the reduction of late neonatal deaths (RR 0.70; 95\% CI 0.61 to 0.79 , fixed-effect (two studies, $\mathrm{n}=20,533)),\left(\mathrm{T}^{2}=0.06, \mathrm{I}^{2}=50 \%\right.$ and $\mathrm{Chi}^{2} \mathrm{P}$ value 0.16 ); and community mobilisation along with antenatal and postnatal home visitation by CHWs (RR 0.74; 95\% CI 0.60 to 0.93 , fixed-effect (three studies, $\mathrm{n}=30,694))$, $\left(\mathrm{I}^{2}=49 \%\right.$ and $\mathrm{Chi}^{2} \mathrm{P}$ value 0.14$)$. Whereas, community support groups and women's groups (RR 0.82; 95\% CI 0.65 to 1.03 , fixed-effect (three studies, $\mathrm{n}=54,221)),\left(\mathrm{I}^{2}=19 \%\right.$ and $\mathrm{Chi}^{2} \mathrm{P}$ value 0.29$)$; and homebased neonatal care (RR 0.31; 95\% CI 0.09 to 1.07 , fixed-effect (one study, $\mathrm{n}=2089)$ ) had non-significant impact on late neonatal mortality.

\section{Secondary outcomes}




\section{Perinatal mortality}

The community-based intervention package also played a role in reducing perinatal mortality. The percentage reduction for perinatal mortality was $20 \%$ (average RR $0.80 ; 95 \%$ CI 0.71 to 0.91 , random-effects (10 studies, $\mathrm{n}=110,291)$ ), and the results were heterogenous $\left(\mathrm{T}^{2}=0.02, \mathrm{I}^{2}=82 \%\right.$ and $\mathrm{Chi}^{2} \mathrm{P}$ value $\left.<0.0001\right)$ (Analysis 1.5). There was a significant direction of effect when packages included community mobilisation and home visitation (average RR $0.72 ; 95 \%$ CI 0.59 to 0.88 , random-effects (three studies, $\mathrm{n}=32,152)),\left(\mathrm{T}^{2}=0.02, \mathrm{I}^{2}=72 \%\right.$ and $\mathrm{Chi}^{2} \mathrm{P}$ value 0.03 ). Conversely, community support and advocacy groups (average RR $0.88 ; 95 \%$ CI 0.72 to 1.06 , random-effects (two studies, $\mathrm{n}=49,727))\left(\mathrm{T}^{2}=0.02, \mathrm{I}^{2}=85 \%\right.$ and $\mathrm{Chi}^{2} \mathrm{P}$ value 0.01$)$, and home visitation by trained TBAs (average RR 0.97; 95\% CI 0.70 to 1.33 , random-effects (four studies, $\mathrm{n}=26,248)$ ), $\left(\mathrm{T}^{2}=0.08\right.$, $\mathrm{I}^{2}=81 \%$ and $\mathrm{Chi}^{2} \mathrm{P}$ value 0.001$)$ had no impact on perinatal deaths.

We also performed a sensitivity analysis of low risk of bias studies (which had used adequate sequence generation and allocation concealment methods) and found a significant $28 \%$ average reduction in perinatal mortality (RR $0.72 ; 95 \% \mathrm{CI} 0.61$ to 0.85 , random-effects (three studies, $\mathrm{n}=45,835)\left(\mathrm{T}^{2}=0.02, \mathrm{I}^{2}=77 \%\right.$ and $\mathrm{Chi}^{2} \mathrm{P}$ 0.01). (Analysis 1.22)

\section{Stillbirths}

Community-based intervention packages showed a $16 \%$ reduction in stillbirths (average RR 0.84; 95\% CI 0.74 to 0.97 , randomeffects (11 studies, $\mathrm{n}=113,821$ ) and the results were heterogenous $\left(\mathrm{T}^{2}=0.03, \mathrm{I}^{2}=66 \%\right.$ and $\mathrm{Chi}^{2} \mathrm{P}$ value 0.001$)$ (Analysis 1.6). On sub-group analysis, we found significant impact of packages that consisted of community mobilisation and home visitation during antenatal and postnatal period (average RR 0.75 ; $95 \%$ CI 0.67 to 0.85 , random-effects (three studies, $\mathrm{n}=32,152)),\left(\mathrm{T}^{2}=0.0, \mathrm{I}^{2}=\right.$ $0 \%$ and $\mathrm{Chi}^{2} \mathrm{P}$ value 0.55 ) and home-based neonatal care (average RR 0.59; $95 \%$ CI 0.38 to 0.93 , random-effects (one study, $\mathrm{n}=$ 2164)). Results were non-significant when packages consisted of building support groups or women's groups for community mobilisation (average RR 1.02; 95\% CI 0.90 to 1.15 , random-effects (three studies, $\mathrm{n}=56,002)$ ), $\left(\mathrm{T}^{2}=0.0, \mathrm{I}^{2}=0 \%\right.$ and $\mathrm{Chi}^{2} \mathrm{P}$ value 0.44 ); training TBAs and their home visitation (average RR 0.96; $95 \%$ CI 0.62 to 1.49 , random-effects (three studies, $\mathrm{n}=22,973$ )), $\left(\mathrm{T}^{2}=0.12, \mathrm{I}^{2}=79 \%\right.$ and $\mathrm{Chi}^{2} \mathrm{P}$ value 0.008$)$ and home visitation and mother education (average RR 0.45 ; $95 \%$ CI 0.11 to 1.84 , random-effects (one study, $\mathrm{n}=530$ )).

We also performed a sensitivity analysis of low risk of bias studies (which had used adequate sequence generation and allocation concealment methods) and found a significant $27 \%$ reduction in stillbirths (RR 0.73 ; 95\%CI 0.67 to 0.81 , fixed-effect (three studies, $\mathrm{n}=45,835)\left(\mathrm{I}^{2}=0 \%\right.$ and $\mathrm{Chi}^{2} \mathrm{P}$ value 0.41$)$. (Analysis 1.23 )

\section{Maternal morbidity and complications during pregnancy}

Community-based intervention packages managed to reduce maternal morbidity on average by $25 \%$ (average RR 0.75 ; $95 \%$ CI 0.61 to 0.92 , random-effects (four studies, $\mathrm{n}=138,290))\left(\mathrm{T}^{2}=\right.$ $0.02, \mathrm{I}^{2}=28 \%$ and $\mathrm{Chi}^{2} \mathrm{P}$ value 0.24 ) (Analysis 1.8 ). When the effect of community-based intervention was estimated for complications of pregnancy, it had no impact in reducing any of the complications during pregnancy, including eclampsia (RR 0.74; 95\% CI 0.43 to 1.27 , fixed-effect (one study, $\mathrm{n}=19,525$ )) (Analysis 1.12), obstructed labour (average RR $0.80 ; 95 \%$ CI 0.36 to 1.77 , random-effects (two studies, $\mathrm{n}=22,800)$ ) $\left(\mathrm{T}^{2}=0.32 \mathrm{I}^{2}=97 \%\right.$ and $\mathrm{Chi}^{2} \mathrm{P}$ value $<0.001$ ) (Analysis 1.10), puerperal sepsis (average RR 0.57 ; $95 \%$ CI 0.26 to 1.27 , random-effects (two studies, $\mathrm{n}=22,800))\left(\mathrm{T}^{2}=0.30, \mathrm{I}^{2}=89 \%\right.$ and $\mathrm{Chi}^{2} \mathrm{P}$ value 0.003$)$ (Analysis 1.11), haemorrhage (average RR 0.1.17; 95\% CI 0.34 to 3.97, random-effects (two studies, $\mathrm{n}=22,800)$ ) $\left(\mathrm{T}^{2}=0.76\right.$, $\mathrm{I}^{2}$ $=97 \%$ and $\mathrm{Chi}^{2} \mathrm{P}$ value $<0.001$ ) (Analysis 1.9) and spontaneous abortion (RR 0.81 ; 95\% CI 0.55 to 1.18 , fixed-effect (one study, $\mathrm{n}=19,525)$ ) (Analysis 1.13).

\section{Referral to health facility}

Significant impact was observed for referral to health facility for any complication during pregnancy. (RR $1.40 ; 95 \%$ CI 1.19 to 1.65 , fixed-effect (two studies, $\mathrm{n}=22,800)),\left(\mathrm{I}^{2}=0 \%\right.$ and $\mathrm{Chi}^{2} \mathrm{P}$ value 0.76 ) (Analysis 1.14). We also found that community-based intervention packages had a non-significant impact on healthcare seeking for maternal morbidities (average RR 1.46; 95\% CI 0.76 to 2.81, random-effects (three studies, $\mathrm{n}=28,304)),\left(\mathrm{T}^{2}=0.27\right.$, $\mathrm{I}^{2}=82 \%$ and $\mathrm{Chi}^{2} \mathrm{P}$ value 0.004 ) (Analysis 1.18 ); however it had a positive impact on healthcare seeking for neonatal morbidities (average RR 1.45; 95\% CI 1.01 to 2.08, random-effects (five studies, $\mathrm{n}=57,157)),\left(\mathrm{T}^{2}=0.14, \mathrm{I}^{2}=94 \%\right.$ and $\mathrm{Chi}^{2} \mathrm{P}$ value $\left.<0.001\right)$ (Analysis 1.19).

\section{Skilled birth attendance and institutional deliveries}

Interventions had no impact on increasing birth attendance by a healthcare provider overall (average RR $1.46 ; 95 \%$ CI 0.62 to 3.43 , random-effects (seven studies, $\mathrm{n}=79,687))\left(\mathrm{T}^{2}=1.28, \mathrm{I}^{2}=\right.$ $99 \%$ and $\mathrm{Chi}^{2} \mathrm{P}$ value $<0.001$ ) (Analysis 1.16), or on institutional deliveries (average RR 1.28; 95\% CI 0.98 to 1.67 , random-effects (eight studies, $\mathrm{n}=80,579))\left(\mathrm{T}^{2}=0.11, \mathrm{I}^{2}=89 \%\right.$ and $\mathrm{Chi}^{2} \mathrm{P}$ value $<0.001$ ) (Analysis 1.15).

\section{Birthweight and breastfeeding rates}

Community-based intervention packages failed to show any impact on improving mean birthweight (MD 0.01; 95\% CI 0.00 to 0.02 , fixed-effect (two studies, $\mathrm{n}=1050)$ ) $\left(\mathrm{I}^{2}=0 \%\right.$ and $\mathrm{Chi}^{2} \mathrm{P}$ value 0.05 ) (Analysis 1.7). However, it showed a statistically significant impact on initiation of breastfeeding within an hour of 
birth. (average RR 1.94; 95\% CI 1.56 to 2.42, random-effects (six studies, $\mathrm{n}=20,627)),\left(\mathrm{T}^{2}=0.06, \mathrm{I}^{2}=97 \%\right.$ and $\mathrm{Chi}^{2} \mathrm{P}$ value $<$ 0.001 ) (Analysis 1.17). Exclusive breastfeeding rates at six months of age were not reported in any study.

\section{Infant's weight for age and height for age}

Infant's weight for age and height for age $\mathrm{Z}$ scores at six months of age were not reported in any of the included studies.

\section{ISCUSSION}

To the best of our knowledge, this is the first systematic review that has evaluated the effectiveness of community-based intervention packages and reported its impact on maternal, perinatal and neonatal outcomes. Prior to this review, other reviewers have generated evidences from reviewing community-based antenatal, intrapartum and postnatal interventions trials from developing countries and recommended their inclusion in community-based neonatal programs based on their effectiveness (Bhutta 2005). Another review by Haws et al evaluated neonatal care packages in terms of their content, impact, efficacy (implementation under ideal circumstances), effectiveness (implementation within health systems), and cost (Haws 2007) with no attempt to look at their direct effects on reducing neonatal mortality and morbidity outcomes.

\section{Summary of main results}

This systematic review of clustered randomised and quasi-randomised controlled trials aimed to provide evidence of the effectiveness of community-based interventions packages on maternal, perinatal and neonatal morbidities, mortality and improving health outcomes.

We found a paucity of eligible studies that implemented interventions (generally as care packages) specifically addressing and reporting maternal outcomes. Our meta-analysis did not find any impact of community-based intervention packages on reducing maternal mortality. The possible reason for these insignificant findings might be inadequate sample size to detect meaningful change in maternal mortality. In addressing maternal mortality impacts, very large sample sizes are required for producing reliable estimates; as in this comparatively rare event, omission of only a few cases can have a disproportionately distorting effect on the maternal mortality ratio. However, significant reduction in maternal morbidity (by 25\%) was observed as a consequence of implementation of community-based interventional care packages. It was also found that referrals to health facilities for pregnancy-related complications increased by $40 \%$.

The evidence of the impact of community-based intervention packages is robust, with consistent evidence of reduction in neonatal deaths. We observed a $24 \%$ reduction in overall neonatal deaths from the studies reviewed. The findings from this pooled analysis also demonstrate an impact of community interventions on reducing stillbirths by $16 \%$ and perinatal mortality by $20 \%$. In our subgroup analysis, we found that community-based packages that disseminated education and promoted awareness related to birth and newborn care preparedness based on building community support groups/women's groups were best for reducing total and early neonatal deaths. On the other hand, packages that comprised community mobilisation and education strategies and home visitation by CHWs managed to reduce neonatal, perinatal deaths and stillbirths, possibly with the reason that these strategies focused on women in the antenatal period and on early newborn care, management and referrals of sick newborns. Home-based neonatal care showed a significant role in reducing total neonatal deaths, stillbirths, and perinatal deaths and was highly significant in reducing early neonatal deaths, but the evidence was derived from only one study. On similar grounds, when community mobilisation was added to home-based neonatal care, it significantly reduced total neonatal deaths by $44 \%$ (one study). This is not surprising as it focused on therapeutic aspects of management of neonatal illnesses and infections and the majority (more than $50 \%$ ) of planned neonatal visits was within the first week of life. Packaged interventional care also improved neonatal care outcomes like breastfeeding, and healthcare seeking for neonatal morbidities, etc; however, paucity of studies precluded robust estimation of pooled effects. We managed to conduct a meta-analysis of studies reporting initiation of breastfeeding within an hour of birth (early breastfeeding), which showed that interventions consisting of antepartum newborn care and breastfeeding education to mothers doubled rates of initiation of breastfeeding. A recent commentary (Jana 2009) on review findings for interventions for promoting the initiation of breastfeeding also suggested that educational strategies during the antenatal period (including breastfeeding education, along with other components of essential newborn care) and maternal support are likely to have the greatest impact on early initiation of breastfeeding.

\section{Overall completeness and applicability of evidence}

Notably, most of the reviewed studies, when implemented, neglected to document the complete description and characteristics of CHWs deployed, especially the level and amount of supervision provided to those workers, which could have helped us in identifying the importance of this factor and its association with other outcomes. This information would be of great relevance to policy and practice. Additional information on the initial level of education of CHWs, provision of refresher training, mode of training (balance of practical/theoretical sessions) would have provided greater assistance in understanding the threshold effect, if any, of these factors on CHW performance in community settings. Importantly, community ownership and supervision of CHWs is a 
key characteristic which is insufficiently described and analysed in available literature.

\section{Quality of the evidence}

The review included 18 randomised or quasi-randomised controlled trials, covering a wide range of intervention packages and settings. Assessment of risk of bias in these studies suggests concerns regarding insufficient information on sequence generation and allocation concealment and regarding failure to adequately address incomplete outcome data, particularly from randomised controlled trials. We therefore performed sensitivity analyses for the primary outcomes based on the randomisation process.

\section{Potential biases in the review process}

We did not find any impact of delivering community-based intervention packages on maternal mortality. The possible reason for this insignificant finding might be inadequate sample size to detect meaningful change in maternal mortality. In addressing maternal mortality impacts, very large sample sizes are required for producing reliable estimates; as in this comparatively rare event, omission of only a few cases can have a disproportionately distorting effect on the maternal mortality ratio.

We planned an a-priori subgroup analysis for mortality outcomes, but the majority of the heterogeneity was found in mortality outcomes. Therefore, findings need to be interpreted with caution. A number of groups showed significant statistical heterogeneity and the sources of this remain unclear.

\section{AUTHORS' CONCLUSIONS}

\section{Implications for practice}

We believe that our review offers encouraging evidence of the value of integrating maternal and newborn care in community settings through a range of strategies that work, many of which can be packaged effectively for delivery through a range of CHWs. While the importance of skilled delivery and facility-based care for maternal care cannot be denied, our review provides encouraging evidence that the benefits of community-based strategies may extend across the continuum of maternal and newborn care. The most successful packages were those that emphasised involving family members through community support and advocacy groups and community mobilisation and education strategies, provision of care through trained CHWs via home visitation, and strengthened proper referrals for sick mothers and newborns.

\section{Implications for research}

Notwithstanding these findings, this analysis largely derives from a limited number of effectiveness trials, as most studies were conducted in efficacy settings. Also the bulk of the data were from studies conducted in Asia, with very limited information from subSaharan and central African settings. There is thus a clear need for additional research at an appropriate scale and in the right settings. There is also a need for high quality randomised controlled trials that employ stringent methods to ensure quality.

Given the rapid rise in healthcare costs, and the imperative of reaching hard-to-reach communities, it has become crucial to focus on developing cost-effective and affordable ways to prevent disease and promote health in community settings. Although this was not one of the main objectives of this review, it plays a fundamental role in selecting and bundling intervention packages for scaling up and particularly in tailoring interventions to available health system resources. Only a few studies reported the actual costs incurred for providing interventions for saving one life or the cost of one averted death. Therefore, cost-effectiveness is a priority area for research for the future and researchers should facilitate cost-effectiveness meta-analysis by collecting and reporting costeffectiveness data in a standardised format (e.g. costs per lives saved or disability-adjusted life years (DALYs) averted).

\section{ACKNOWLEDGEMENTS}

As part of the pre-publication editorial process, this review has been commented on by three peers (an editor and two referees who are external to the editorial team), a member of the Pregnancy and Childbirth Group's international panel of consumers and the Group's Statistical Adviser. 


\section{R E F E R E N C E S}

\section{References to studies included in this review}

Alisjahbana 1995 \{published data only\}

Alisjahbana A, Williams C, Dharmayanti R, Hermawan D, Kwast BE, Koblinsky M. An integrated village maternity service to improve referral patterns in a rural area in WestJava. International Journal of Gynecology \& Obstetrics 1995; 48 Suppl:S83-S94.

\section{Azad 2010 \{published data only\}}

Azad K, Barnett S, Banerjee B, Shaha S, Khan K, Rego $A R$, et al.The effect of scaling up women's groups on birth outcomes in three rural districts of Bangladesh: a clusterrandomised controlled trial. Lancet 2010;375(9721): $1142-4$.

Bang 1999 \{published data only\}

Bang AT, Bang RA, Baitule SB, Reddy HM, Deshmukh MD. Reduced incidence of neonatal morbidities: effect of home-based neonatal care in rural Gadchiroli, India. Management of birth asphyxia in home deliveries in rural Gadchiroli: the effect of two types of birth attendants and of resuscitating with mouth-to-mouth, tube-mask or bagmask. Journal of Perinatology 2005;25(Suppl 1):S82-S91. * Bang AT, Bang RA, Baitule SB, Reddy MH, Deshmukh MD. Effect of home-based neonatal care and management of sepsis on neonatal mortality: field trial in rural India. Lancet 1999;354(9194):1955-61.

Bang AT, Bang RA, Reddy HM, Deshmukh MD, Baitule SB. Reduced incidence of neonatal morbidities: effect of home-based neonatal care in rural Gadchiroli, India. Journal of Perinatology 2005;25 Suppl 1:S51-S61. Bang AT, Reddy HM, Deshmukh MD, Baitule SB, Bang RA. Neonatal and infant mortality in the ten years (1993 to 2003) of the Gadchiroli field trial: effect of home-based neonatal care. Journal of Perinatology 2005;25 Suppl 1: S92-S107.

Baqui -home care (a) 2008 \{published data only\} Baqui AH, Arifeen SE, Darmstadt GL, Ahmed S, Williams EK, Seraji HR, et al.Effect of community based newborncare intervention package implemented through two servicedelivery strategies in Sylhet district, Bangladesh: a cluster randomised controlled trial. Lancet 2008;371:1936-44.

Baqui-CARE INDIA 2008 \{published data only\} Baqui AH, Rosecrans AM, Williams EK, Agrawal PK, Ahmed S, Darmstadt GL, et al.NGO facilitation of a government community-based maternal and neonatal health programme in rural India: improvements in equity. Health Policy and Planning 2008;23:234-43.

* Baqui AH, Williams EK, Rosecrans AM, Agrawal PK, Ahmed S, Darmstadt GL, et al.Impact of an integrated nutrition and health programme on neonatal mortality in rural northern India. Bulletin of the World Health Organization 2008;86(10):796-804.

Baqui-com care (a) 2008 \{published data only\} Baqui AH, Arifeen SE, Darmstadt GL, Ahmed S, Williams EK, Seraji HR, et al.Effect of community based newborn- care intervention package implemented through two servicedelivery strategies in Sylhet district, Bangladesh: a cluster randomised controlled trial. Lancet 2008;371:1936-44.

Bari 2006 \{published data only\} Bari S, Mannan I, Rahman MA, Darmstadt GL, Seraji MHR, Baqui $\mathrm{AH}$, et al.Trends in use of referral hospital services for care of sick newborns in a community-based intervention in Tangail District, Bangladesh. Journal of Health, Population, and Nutrition 2006;24(4):519-29.

Bhutta 2008 \{published and unpublished data\} Bhutta ZA, Memon ZA, Soofi S, Salat MS, Cousens S, Martines J. Implementing community-based perinatal care: results from a pilot study in rural Pakistan. Bulletin of the World Health Organization 2008;86(6):452-9.

Bhutta 2010 \{unpublished data only\} Bhutta ZA. Community-based perinatal and newborn care in rural Pakistan: a cluster randomised controlled trial. Personal communication 2010.

Foord 1995 \{published data only\}

* Foord F. Gambia: evaluation of the mobile health care service in West Kiang district. World Health Statistics Quarterly 1995;48(1):18-22.

Fox-Rushby JA, Foord F. Costs, effects and cost-effectiveness analysis of a mobile maternal health care services in West Kiang, The Gambia. Health Policy and Planning 1996;35 (2):123-43.

Greenwood 1990 \{published data only\} Greenwood AM, Bradley AK, Byass P, Greenwood BM, Snow RW, Bennett $S$. Evaluation of a primary health care programme in The Gambia. I.The impact of trained traditional birth attendants on the outcome of pregnancy. Journal of Tropical Medicine and Hygiene 1990;93:58-66.

Jokhio 2005 \{published and unpublished data\} Jokhio AH, Winter HR, Cheng KK. An intervention involving traditional birth attendants and perinatal and maternal mortality in Pakistan. New England Journal of Medicine 2005;352:2091-9.

Kafatos 1991 \{published data only\}

* Kafatos AG, Teltoura S, Pantelakis SN, Doxiadis SA. Maternal and infant health education in a rural Greek community. Hygiene 1991;10:32-7.

Kafatos AG, Vlachonikolis IG, Codrington CA. Nutrition during pregnancy: the effects of an educational intervention program in Greece. American Journal of Clinical Nutrition 1989;50:970-9.

Kumar 2008 \{published and unpublished data\} Darmstadt GL, Kumar V, Yadav R, Singh V, Singh P, Mohanty S, et al.Introduction of community based skin to skin care in rural Uttar Pradesh, India. Journal of Perinatology 2006;26:597-604.

* Kumar V, Mohanty S, Kumar A, Misra RP, Santosham $\mathrm{M}$, Awasthi S, et al.Effect of community based behaviour change management on neonatal mortality in Shivgarh, 
Uttar Pradesh, India: a cluster-randomised controlled trial. Lancet 2008;372(9644):1151-62.

Manandhar 2004 \{published data only\}

* Manandhar DS, Osrin D, Shrestha BP, Mesko N, Morrison J, Tumbahangphe KM, et al.Effect of participatory intervention with women's groups on birth outcomes in Nepal: cluster randomised control trial. Lancet 2004;364: 970-9.

MIRA (Mother Infant Research Unit). The MIRA Makwanpur Study. Personal communication 2002. Morrison J, Tamang S, Mesko N, Osrin D, Shrestha B, Manandhar $\mathrm{M}$, et al.Women's health groups to improve perinatal care in rural Nepal. BMC Pregnancy and Childbirth 2005;5:6.

Osrin D, Mesko N, Shrestha BP, Shrestha D, Tamang $S$, Thapa $S$, et al.Implementing a community-based participatory intervention to improve essential newborn care in rural Nepal. Transaction of the Royal Society of Tropical Medicine and Hygiene 2003;97(1):18-21.

Wade A, Osrin D, Shrestha BP, Sen A, Morrison J, Tumbahangphe KM, et al.Behaviour change in perinatal care practices among rural women exposed to a women's group intervention in Nepal. BMC Pregnancy and Childbirth 2006;6:20.

Ronsmans 1997 \{published data only\}

Ronsmans C, Vanneste AM, Chakraborty J, Ginneken JV. Decline in maternal mortality in Matlab, Bangladesh: a cautionary tale. Lancet 1997;350:1810-4.

Srinivasan 1995 \{published data only\}

Srinivasan V, Radhakrishna S, Sudha R, Malathi MV, Jabbar $S$, Ramakrishnan R, et al.Randomized controlled field trial of two antenatal care packages in rural south India. Indian Journal of Medical Research 1995;102:86-94.

Syed 2006 \{published and unpublished data\} Syed U, Asiruddin S, Helal SI, Mannan II, Murray J. Immediate and early postnatal care for mothers and newborns in rural Bngladesh. Journal of Health, Nutrition and Population 2006;24(4):508-18.

Tripathy 2010 \{published data only\}

Tripathy P, Nair N, Barnett S, Mahapatra R, Borghi J, Rath $S$, et al.Effect of a participatory intervention with women's groups on birth outcomes in Jharkhand and Orissa, India: the EKJUT cluster-randomised controlled trial. Lancet 2010;375(9721):1182-92.

\section{References to studies excluded from this review}

Baqui 2009 \{published data only\}

Baqui AH, Arifeen SE, Rosen HE, Mannan I, Rahman $\mathrm{SM}$, Al-Mahmud AB, et al.Community-based validation of assessment of newborn illness by trained community health workers in Sylhet district of Bangladesh. Tropical Medicine and International Health 2009;14(12):1448-56.

Bashour 2008 \{published data only\} Bashour HN, Kharouf MH, Abdulsalam AA, El Asmer K, Tabba MA, Cheikha SA. Effect of postnatal home visits on maternal/infant outcomes in Syria: a randomised controlled trial. Public Health Nursing 2008;25(2):115-25.

Bhandari 2003 \{published data only\}

Bhandari N, Bahl R, Mazumdar S, Martines J, Black RE, Bhan MK, et al.Effect of community-based promotion of exclusive breastfeeding on diarrhoeal illness and growth: a cluster randomised controlled trial. Lancet 2003;361 (9367):1418-23.

Bhandari 2004 \{published data only\}

Bhandari N, Mazumder S, Bahl R, Martines J, Black RE, Bhan MK, et al.Use of multiple opportunities for improving feeding practices in under-two within child health programmes. Health Policy and Planning 2005;20 (5):328-36.

Bolam 1998 \{published data only\}

Bolam A, Manandhar DS, Shrestha P, Ellis M, Costello AM. The effects of postnatal health education for mothers on infant care and family planning practices in Nepal: a randomised controlled trial. BMJ 1998;316(7134):805-11.

Borghi 2005 \{published data only\}

Borghi J, Thapa B, Osrin D, Jan S, Morrison J, Tamang S, et al.Economic assessment of a women's group intervention to improve birth outcomes in rural Nepal. Lancet 2005;366 (9500):1822-4.

\section{Cooper 2002 \{published data only\}}

Cooper P. A controlled trial of community based motherinfant intervention in a South African peri-urban settlement. Current Controlled Trials (www.controlled-trials.com) (accessed 2007).

* Cooper PJ, Landman M, Tomlinson M, Molteno C, Swartz L, Murray L. Impact of a mother-infant intervention in an indigent peri-urban South African context. Pilot study. British Journal of Psychiatry 2002;180:76-81.

Cooper PJ, Tomlinson M, Swartz L, Landman M, Molteno C, Stein A, et al.Improving quality of mother-infant relationship and infant attachment in socioeconomically deprived community in South Africa: randomised controlled trial. BMJ 2009;338:b974.

Dongre 2009 \{published data only\}

Dongre AR, Deshmukh PR, Garg BS. A community-based approach to improve health care seeking for newborn danger signs in rural Wardha, India. Indian Journal of Pediatrics 2009;76(1):45-50.

El-Mohandes 2003 \{published data only\} El-Mohandes AAE, Katz KS, El-Khorazaty MN, McNeelyJohnson D, Sharps PW, Jarrett MH, et al.The effect of a parenting education program on the use of preventive paediatric health care services among low-income, minority mothers: a randomised, controlled study. Pediatrics 2003; 111(6):1324-32.

El-Mohandes 2005 \{published data only\}

* El-Mohandes A, Kiely M, El-Khorazaty N, Gantz M, Blake S, Subramanian S. Reduction of intimate partner violence in pregnancy: the effect of an integrated intervention in an African-American low income population. Pediatric 
Academic Societies Annual Meeting; 2005 May 14-17; Washington DC, USA. 2005.

El-Mohandes AAE. A psycho-behavioral intervention on African American pregnant women with a history of intimate partner violence (IPV) improves birth weight distribution of their newborns. Pediatric Academic Societies Annual Meeting; 2006 April 29-May 2; San Francisco, CA, USA. 2006

Katz K, Subramanian S, Rodan M, Schwartz D, ElKhorazaty N, El-Mohandes A, et al.Randomized controlled trial (RCT) of depression counselling for low-income African American (AA) women in prenatal care. Pediatric Academic Societies Annual Meeting; 2005 May 14-17; Washington DC, USA. 2005:Abstract no: 1715.

El-Mohandes 2008 \{published data only\} El-Khorazaty MN, El-Mohandes AAE, Kiely M. Risk factors for poor pregnancy outcomes among minority women: application of classification and regression trees (CART) methodology to a behavioral intervention randomised trial. Pediatric Academic Societies and Asian Society for Pediatric Research Joint Meeting; 2008 May 2-6; Honolulu, Hawaii. 2008.

* El-Mohandes AA, Kiely M, Joseph JG, Subramanian S, Johnson AA, Blake SM, et al.An intervention to improve postpartum outcomes in African-American mothers: a randomised controlled trial. Obstetrics \& Gynecology 2008; 112(3):611-20.

Gokcay 1993 \{published data only\} Gokcay G, Bulut A, Neyzi O. Paraprofessional women as health care facilitators in mother and child health. Tropical Doctor 1993;23:79-81.

Haider 2000 \{published data only\}

* Haider R, Ashworth A, Kabir I, Huttly SRA. Effect of community-based peer counsellors on exclusive breastfeeding practices in Dhaka, Bangladesh: a randomised controlled trial. Lancet 2000;356:1643-7.

Haider R, Kabir I, Huttly SR, Ashworth A. Training peer counsellors to promote and support exclusive breastfeeding in Bangladesh. Journal of Human Lactation 2002;18(1): $7-12$.

Johnson 1993 \{published data only\}

Johnson Z, Howell F, Molloy B. Community mother's programme: randomised controlled trial of non-professional intervention in parenting. BMJ 1993;306:1449-52. * Johnson Z, Molloy B, Scallan E, Fitzpatrick P, Rooney B, Keegan T, et al.Community mothers programme-seven year follow-up of a randomised controlled trial of nonprofessional intervention in parenting. Journal of Public Health Medicine 2000;22:337-42.

Joseph 2005 \{published data only\}

Joseph J, for NIH-DC initiative to reduce infant mortality. Randomized trial to reduce 4 behaviours linked to adverse pregnancy outcomes among 1048 inner-city African American women [abstract]. Pediatric Academic Societies Annual Meeting; 2005 May 14-17; Washington DC, USA. 2005:Abstract no: 1701.

\section{Joseph 2006 \{published data only\}}

Joseph J. Overall effects of a behavioral intervention to reduce pregnancy risks among 1044 African American women in Washington DC: results of a randomised clinical trial [abstract]. Pediatric Academic Societies Annual Meeting; 2006 April 29-May 2; San Francisco, CA, USA. 2006.

Joseph 2009 \{published data only\}

Joseph JG, El-Mohandes AA, Kiely M, El-Khorazaty MN, Gantz MG, Johnson AA, et al.Reducing psychosocial and behavioral pregnancy risk factors: results of a randomised clinical trial among high-risk pregnant African American women. American Journal of Public Health 2009;99(6): 1053-61.

\section{Katz 2001 \{published data only\}}

Katz KS, El-Mohandes PA, Johnson DM, Jarrett PM, Rose A, Cober M. Retention of low income mothers in a parenting intervention study. Journal of Community Health 2001;26(3):203-18.

Kawuwa 2007 \{published data only\} Kawuwa MB, Mairiga AG, Usman HA. Community perspective of maternal mortality: experience from Konduga local government area, Borno State, Nigeria. Annals of African Medicine 2007;6(3):109-14.

Kiely 2007 \{published data only\}

El-Mohandes AAE, Kiely M, Gantz MG, El-Khorazaty N. A multiple risk factor behavioral intervention reduces environmental tobacco smoke exposure. Pediatric Academic Societies Annual Meeting; 2007 May 5-8; Toronto, Canada. 2007.

Kiely M, El-Khorazaty MN, El-Mohandes AAE. Depression and smoking during pregnancy impact the efficacy of an integral behavioral intervention to resolve risks. Pediatric Academic Societies Annual Meeting; 2007 May 5-8; Toronto, Canada. 2007.

Koniak-Griffin 1991 \{published data only\} Koniak-Griffin D, Verzemnieks I. Effects of nursing intervention on adolescents' maternal role attainment. Issues in Comprehensive Pediatric Nursing 1991;14:121-38.

Koniak-Griffin 2000 \{published data only\}

Koniak-Griffin D, Anderson NL, Brecht ML, Verzemnieks I, Lesser J, Kim S. Public health nursing care for adolescent mothers: impact on infant health and selected maternal outcomes at 1 year post birth. Journal of Adolescent Health 2002;30(1):44-54.

* Koniak-Griffin D, Anderson NL, Verzemnieks I, Brecht ML. A public health nursing early intervention program for adolescent mothers: outcomes from pregnancy through 6 weeks postpartum. Nursing Research 2000;49(3):130-8. Koniak-Griffin D, Verzemnieks IL, Anderson NL, Brecht ML, Lesser J, Kim S, et al.Nurse visitation for adolescent mothers: two-year infant health and maternal outcomes. Nursing Research 2003;52(2):127-36.

Le 2009 \{published data only\} Le PV, Jones-Le E, Bell C, Miller S. Preferences for perinatal health communication of women in rural Tibet. Journal 
of Obstetric, Gynecologic and Neonatal Nursing 2009;38: 108-17.

Lumley 2006 \{published data only\}

Lumley J, Small R, Brown S, Watson L, Gunn J, Mitchell $\mathrm{C}$, et al.PRISM (program of resources, information and support for mothers) protocol for a community-randomised trial. BMC Public Health 2003;3:36.

* Lumley J, Watson L, Small R, Brown S, Mitchell C, Gunn J. PRISM (program of resources, information and support for mothers): a community-randomised trial to reduce depression and improve women's physical health six months after birth. BMC Public Health 2006;6:37.

MacArthur 2003 \{published data only\}

MacArthur C, Winter HR, Bick DE, Knowles H, Lilford $\mathrm{R}$, Henderson $\mathrm{C}$, et al.Effects of redesigned community postnatal care on women's health 4 months after birth: a cluster randomised trial. Lancet 2002;359:378-85.

* MacArthur C, Winter HR, Bick DE, Lilford RJ, Lancashire RJ, Knowles H, et al.Redesigning postnatal care: a randomised controlled trial of protocol-based midwiferyled care focused on individual women's physical and psychological health needs. Health Technology Assessment 2003;7(37):1-98.

Mannan 2008 \{published data only\}

Mannan I, Rahman SM, Sania A, Seraji HR, Arifeen SE, Winch PJ, et al.Can early postpartum home visits by trained community health workers improve breastfeeding of newborns?. Journal of Perinatology 2008;28:632-40.

Mclnnes 2000 \{published data only\}

McInnes RJ, Love JG, Stone DH. Evaluation of a community-based intervention to increase breastfeeding prevalence. Journal of Public Health Medicine 2000;22(2): $138-45$.

McPherson 2006 \{published data only\}

McPherson RA, Khadka N, Moore JM, Sharma M. Are birth-preparedness programmes effective? Results from a field trial in Siraha district, Nepal. Journal of Health, Population, and Nutrition 2006;24(4):479-88.

McPherson 2007 \{published data only\} McPherson R, Baqui A, Winch P, Ahmed S. Communitybased maternal and neonatal care program (CB-MNC): summative report on program activities and results in Banke, Jhapa and Kachanpur districts from September 2005 September 2007. USAID, 2007.

Moran 2006 \{published data only\}

Moran AC, Sangli G, Dineen R, Rawlins B, Yaméogo, Baya B. Birth-preparedness for maternal health: findings from Kouéla district, Burkina Faso. Journal of Health, Population, and Nutrition 2006;24(4):489-97.

More 2008 \{published data only\}

More NS, Bapat U, Das S, Patil S, Porel M, Vaidya L, et al.Cluster-randomised controlled trial of community mobilisation in Mumbai slums to improve care during pregnancy, delivery, postpartum and for the newborn. Trials 2008;9:7.
Morrell 2000 \{published data only\}

* Morrell CJ, Spiby H, Stewart P, Walters S, Morgan A. Costs and benefits of community postnatal support workers: a randomised controlled trial. Health Technology Assessment 2000;4(6):1-100.

Morrell CJ, Spiby H, Stewart P, Walters S, Morgan A. Costs and effectiveness of community postnatal support workers: randomised controlled trial. BMJ 2000;321(7261):593-8.

Mullany 2007 \{published data only\}

Mullany BC, Becker S, Hindin MJ. The impact of including husbands in antenatal health education services on maternal health practices in urban Nepal: results from a randomised controlled trial. Health Education Research 2007;22(2): 166-76.

O'Rourke 1998 \{published data only\} O'Rourke K, Howard-Grabman L, Seoane G. Impact of community organization of women on perinatal outcome in rural Bolivia. Pan American Journal of Public Health 1998;3 (1):9-14.

Omer 2008 \{published data only\} Omer K, Mhatre S, Ansari N, Laucirica J, Andersson $\mathrm{N}$. Evidence-based training of frontline health workers for door-to-door health promotion: a pilot randomised controlled cluster trial with lady health workers in Sindh Province, Pakistan. Patient Education and Counseling 2008; 72(2):178-85.

Purdin 2009 \{published data only\} Purdin S, Khan T, Saucier R. Reducing maternal mortality among Afghan refugees in Pakistan. International Journal of Gynecology \& Obstetrics 2009;105(1):82-5.

Rahman 2008 \{published data only\}

Rahman A, Malik A, Sikander S, Roberts C, Creed F. Cognitive behaviour therapy-based intervention by community health workers for mothers with depression and their infants in rural Pakistan: a cluster-randomised controlled trial. Lancet 2008;372(9642):902-9.

Shaheen 2003 \{published data only\}

Shaheen M, Salam R, Al Sabbah H, Shalabi T, Swaitee $\mathrm{Y}$. Improving postpartum care among low parity mothers in Palestine. Ramallah, Palestine: Center for Development in Primary Health Care (CDPHC) Al Quds University, 2003.

Subramanian 2005 \{published data only\} Subramanian S, the NIH-DC Initiative. Pregnancy and infant outcomes in a multicenter, randomised controlled trial for psychosocial risks (PS) in urban, low income African American women (AA). Pediatric Academic Societies Annual Meeting; 2005 May 14-17; Washington DC, USA. 2005:Abstract no: 881 .

Turan 2003 \{published data only\} Turan JM, Say L. Community-based antenatal education in Istanbul, Turkey: effects on health behaviours. Health, Policy and Planning 2003;18(4):391-8. 
Wiggins 2004 \{published data only\}

Austerberry H, Wiggins M, Turner H, Oakley A. Evlauating social support and health visiting. Community Practioner 2004;77(12):460-4.

Wiggins M, Oakley A, Roberts I, Turner H, Rajan L, Austerberry H, et al.Postanatal support for mothers living in disadvantaged inner city areas: a randomised controlled trial. Journal of Epidemiology and Community Health 2005; 59:288-95.

* Wiggins M, Oakley A, Roberts I, Turner H, Rajan L, Austerberry $\mathrm{H}$, et al.Social support and family health study: a randomised controlled trial and economic evaluation of two alternative forms of postnatal support for mothers living in disadvantaged inner-city areas. Health Technology Assessment 2004;8(23):1-120.

Xu 1995 \{published data only\}

$\mathrm{Xu} \mathrm{Z}$. China: lowering maternal mortality in Miyun County, Beijing. World Health Statistics Quarterly 1995;48 (1):11-4.

\section{Additional references}

\section{Ashford 2002}

Ashford L. Hidden suffering: disabilities from pregnancy and childbirth in less developed countries. http:// www.prb.org/pdf/HiddenSufferingEng.pdf (accessed 3 Sptember 2008)

\section{Bhutta 2005}

Bhutta ZA, Darmstadt GL, Hasan BS, Haws RA. Community-based interventions for improving perinatal and neonatal health outcomes in developing countries: a review of the evidence. Pediatrics 2005;115:519-617.

\section{Bhutta 2010}

Bhutta ZA, Chopra M, Axelson H, Berman P, Boerma T, Bryce J, et al.Countdown to 2015 decade report (200010): taking stock of maternal, newborn, and child survival. Lancet 2010;375:2032-44.

\section{Black 2010}

Black RE, Cousens S, Johnson HL, Lawn JE, Rudan I, Bassani DG, et al.for the Child Health Epidemiology Reference Group of WHO and UNICEF. Global, regional, and national causes of child mortality in 2008: a systematic analysis. Lancet 2010;375:1969-87.

\section{Darmstadt 2005}

Darmstadt GL, Bhutta ZA, Cousens S, Adam T, Walker N, de-Bernis L. Evidence-based, cost effective interventions: how many newborn babies can we save?. Lancet 2005;365: $977-88$.

\section{Deeks 2001}

Deeks JJ, Altman DG, Bradburn MJ. Statistical methods for examining heterogeneity and combining results from several studies in meta-analysis. In: Egger M, Davey Smith G, Altman DG editor(s). Systematic reviews in health care: meta-analysis in context. London: BMJ Books, 2001.

\section{Ensor 2004}

Ensor T, Cooper S. Overcoming barriers to health service access: influencing the demand side. Health Policy and Planning 2004;19:69-79.

Filippi 2006

Filippi V, Ronsmans C, Campbell OMR, Graham WJ, Mills A, Borghi J, et al.Maternal health in poor countries: the broader context and a call for action. Lancet 2006;368: $1535-41$.

\section{Haws 2007}

Haws RA, Thomas AL, Bhutta ZA, Darmstadt GL. Impact of packaged interventions on neonatal health: a review of the evidence. Health Policy and Planning 2007;22:193-215.

Higgins 2009

Higgins JPT, Green S, editors. Cochrane Handbook for Systematic Reviews of Interventions Version 5.0.2 [updated September 2009]. The Cochrane Collaboration, 2009. Available from www.cochrane-handbook.org.

Hogan 2010

Hogan MC, Foreman KJ, Naghavi M, Ahn SY, Wang M, Makela SM, et al.Maternal mortality for 181 countries, 1980-2008: a systematic analysis of progress towards Millennium Development Goal 5. Lancet 2010;375(9726): 1609-23.

Hoj 2003

Hoj L, Da Silva D, Hedegaard K, Sandstrom A, Aaby P. Maternal mortality: only 42 days?. BJOG: an international journal of obstetrics and gynaecology 2003;110:995-1000.

\section{Hurt 2002}

Hurt LS, Ronsmans C. Time since pregnancy and mortality in women of reproductive age in Matlab, Bangladesh. Paper presented at the British Society for Population Studies. London, UK, 2002.

Jana 2009

Jana AK. Interventions for promoting the initiation of breastfeeding: RHL commentary. The WHO Reproductive Health Library. Geneva: World Health Organization, 2009.

Murray 1998

Murray CJL, Lopez AD. Health dimensions of sex and reproduction. Global burden of disease and injury series. Vol. 3, Boston: Harvard University Press, 1998.

Ray 2004

Ray A M, Salihu HM. The impact of maternal mortality interventions using traditional birth attendants and village midwives. Journal of Obstetrics and Gynaecology 2004;24(1): $5-11$.

RevMan 2008

The Nordic Cochrane Centre, The Cochrane Collaboration. Review Manager (RevMan). 5.0. Copenhagen: The Nordic Cochrane Centre, The Cochrane Collaboration, 2008.

Ronsmans 2006

Ronsmans C, Graham WJ, The Lancet Maternal Survival Series steering group. Maternal mortality: who, when, where, and why. Lancet 2006;368:1189-200. 


\section{Rosato 2008}

Rosato M, Laverack G, Grabman LH, Tripathy P, Nair N, Mwansambo C, et al.Alma-Ata: rebirth and revision 5. Community participation: lessons for maternal, newborn, and child health. Lancet 2008;372:962-71.

Sachs 2005

Sachs JD, McArthur JW. The Millennium Project: a plan for meeting the Millenium Development. Lancet 2005;365: $347-53$.

Say 2004

Say L, Pattinson RC, Gulmezoglu M. WHO systematic review of maternal morbidity and mortality: the prevalence of severe acute maternal morbidity (near miss). Reproductive Health 2004;1:3.

Sibley 2007

Sibley LM, Sipe TA, Brown CM, Diallo MM, McNatt $\mathrm{K}$, Habarta N. Traditional birth attendant training for improving health behaviours and pregnancy outcomes. Cochrane Database of Systematic Reviews 2007, Issue 3. [DOI: 10.1002/14651858.CD005460.pub2]

\section{Thaver 2009}

Thaver D, Zaidi AKM, Owais A, Haider BA, Bhutta ZA. The effect of community health educational interventions on newborn survival in developing countries. Cochrane Database of Systematic Reviews 2009, Issue 1. [DOI: 10.1002/14651858.CD007647]

\section{Walsh 1994}

Walsh JA, Measham AR, Feifer CN, Gertler PJ. The impact of maternal health improvement on perinatal survival: cost-effective alternatives. International Journal of Health Planning and Management 1994;9(2):131-49.

\section{WHO 1996}

World Health Organization. Essential newborn care: report of a technical working group. WHO/FRH/MSM/96. Geneva: World Health Organization., 1996.

\section{WHO 2000}

World Health Organization. The World Health Report 2005: make every mother or child count. Geneva: World Health Organization, 2000.

* Indicates the major publication for the study 


\title{
CHARACTERISTICS OF STUDIES
}

\section{Characteristics of included studies [ordered by study ID]}

\author{
Alisjahbana 1995
}

Methods

The study was a longitudinal study in which intervention clusters were compared with controlled clusters, following pregnant women over a 15-month period from 1 March 1992 to 1 May 1993 in an implementation area and control area. Both the areas were located in West Java, Indonesia

Participants

All mothers and infants delivered between 1 June 1992 and 31 May 1993. Outcomes were given for 3275 women from intervention and control clusters

Interventions

Intervention arm

In intervention areas TBAs were trained for enhanced complication referrals, teaching mothers about danger signs. Improved accessibility to healthcare services and trained hospital doctors and nurses for appropriate care management, distributed home-based maternal and neonatal action records

\section{Control arm}

Routine services provided by government healthcare facilities and hospitals in the control area

Outcomes Antenatal care, eclampsia during pregnancy, referrals by TBAs, Intrapartum complications

Notes

The population was around 90,000 in the intervention area and 40,000 in the comparison area. 47 female interviewers and 4 male supervisors, who were graduates from the social science faculty, were employed

\begin{tabular}{|c|c|c|}
\hline Item & Authors' judgement & Description \\
\hline Adequate sequence generation? & No & $\begin{array}{l}\text { Quote: "The study design was longitudi- } \\
\text { nal, following pregnant women over a 15- } \\
\text { month period from } 1 \text { March } 1992 \text { to } 31 \\
\text { May } 1993 \text { in an implementation area and } \\
\text { control area" } \\
\text { Comment: probably not done. }\end{array}$ \\
\hline Allocation concealment? & No & This was a quasi-experimental design. \\
\hline $\begin{array}{l}\text { Blinding? } \\
\text { All outcomes }\end{array}$ & No & $\begin{array}{l}\text { Quote: "Both the intervention and control } \\
\text { areas were at the distance of } 60 \mathrm{~km} \text {, thus } \\
\text { the probability that contamination could } \\
\text { occur was low" } \\
\text { Comment: since it was a cluster design, } \\
\text { contamination was assured to be main- } \\
\text { tained. Not possible to blind those deliver- }\end{array}$ \\
\hline
\end{tabular}

Community-based intervention packages for reducing maternal and neonatal morbidity and mortality and improving neonatal 
Alisjahbana 1995 (Continued)

ing and receiving intervention

\begin{tabular}{lll}
\hline $\begin{array}{l}\text { Incomplete outcome data addressed? } \\
\text { All outcomes }\end{array}$ & Unclear & $\begin{array}{l}\text { Insufficient information to permit judge- } \\
\text { ment. }\end{array}$ \\
\hline Free of selective reporting? & Yes & $\begin{array}{l}\text { Report on outcomes as reflected in objec- } \\
\text { tives. }\end{array}$ \\
\hline
\end{tabular}

Azad 2010

Methods

This was a cluster-randomised controlled trial conducted in Bangladesh. 18 clusters in 3 districts were randomly assigned to either intervention or control. Analysis was by intention to treat

Participants

Women of reproductive age, mothers-in-law, adolescents. Total of 30952 births and 29 889 live births were reported during the trial period

Interventions Intervention arm

In intervention clusters a woman facilitator convened 18 groups monthly to support action learning for women, and to develop and implement strategies to address maternal and newborn health problems. Implemented a participatory learning and action cycle in which they identified and prioritised problems, then formulated strategies, implemented, monitored and finally evaluated the process. Intervention group was again divided into two according to the trained TBAs for asphyxia or not

Control arm

Control group was not provided with participatory learning groups

Outcomes

Miscarriage, stillbirth, neonatal mortality and maternal mortality

Notes

Risk of bias

\begin{tabular}{lll}
\hline Item & Authors' judgement & Description \\
\hline Adequate sequence generation? & Unclear & $\begin{array}{l}\text { Quote: "Within each district, the interven- } \\
\text { tion team randomly allocated unions } 4 \text { to } \\
\text { intervention or control, with three inter- } \\
\text { vention and three control unions per dis- } \\
\text { trict" } \\
\text { Comment: insufficient information to per- } \\
\text { mit judgement. }\end{array}$ \\
\hline Allocation concealment? & Yes & $\begin{array}{l}\text { Comment: since it was a cluster-ran- } \\
\text { domised trial, allocation concealment } \\
\text { should not be an issue as in this design all } \\
\text { the clusters are randomised at once }\end{array}$
\end{tabular}


Azad 2010 (Continued)

\begin{tabular}{|c|c|c|}
\hline $\begin{array}{l}\text { Blinding? } \\
\text { All outcomes }\end{array}$ & No & $\begin{array}{l}\text { Quote: "The intervention and participants } \\
\text { were not blinded to group allocation" }\end{array}$ \\
\hline $\begin{array}{l}\text { Incomplete outcome data addressed? } \\
\text { All outcomes }\end{array}$ & No & $\begin{array}{l}\text { Exclusion }(0 \%) \text { and attrition }(14.2 \%) \text { was } \\
\text { reported along with their reasons }\end{array}$ \\
\hline Free of selective reporting? & Unclear & $\begin{array}{l}\text { The study appears to be free of selective } \\
\text { reporting. }\end{array}$ \\
\hline
\end{tabular}

Bang 1999

Methods

Participants

Interventions
This was a clustered controlled trial done in Gadchiroli district of India. Intervention was implemented in 39 villages and 47 villages were kept as control. Village women with 5-10 years of schooling who were willing were chosen to be VHW. Population characteristics at baseline in intervention and control area were similar

All pregnant women, neonates and grandmothers in study villages. Total number of live births during the trial period were 8192

\section{Intervention arm}

Training of female VHWs to take histories, observe labour, examine neonate and record findings with the help of colour photographs for visual reference

Training of VHWs in home-based management of neonatal illnesses including pneumonia

Health education of mothers and grandmothers about care of pregnant women and of neonates (nutrition in pregnancy, initiating early and exclusive breastfeeding, prevention of infection, temperature maintenance, importance of weight gain, recognising danger signs or symptoms in neonates and seeking immediate help from a health worker

\section{Control arm}

Training of traditional birth attendants and management of pneumonia in children was not given by project team in the control area, where these tasks were done by the government health services and the Integrated Child Development Service (ICDS) workers

Outcomes Neonatal mortality rate, infant mortality rate, perinatal mortality rate, still birth rate

Notes

Supplementary feeding was provided to children, pregnant and lactating women, diarrhoea and ARI infection in children by ICDS. For this review we will compare the outcomes of 3rd year with the control

\section{Risk of bias}

\begin{tabular}{lll}
\hline Item & Authors' judgement & Description \\
\hline Adequate sequence generation? & No & Quote: "Intervention was implemented in \\
& & $\begin{array}{l}\text { 39 villages and 47 villages were kept as con- } \\
\text { trol' }\end{array}$
\end{tabular}


Bang 1999 (Continued)

Comment: probably not done.

\begin{tabular}{l|l|l}
\hline Allocation concealment? & Yes & $\begin{array}{l}\text { Comment: since it is a cluster-randomised } \\
\text { trial, allocation concealment should not be } \\
\text { an issue as in this design all clusters are ran- } \\
\text { domised at once }\end{array}$ \\
\hline $\begin{array}{l}\text { Blinding? } \\
\text { All outcomes }\end{array}$ & Unclear & $\begin{array}{l}\text { Insufficient information about to permit } \\
\text { any judgement. }\end{array}$ \\
\hline $\begin{array}{l}\text { Incomplete outcome data addressed? } \\
\text { All outcomes }\end{array}$ & Unclear & $\begin{array}{l}\text { Number of pregnant women excluded and } \\
\text { attrition not mentioned nor their reasons }\end{array}$ \\
\hline \begin{tabular}{l} 
Free of selective reporting? \\
\hline
\end{tabular} & Yes & $\begin{array}{l}\text { Study appears to be free of selective report- } \\
\text { ing. }\end{array}$ \\
\hline
\end{tabular}

Baqui -home care (a) 2008

Methods

Participants

Interventions
This was a cluster-randomised controlled trial done in 3 rural sub districts (Beanibazar, Zakiganj, Kanaighat) of Sylhet district of Bangladesh. 24 clusters were randomly assigned to 1 of 2 intervention arms. Baseline household survey to enumerate ever-married women, maternal and newborn care knowledge and practices and neonatal mortality was done. CHW identified pregnancies and provided intervention package. Interim sample household surveys were done to measure intervention inputs, coverage and changes in key new born care practices in all 3 study arms

All pregnant women during the intervention were eligible to participate. Baseline characteristics of subjects in all arms were similar. Data was reported from 1760 livebirths in home-care arm

\section{Intervention arm}

Intervention 1: $\mathrm{HC}$ model with training of CHWs in $\mathrm{BCC}$ and $\mathrm{ENC}$. CHWs visited pregnant women in antenatal and postnatal period to promote birth/newborn care preparedness, provide iron folate supplements and to counsel on breastfeeding issues. Also included home screening/management/referral of sick newborns

-TBA training on cleanliness during delivery, maternal danger signs, and newborn care. Specific recruitment of volunteer community-resource people to improve attendance at community meetings, and care seeking for maternal and neonatal complications

\section{Control arm}

Families in the comparison arm received the usual health services provided by the government, non-government organisations, and private providers. Refresher training sessions for management of maternal and newborn complications were provided for government health workers in all three study arms. Projahnmo staff ensured adequate supplies of antibiotics for treatment of newborn infections at government sub-district hospitals, which served residents in all three study arms. For tetanus-toxoid vaccination in all study arms and for provision of iron and folic acid supplements in the community-care and comparison arms, they relied on existing government mechanisms 
Baqui -home care (a) 2008 (Continued)

Change in rate of neonatal mortality, stillbirth, abortion, antenatal visits from trained
providers, use of iron and folic acid supplements, use of clean cord cutting instruments,
delays in newborn first bath, and breastfeeding within 1 hour of birth and Tetanus-
toxoid immunisation coverage

Notes

Refresher training sessions for management of maternal and newborn complications were provided GHWs in all 3 study arms

\section{Risk of bias}

\begin{tabular}{|c|c|c|}
\hline Item & Authors' judgement & Description \\
\hline Adequate sequence generation? & Yes & $\begin{array}{l}\text { Quote: "each cluster [was] randomly as- } \\
\text { signed to one of the two intervention arms } \\
\text { to the comparison arm with computer-gen- } \\
\text { erated pseudo-random number sequence } \\
\text { without stratification or matching" } \\
\text { Comment: probably done. }\end{array}$ \\
\hline Allocation concealment? & Yes & $\begin{array}{l}\text { Comment: since it is a cluster-randomised } \\
\text { trial, allocation concealment should not be } \\
\text { an issue as in this design as all clusters are } \\
\text { randomised }\end{array}$ \\
\hline $\begin{array}{l}\text { Blinding? } \\
\text { All outcomes }\end{array}$ & No & $\begin{array}{l}\text { Quote: "the nature of intervention meant } \\
\text { masking was unachievable" } \\
\text { Comment: not done. }\end{array}$ \\
\hline $\begin{array}{l}\text { Incomplete outcome data addressed? } \\
\text { All outcomes }\end{array}$ & Yes & $\begin{array}{l}\text { Exclusion data were not reported nor rea- } \\
\text { sons. Attrition }(15 \%) \text { was mentioned but } \\
\text { reasons were not mentioned }\end{array}$ \\
\hline Free of selective reporting? & Yes & $\begin{array}{l}\text { Study appears to be free of selective report- } \\
\text { ing. }\end{array}$ \\
\hline
\end{tabular}




\begin{abstract}
Methods
This was Integrated Nutrition and Health Program (INHP), a quasi-experimental study, a collaborative project of CARE-India and Government of India. Barabanki served as the intervention district, while Unnao, was used as a comparison district. In both the INHP and standard government health services, health education and services were provided by auxiliary nurse-midwives, and maternal and child health promotion (anganwadi) workers and change agents. The anganwadi workers, auxiliary nurse-midwives, and change agents in the intervention district received a total of 6 days of training on the care of mothers and newborn babies. A baseline household survey was conducted between January and June 2003. Household surveys were repeated at the end of the project, between January and March 2006
\end{abstract}

13,826 pregnant women participated irrespective of their gestational age. Baseline characteristics of both the group were comparable

\section{Intervention arm}

- Antenatal Interventions: early registration of pregnancy with aganwadi worker and auxiliary nurse-midwife, at least 3 antenatal check-ups, 2 doses of tetanus toxoid immunisation per pregnancy, daily iron-folic acid supplements for 3 months, reduction of pregnant women's workload (rest at least 2 hours/day), consumption of an additional meal or snack per day and micronutrient rich foods, birth preparedness: identification of trained provider and a clean delivery site, savings for emergency, arrangement for transport if needed, obtaining disposable delivery kit or prepare delivery kit, identify and seek care for danger signs in mothers and neonates

- At the time of delivery: clean surface for delivery, clean hands, new blade, clean cord tie, clean cloth to wrap neonate, breastfeed within 1 hour of delivery, dry and wrap neonate immediately after birth, delay first bath for 3 days, seek trained care promptly in case of danger signs for mother or baby

-Postnatal interventions: early and exclusive breastfeeding, cord care and thermal care, apply no substance to the cord stump, detect danger signs and seek care from trained health providers

\section{Control arm}

No interventions were provided to control arm

Outcomes

Antenatal check ups, antenatal immunisation, iron-folic acid consumption, saved money for childbirth, other birth planning steps, institutional delivery, delivery attended by health provider, clean cord care, thermal care for first 6 hours, breastfeeding within $1^{\text {st }}$ hour of birth, neonatal check ups.

Notes

Intervention was implemented in 8 Indian states.

\section{Risk of bias}

Item Authors' judgement $\quad$ Description

Adequate sequence generation? No

Quote: “used a computer programme to randomly select nine blocks in the intervention district and weight blocks in the comparison district"; "quasi-experimental design" 
Baqui-CARE INDIA 2008 (Continued)

Comment: probably done but not a true random allocation.

\begin{tabular}{l|l|l}
\hline $\begin{array}{l}\text { Allocation concealment? } \\
\text { Yes }\end{array}$ & Unclear & $\begin{array}{l}\text { Comment: since it is a cluster trial, alloca- } \\
\text { tion concealment should not be an issue as } \\
\text { in this design as all clusters are randomised }\end{array}$ \\
\hline $\begin{array}{l}\text { Blinding? } \\
\text { All outcomes }\end{array}$ & Unclear & $\begin{array}{l}\text { Insufficient information to permit judge- } \\
\text { ment. }\end{array}$ \\
\hline $\begin{array}{l}\text { Incomplete outcome data addressed? } \\
\text { All outcomes }\end{array}$ & Unclear & $\begin{array}{l}\text { Insufficient information to permit judge- } \\
\text { ment. }\end{array}$ \\
\hline \begin{tabular}{l} 
Free of selective reporting? \\
\hline
\end{tabular} & $\begin{array}{l}\text { Insufficient information to permit judge- } \\
\text { ment. }\end{array}$ \\
\hline
\end{tabular}

Baqui-com care (a) 2008

Methods

Participants

Interventions

Outcomes
This was a cluster-randomised controlled trial done in 3 rural sub districts (Beanibazar, Zakiganj, Kanaighat) of Sylhet district of Bangladesh. 24 clusters were randomly assigned to 1 of 2 intervention arms. Baseline household survey to enumerate ever-married women, maternal and newborn care knowledge and practices and neonatal mortality was done. CHW identified pregnancies and provided intervention package. Interim sample household surveys were done to measure intervention inputs, coverage and changes in key new born care practices in all 3 study arms

All pregnant women during the intervention were eligible to participate. Baseline characteristics of subjects in all arms were similar. Data was reported from 1661 livebirths in community-care arm

\section{Intervention arm}

Intervention 2: community-care (CC) model with community meetings with pregnant women and family members and advocacy meetings with local leaders

-TBA training on cleanliness during delivery, maternal danger signs, and newborn care. Specific recruitment of volunteer community-resource people to improve attendance at community meetings, and care seeking for maternal and neonatal complications

\section{Control arm}

Families in the comparison arm received the usual health services provided by the government, non-government organisations, and private providers. Refresher training sessions for management of maternal and newborn complications were provided for government health workers in all three study arms. Projahnmo staff ensured adequate supplies of antibiotics for treatment of newborn infections at government sub-district hospitals, which served residents in all three study arms. For tetanus-toxoid vaccination in all study arms and for provision of iron and folic acid supplements in the community-care and comparison arms, they relied on existing government mechanisms

Change in rate of neonatal mortality, stillbirth, abortion, antenatal visits from trained providers, use of iron and folic acid supplements, use of clean cord cutting instruments, delays in newborn first bath, and breastfeeding within 1 hour of birth and tetanus-toxoid 
immunisation coverage

\begin{tabular}{ll} 
Notes & $\begin{array}{l}\text { Refresher training sessions for management of maternal and newborn complications } \\
\text { were provided GHWs in all } 3 \text { study arms }\end{array}$ \\
\hline
\end{tabular}

\section{Risk of bias}

\begin{tabular}{|c|c|c|}
\hline Item & Authors' judgement & Description \\
\hline Adequate sequence generation? & Yes & $\begin{array}{l}\text { Quote: "each cluster were randomly as- } \\
\text { signed to one of the two intervention arms } \\
\text { to the comparison arm with computer-gen- } \\
\text { erated pseudo-random number sequence } \\
\text { without stratification or matching" } \\
\text { Comment: probably done. }\end{array}$ \\
\hline Allocation concealment? & Yes & $\begin{array}{l}\text { Comment: since it is a cluster-randomised } \\
\text { trial, allocation concealment should not be } \\
\text { an issue as in this design as all clusters are } \\
\text { randomised }\end{array}$ \\
\hline $\begin{array}{l}\text { Blinding? } \\
\text { All outcomes }\end{array}$ & No & $\begin{array}{l}\text { Quote: "the nature of intervention meant } \\
\text { masking was unachievable" } \\
\text { Comment: not done. }\end{array}$ \\
\hline $\begin{array}{l}\text { Incomplete outcome data addressed? } \\
\text { All outcomes }\end{array}$ & Yes & $\begin{array}{l}\text { Exclusion data were not reported nor its } \\
\text { reasons. Attrition }(15 \%) \text { was mentioned } \\
\text { but their reasons were not mentioned }\end{array}$ \\
\hline Free of selective reporting? & Yes & $\begin{array}{l}\text { Study appears to be free of selective report- } \\
\text { ing. }\end{array}$ \\
\hline
\end{tabular}

Bari 2006

Methods

The cluster-randomised trial has 2 arms: an intervention arm with CHWs delivering a package of maternal and newborn-care interventions in the home and a comparison arm. Mirzapur upazila has 13 unions, with a population of around 24,000 each; of these, 6 were randomly allocated to each study arm, excluding the 1 urban union

Participants

Pregnant women, mother of neonates and sick newborns participated. The total of 792 sick newborns were assessed during the study period

Interventions

\section{Intervention arm}

$36 \mathrm{CHWs}$ were recruited and provided 1 month of initial training to equip them to provide a package of maternal and newborn care. These CHWs had a minimum of 10th grade education and resided in the population they would serve. Each CHW was responsible for about 4000 people. The CHWs carried out bi-monthly pregnancy surveillance and registration of married women of reproductive age (MWRA) and made 


\begin{tabular}{|c|c|c|}
\hline & \multicolumn{2}{|c|}{$\begin{array}{l}\text { home-visits in the third and the eighth month of pregnancy to counsel families on } \\
\text { birth and neonatal care preparedness (BNCP). After delivery, the CHWs made home- } \\
\text { visits to promote evidence-based domiciliary newborn care and to identify and refer sick } \\
\text { newborns and mothers on day } 0 \text { (day of birth), } 3,6 \text {, and } 9 \text {. Care-seeking for sick newborns } \\
\text { through health education of families, identification and referral of sick newborns in the } \\
\text { community by community health workers (CHWs), and strengthening of neonatal care } \\
\text { in Kumudini Hospital, Mirzapur } \\
\text { Control arm } \\
\text { In the control arm, interventions by CHW were not intervened while they were served } \\
\text { by the same hospital }\end{array}$} \\
\hline Outcomes & \multicolumn{2}{|c|}{ Newborn sickness and referrals to newborn sickness. } \\
\hline \multicolumn{3}{|l|}{ Notes } \\
\hline \multicolumn{3}{|l|}{ Risk of bias } \\
\hline Item & Authors' judgement & Description \\
\hline Adequate sequence generation? & Unclear & $\begin{array}{l}\text { Quote: "Mirzapur upazila has } 13 \text { unions, } \\
\text { with a population of around } 24,000 \text { each; } \\
\text { of these, } 6 \text { were randomly allocated to each } \\
\text { study arm, excluding the one urban union" } \\
\text { Comment: insufficient information to per- } \\
\text { mit judgement. }\end{array}$ \\
\hline Allocation concealment? & Yes & $\begin{array}{l}\text { Comment: since it is a cluster trial, alloca- } \\
\text { tion concealment should not be an issue as } \\
\text { in this design as all clusters are randomised }\end{array}$ \\
\hline $\begin{array}{l}\text { Blinding? } \\
\text { All outcomes }\end{array}$ & Unclear & $\begin{array}{l}\text { Insufficient information to permit judge- } \\
\text { ment. }\end{array}$ \\
\hline $\begin{array}{l}\text { Incomplete outcome data addressed? } \\
\text { All outcomes }\end{array}$ & Unclear & $\begin{array}{l}\text { Insufficient information to permit judge- } \\
\text { ment. }\end{array}$ \\
\hline Free of selective reporting? & Yes & $\begin{array}{l}\text { Study appears to be free of selective report- } \\
\text { ing. }\end{array}$ \\
\hline
\end{tabular}



Pakistan. 24 village clusters were identified of primary care facility. Out of those 8 clusters were randomly selected for this pilot study. 4 districts chosen to receive intervention were matched with 4 control clusters for population size, and birth and neonatal mortalities rates. More household in intervention clusters and electricity ( $87 \%$ vs $70 \%)$ and water pumps (67\% vs $56 \%)$. All other baseline characteristics were comparable

Participants

Women of reproductive age and pregnant women participated. Total number births during the trial period were 5134 among which 4815 were live births

Interventions

Intervention arm

- Standard curriculum (for all villages): promotion of antenatal care, iron and folate use during pregnancy, immediate new born care, cord care, promotion of exclusive breastfeeding

- Additional curriculum (for intervention village clusters): promotion of maternal nutrition and rest, early breastfeeding (within first hour) and colostrum administration (avoidance of prelacteal feeds), thermoregulation, home care of low birthweight infants, treatment of pneumonia with oral TMP-SMX, recognition of danger signs, training in group counselling and communication strategies

- LHWs were encouraged to visit all pregnant women twice during pregnancy, within 24 hrs of birth and 4 times in the first postnatal month and were encouraged to link up with local Dais.

- LHWs were supported by the creation of voluntary community health committee which helped in conducting community education group sessions

\section{Control arm}

In communities in which the intervention package was not implemented, the LHW training programme continued as usual, with regular refresher sessions, but no attempt was made to link LHWs with the Dais.

Outcomes

Stillbirths, early neonatal deaths, late neonatal deaths, total neonatal deaths, perinatal deaths

Notes

Intervention was supported by the creation of voluntary community health committees Special training in basic and intermediate newborn care was offered to all public-sector rural health centre and hospital-based medical and nursing staff, irrespective of whether the intervention was implemented in their community. All health-care facilities were provided with basic and intermediate newborn care equipment courtesy of the United Nations Children's Fund (UNICEF) in Sindh

Risk of bias

\begin{tabular}{lll}
\hline Item & Authors' judgement & Description \\
\hline Adequate sequence generation? & Unclear & $\begin{array}{l}\text { Quote: “eight clusters were randomly se- } \\
\text { lected”. } \\
\text { Comment: insufficient information to per- } \\
\text { mit judgement. }\end{array}$
\end{tabular}

Community-based intervention packages for reducing maternal and neonatal morbidity and mortality and improving neonatal 
Bhutta 2008 (Continued)

\begin{tabular}{l|l|l}
\hline $\begin{array}{l}\text { Allocation concealment? } \\
\text { Yes }\end{array}$ & Yes & $\begin{array}{l}\text { Comment: since it is a cluster-randomised } \\
\text { trial, allocation concealment should not be } \\
\text { an issue as in this design all clusters are ran- } \\
\text { domised at once }\end{array}$ \\
\hline $\begin{array}{l}\text { Blinding? } \\
\text { All outcomes }\end{array}$ & Unclear & $\begin{array}{l}\text { Data collectors were independent of imple- } \\
\text { menters. }\end{array}$ \\
\hline $\begin{array}{l}\text { Incomplete outcome data addressed? } \\
\text { All outcomes }\end{array}$ & Yes & $\begin{array}{l}\text { Insufficient information to permit judge- } \\
\text { ment. }\end{array}$ \\
\hline $\begin{array}{l}\text { Free of selective reporting? } \\
\text { S }\end{array}$ & & $\begin{array}{l}\text { Study appears to be free of selective report- } \\
\text { ing. }\end{array}$ \\
\hline
\end{tabular}

Bhutta 2010

Methods

This is a cluster-randomised trial of community-based interventions to reduce neonatal deaths due to birth asphyxia, neonatal sepsis and prematurity in rural areas of Pakistan

Participants

Pregnant women, other family members. Total number of births in trial period were 24, 095 and live births were 23,033

Interventions

\section{Intervention arm}

LHWs = along with the basic training (for control group) they received additional training on recognition of high-risk pregnancies and referrals to LBW infants. TBAs = along with the basic training (for control group) they received additional training on promotion of LHW attendance at births

To create awareness in the community and at the household level in control and intervention clusters, female and male supports groups (health committees) were formed/ strengthened. The LHW formed female health committee and male activists formed male health committees in the LHW catchment area. Meetings of both groups were arranged with the assistance of the community health committee and LHWs on monthly basis for dissemination of health messages and education related to maternal and newborn health and problems. Separate community group education sessions for mothers, mother in laws, married women especially with pregnancy and fathers, father in laws for health education of the communities were conducted through the supports groups in the LHW catchment area using educational material as flip charts on antenatal care, identification of danger signs related to pregnancy and recognition of simple risk factors for high-risk pregnancies and births (these include severe maternal malnutrition, illness, short stature, previous perinatal deaths etc), birth preparedness (transport, money, skilled birth attendant, facility), essential and immediate newborn care and recognition of danger signs and sepsis with early and appropriate referral

Control Arm: LHW training programme continued as usual, with regular refresher sessions, but no attempt was made to link LHWs with the Dais. They were however provided with regular refresher training according to the standard national LHW program curriculum including monthly debriefing sessions in public sector health facilities 
Bhutta 2010 (Continued)

\begin{tabular}{l|l} 
Outcomes & $\begin{array}{l}\text { Neonatal mortality rates, perinatal mortality rates, birth asphyxia-related neonatal mor- } \\
\text { tality rates, neonatal mortality rates in low birthweight infants, neonatal mortality rates } \\
\text { due to sepsis }\end{array}$ \\
\hline Notes & $\begin{array}{l}\text { This is an ongoing trial. Results from 8th community surveillance are included in this } \\
\text { review }\end{array}$ \\
\hline
\end{tabular}

Risk of bias

\begin{tabular}{|c|c|c|}
\hline Item & Authors' judgement & Description \\
\hline Adequate sequence generation? & Yes & $\begin{array}{l}\text { Quote: "Twenty-six such clusters with } \\
\text { available LHWs were identified in the dis- } \\
\text { trict, } 8 \text { of which were involved in the pilot } \\
\text { study. Two further clusters were excluded as } \\
\text { they had very few LHWs. The full cluster } \\
\text { RCT was thus implemented in the remain- } \\
\text { ing } 16 \text { clusters" ; "used restricted, stratified } \\
\text { randomization to allocate clusters to the } \\
\text { intervention and control arms (21). Three } \\
\text { strata (comprising } 2,6 \text { and } 8 \text { clusters) were } \\
\text { identified based on their size and the num- } \\
\text { ber of LHWs per } 1000 \text { population. We } \\
\text { identified } 126 \text { random allocations which } \\
\text { resulted in similar population sizes in the } 2 \\
\text { arms....From this list of "balanced" alloca- } \\
\text { tions we selected one scheme at random." } \\
\text { Comment: Probably done }\end{array}$ \\
\hline Allocation concealment? & Yes & $\begin{array}{l}\text { Comment: since it is a cluster-randomised } \\
\text { trial, allocation concealment should not be } \\
\text { an issue as in this design all clusters are ran- } \\
\text { domised at once }\end{array}$ \\
\hline $\begin{array}{l}\text { Blinding? } \\
\text { All outcomes }\end{array}$ & Yes & $\begin{array}{l}\text { Quote: "established } 13 \text { independent data } \\
\text { collection teams who undertook quarterly } \\
\text { visits to all villages in intervention and con- } \\
\text { trol clusters." } \\
\text { Comment: data collectors were indepen- } \\
\text { dent of implementers. }\end{array}$ \\
\hline $\begin{array}{l}\text { Incomplete outcome data addressed? } \\
\text { All outcomes }\end{array}$ & Yes & $\begin{array}{l}\text { Attrition was } 12.4 \% \text { in intervention clus- } \\
\text { ters and } 10.8 \% \text { in control clusters }\end{array}$ \\
\hline Free of selective reporting? & Yes & $\begin{array}{l}\text { Study appears to be free of selective report- } \\
\text { ing. }\end{array}$ \\
\hline
\end{tabular}

Community-based intervention packages for reducing maternal and neonatal morbidity and mortality and improving neonatal 


\begin{tabular}{|c|c|c|}
\hline Methods & \multicolumn{2}{|c|}{$\begin{array}{l}\text { This was a cluster-controlled trial. In this study West Kiang was chosen as the district } \\
\text { where interventions were carried out }\end{array}$} \\
\hline Participants & \multicolumn{2}{|c|}{ Total of 1516 pregnant women participated. } \\
\hline Interventions & \multicolumn{2}{|c|}{$\begin{array}{l}\text { Intervention arm: } \\
\text { In the intervention arm, } \mathrm{MCH} \text { (maternal and child health) team consisted of community } \\
\text { health nurses, midwives and TBAs trained to: provide surveillance for early identification } \\
\text { of pregnant women, register pregnant women in an antenatal care programme, treat } \\
\text { anaemia and infections, identify potential obstetrics problems with prompt referrals for } \\
\text { tertiary care when indicated and to treat emergency cases and transfer to specialised care } \\
\text { rapidly } \\
\text { Control arm } \\
\text { In control areas, health services were provided by government health }\end{array}$} \\
\hline Outcomes & \multicolumn{2}{|c|}{ Haemoglobin check, stillbirths, perinatal deaths. } \\
\hline \multicolumn{3}{|l|}{ Notes } \\
\hline \multicolumn{3}{|l|}{ Risk of bias } \\
\hline Item & Authors' judgement & Description \\
\hline Adequate sequence generation? & No & $\begin{array}{l}\text { Quote: "West Kiang was chosen as the dis- } \\
\text { trict where interventions were carried out } \\
\text { and controlled clusters were from Upper } \\
\text { Budibho" }\end{array}$ \\
\hline Allocation concealment? & No & It is a quasi-experimental design. \\
\hline $\begin{array}{l}\text { Blinding? } \\
\text { All outcomes }\end{array}$ & Unclear & $\begin{array}{l}\text { Insufficient information to permit judge- } \\
\text { ment. }\end{array}$ \\
\hline $\begin{array}{l}\text { Incomplete outcome data addressed? } \\
\text { All outcomes }\end{array}$ & Unclear & $\begin{array}{l}\text { Insufficient information to permit judge- } \\
\text { ment. }\end{array}$ \\
\hline Free of selective reporting? & Unclear & $\begin{array}{l}\text { Insufficient information to permit judge- } \\
\text { ment. }\end{array}$ \\
\hline
\end{tabular}

Greenwood 1990

\begin{tabular}{l|l} 
Methods & $\begin{array}{l}\text { The study was cluster controlled trial. The study was carried out during a 5-year period } \\
\text { in } 41 \text { villages and hamlets on the north bank of the river Gambia }\end{array}$ \\
\hline Participants & Total of 1913 women aged $15-44$ years of age. \\
\hline Interventions & $\begin{array}{l}\text { Intervention arm } \\
\text { Government of Gambia implemented Primary Health Care service for which they se- } \\
\text { lected village health workers and trained TBAs regarding clean deliveries at home, refer- }\end{array}$
\end{tabular}


Greenwood 1990 (Continued)

\begin{tabular}{|c|c|c|}
\hline & \multicolumn{2}{|c|}{$\begin{array}{l}\text { rals for delivery and promotion of antenatal and postnatal care among mothers. Women } \\
\text { selected for TBA training received a 10-week training course at the regional medical cen- } \\
\text { tres and they have subsequently received support from government employed commu- } \\
\text { nity nurses. They also received obstetric pack. They were also trained to deliver chemo- } \\
\text { prophylaxis to mothers for Malaria } \\
\text { Control arm } \\
\text { Health services were provided by government health staff. }\end{array}$} \\
\hline Outcomes & \multicolumn{2}{|c|}{ Institutional deliveries, complication during pregnancy. } \\
\hline \multicolumn{3}{|l|}{ Notes } \\
\hline \multicolumn{3}{|l|}{ Risk of bias } \\
\hline Item & Authors' judgement & Description \\
\hline Adequate sequence generation? & No & $\begin{array}{l}\text { Quote: "all the villages with } \mathrm{PHC} \text { were } \\
\text { taken as interventional villages and villages } \\
\text { with no } \mathrm{PHC} \text { were kept as control arm" }\end{array}$ \\
\hline Allocation concealment? & No & It is a quasi-experimental study. \\
\hline $\begin{array}{l}\text { Blinding? } \\
\text { All outcomes }\end{array}$ & Unclear & $\begin{array}{l}\text { Insufficient information to permit judge- } \\
\text { ment. }\end{array}$ \\
\hline $\begin{array}{l}\text { Incomplete outcome data addressed? } \\
\text { All outcomes }\end{array}$ & Unclear & $\begin{array}{l}\text { Insufficient information to permit judge- } \\
\text { ment. }\end{array}$ \\
\hline Free of selective reporting? & Unclear & $\begin{array}{l}\text { Insufficient information to permit judge- } \\
\text { ment. }\end{array}$ \\
\hline
\end{tabular}

Jokhio 2005

Methods

This was a cluster-randomised controlled trial in Larkana, Sind, Pakistan. Larkana's 7 talukas were allocated to intervention or control groups using computer-generated procedure. TBA registered pregnant women in their catchment area. TBAs were issued delivery kits from primary care centres. TBA visited each enrolled woman at least 3 times during pregnancy to check for danger signs. LHW were trained to support the traditional attendants and data recording

Participants

19,525 pregnant women participated. The Larkana city and its immediate environs were excluded because of better access to healthcare services. Baseline maternal characteristics were similar for the study groups and across clusters with respect to all measured variables except years of education which were slightly greater among women in the control group

Interventions

\section{Intervention arm}

- Training of traditional birth attendants by obstetricians and female paramedics using picture cards containing advice on antepartum, intrapartum and postpartum care, 
conducting clean delivery, use of disposable delivery kit, referring women to emergency obstetrical care and care of the newborn

- Reinforcement by TBAs to pregnant women to seek emergency obstetrical care if need arise

\section{Control arm}

- In controlled clusters TBAs were not provided any training and were not supplied with delivery kits. LHW provided normal monthly home visits to pregnant women and children

Outcomes

Notes
Perinatal mortality, maternal mortality, major complication of pregnancy (haemorrhage, obstructed labour, puerperal sepsis, eclampsia, abortion), referral by TBA for emergency obstetrical care, type and place of delivery and delivery attendants

Obstetrical consultation was also provided by 2 teams from public-sector tertiary care centres in Larkana city. The delivery kit included sterilised disposable gloves, soap, gauze, cotton balls, antiseptic solution, an umbilical-cord clamp and a surgical blade. Maternal deaths were ascertained by LHW on the basis of oral reports

\section{Risk of bias}

\begin{tabular}{|c|c|c|}
\hline Item & Authors' judgement & Description \\
\hline Adequate sequence generation? & Yes & $\begin{array}{l}\text { Quote: "with a computerized-generated } \\
\text { procedure Larkana's seven talukas were al- } \\
\text { located to intervention or control groups" } \\
\text { Comment: probably done. }\end{array}$ \\
\hline
\end{tabular}

Allocation concealment? $\quad$ Yes

Blinding?

Yes

All outcomes

Yes
Yes

Incomplete outcome data addressed All outcomes
Yes
Comment: since it is a cluster-randomised trial, allocation concealment should not be an issue as in this design all clusters are randomised

Quote: "LHW who recorded outcomes could not be blinded to the intervention status of the women but were not made aware of the main study objective or the outcome measured for the planned comparison"

Comment: probably done.

21 women from intervention arm and 11 women from control arm loss to follow-up, (attrition: $0.16 \%$ ), reasons for attrition not mentioned. Exlusion (18.5\%) reasons were not reported

Study has mentioned data regarding all outcome measure as per objectives 

vention and control. An intensive training course in nutrition counselling was established for the 10 nurses employed at intervention group clinics. Baseline biosocial data and anthropometric measurements were collated for each subject and each subject was given a standardised clinical examination. Dietary habits and nutrient intake were studied in depth in a sub sample. Food intake was assessed in both the groups by 24-hour dietary recall and food weighing inventory method at the beginning and every 4 weeks until delivery. Comparison was made for biochemical measurements between those subjects tested during early pregnancy $(<21$ week) and those tested during late pregnancy $(>32$ weeks)

Participants

All pregnant women irrespective of their gestational age. Both groups differed in their baseline characteristics with respect to maternal height (greater in control group $\mathrm{P}<0$. 001). Three hundred women from intervention clinics and 268 from control clinics were selected

Interventions

\section{Intervention arm:}

Nutrition education for women in intervention group was provided through home visits every 2 weeks. Women were educated about basics of nutrition during pregnancy for maternal and fetal health, including food sources, methods for selecting a balanced diet, practical techniques for improving their diet quality, encouragement to consume locally grown foods and to prepare and preserve foods

\section{Control arm}

Health services were provided by government health services.

Outcomes

Biochemical measures: haemoglobin, serum iron, total iron binding capacity, $ß$-carotene, vitamin $\mathrm{A}$, vitamin $\mathrm{C}, \mathrm{RBC}$ glutathione reductase. Maternal and pregnancy outcomes: weight gain during pregnancy, birthweight, length at birth, head circumference, thoracic circumference, small-for-gestational age, gestational age, morbidity and mortality

Notes

To ensure accuracy and consistency program's nurse coordinator accompanied each nurse on their home visits to observe data gathering and any associated problems

Risk of bias

\begin{tabular}{lll}
\hline Item & Authors' judgement & Description \\
\hline Adequate sequence generation? & Yes & $\begin{array}{l}\text { Quote: "the county' } 20 \text { clinics were ran- } \\
\text { domly divided into an intervention and a } \\
\text { control group" } \\
\text { Comment: probably done. }\end{array}$ \\
\hline $\begin{array}{l}\text { Allocation concealment? } \\
\text { Yes }\end{array}$ & & $\begin{array}{l}\text { Comment: since it is a cluster-randomised } \\
\text { trial, allocation concealment should not be } \\
\text { an issue as in this design all clusters are ran- } \\
\text { domised at once }\end{array}$ \\
\hline $\begin{array}{l}\text { Blinding? } \\
\text { All outcomes }\end{array}$ & Unclear & $\begin{array}{l}\text { Insufficient information to permit judge- } \\
\text { ment. }\end{array}$
\end{tabular}


Kafatos 1991 (Continued)

\begin{tabular}{|c|c|c|}
\hline $\begin{array}{l}\text { Incomplete outcome data addressed? } \\
\text { All outcomes }\end{array}$ & Unclear & $\begin{array}{l}\text { Insufficient information to permit judge- } \\
\text { ment. }\end{array}$ \\
\hline Free of selective reporting? & Unclear & $\begin{array}{l}\text { Study has mentioned data regarding all out- } \\
\text { come measure as per objectives }\end{array}$ \\
\hline
\end{tabular}

Kumar 2008

$\begin{array}{ll}\text { Methods } & \text { This was a 3-arm cluster-randomised trial done in Shivgarh, India. A control group } \\ \text { received usual services of government of India and NGO. In intervention areas commu- } \\ \text { nity stakeholders, newborn stakeholders and households with immediate support groups } \\ \text { were targeted. CHWs were recruited and received classroom based and apprenticeship } \\ \text { based field training on Knowledge, attitudes and practices about essential newborn care, } \\ \text { behaviour change management and trust building. Pregnant women were identified by } \\ \text { Saksham Sahayak and } 2 \text { antenatal visits (60 and 30 days before expected delivery) and } \\ 2 \text { postnatal visits (within } 24 \text { hours of birth and day 3) were carried out to implement } \\ \text { intervention }\end{array}$

Participants Pregnant women, mother-in-law, other female members who played supportive role, male members including father-in-law and husband, family's immediate support group included neighbours and relatives who influenced family behaviours and helped with delivery. Baseline characteristics of all 3 arms were comparable. Total of 3837 deliveries were analysed at the end

Interventions

\section{Intervention arm}

Intervention package consisted of home visits and group meetings of stake holders about birth preparedness, hygienic delivery and immediate newborn care including clean umbilical cord, skin care, thermal care including skin-to-skin care, breastfeeding and care seeking from trained providers. Messages were designed to promote newborn care practices to align with existing cultural values and traditions

\section{Control arm}

Received the usual services of governmental and non-governmental organisations in the area

Outcomes

Miscarriages, stillbirths, neonatal deaths and maternal mortality (combined from both the intervention arms)

Notes

Volunteers from within the community called Saksham Karia played a key part in program advocacy, trust building and social legitimisations of changes in behaviour. No treatment was offered to sick neonates; however, they were advised to seek care at nearest health facility

\section{Risk of bias}

Item

Authors' judgement

\section{Description}


Kumar 2008 (Continued)

\begin{tabular}{|c|c|c|}
\hline Adequate sequence generation? & Yes & $\begin{array}{l}\text { Quote: "stratified cluster randomisation } \\
\text { was done at John Hopkins University to } \\
\text { allocate } 39 \text { clusters units randomly to the } \\
\text { three study groups" } \\
\text { Comment: probably done. }\end{array}$ \\
\hline Allocation concealment? & Yes & $\begin{array}{l}\text { Comment: since it is a cluster-randomised } \\
\text { trial, allocation concealment should not be } \\
\text { an issue as in this design all clusters are ran- } \\
\text { domised at once }\end{array}$ \\
\hline $\begin{array}{l}\text { Blinding? } \\
\text { All outcomes }\end{array}$ & Yes & $\begin{array}{l}\text { Quote: "allocation was not masked; how- } \\
\text { ever; boundaries to limit communication } \\
\text { between the two teams were closely moni- } \\
\text { tored" }\end{array}$ \\
\hline $\begin{array}{l}\text { Incomplete outcome data addressed? } \\
\text { All outcomes }\end{array}$ & Yes & $\begin{array}{l}\text { Attrition }(4.1 \%) \text { was given along with its } \\
\text { reasons. }\end{array}$ \\
\hline Free of selective reporting? & Yes & $\begin{array}{l}\text { Study has mentioned data regarding all out- } \\
\text { come measure as per objectives }\end{array}$ \\
\hline
\end{tabular}

Manandhar 2004

Methods

Participants
This was a cluster-RCT conducted in Makwanpur district of Nepal. A village development committee (VDC) was taken as a unit of randomisation. 42 rural VDC were matched into 21 pairs on the basis of geography, ethnicity and population. Between 1998-2000 local community leaders and interested parties were taken into confidence. Married women of reproductive age were identified through a door-to-door baseline survey. A community surveillance system was put in place. It was responsible for monthly visits by local women for enumerations and to monitor pregnancy status of women in cohort. After identification of pregnancy interviews were carried out by VDC interviewer at 7 months of gestation and 1 month postpartum. All pregnancies occurring within the cohort were followed at least 6 weeks after delivery. In the first year facilitation team's skills were developed and groundwork was laid by exploring ideas about child birth.

Inclusion criteria included age between 15-49 years, married, and potential to conceive within the period of study. Exclusion criteria were age under 15 or over 49 years, unmarried, permanently separated or widowed and no potential for conception within period of study. Total of 28,931 women were allocated in the intervention and control arms, among which 6053 pregnancies were reported while 6215 deliveries were analysed

Interventions

\section{Intervention arm}

Monthly meetings of mother's groups to identify maternal and neonatal problems, prioritisation of problems, identification of possible solution, planning, implementation and monitoring those solutions and sharing information with others. Primary cycle consisted of series of 10 meetings

\section{Control arm}


Participatory activities were not conducted in the control areas

\begin{tabular}{l|l} 
Outcomes & $\begin{array}{l}\text { Neonatal mortality rate, perinatal mortality rate, antenatal care services usage, perinatal } \\
\text { illness, birthing practices, healthcare seeking behavior, newborn care practices, breast- } \\
\text { feeding practices, infant mortality }\end{array}$ \\
\hline Notes & $\begin{array}{l}\text { Perinatal birth attendants were available in all localities. } \\
\text { Health-service strengthening activities were undertaken in both intervention and control } \\
\text { areas }\end{array}$ \\
\hline
\end{tabular}

\section{Risk of bias}

\begin{tabular}{l|l|l}
\hline Item & Authors' judgement & Description \\
\hline Adequate sequence generation? & No & $\begin{array}{l}\text { Quote: "allocated one cluster in each pair to } \\
\text { either intervention or control on the basis } \\
\text { of a coin toss" } \\
\text { Comment: probably not done. }\end{array}$ \\
\hline Allocation concealment? & Yes & $\begin{array}{l}\text { Comment: since it is a cluster-randomised } \\
\text { trial, allocation concealment should not be } \\
\text { an issue as in this design all clusters are ran- } \\
\text { domised at once }\end{array}$ \\
\hline $\begin{array}{l}\text { Blinding? } \\
\text { All outcomes }\end{array}$ & No & $\begin{array}{l}\text { Quote: "because of the nature of interven- } \\
\text { tion the trial allocation was not masked" }\end{array}$ \\
\hline $\begin{array}{l}\text { Incomplete outcome data addressed? } \\
\text { All outcomes }\end{array}$ & Yes & $\begin{array}{l}\text { Exclusion (77\%) was mentioned but rea- } \\
\text { sons were not mentioned in the text. At- } \\
\text { tirition (7.4\%) was mentioned along with } \\
\text { its reasons }\end{array}$ \\
\hline
\end{tabular}

Ronsmans 1997

Methods
Matlab is a rural area located about $60 \mathrm{~km}$ from Dhaka, the capital of Bangladesh. The Matlab area has a population of 200,000 and is divided into a treatment area, commonly called the MCH-FP, and the comparison area. The MCH-FP area has received extensive services in health and family planning since 1977, whereas the comparison area has not. Most deliveries in the MCH-FP and comparison areas are attended by a traditional birth attendant; some of these attendants have received training from the Government since 1977 . When difficulties arise during pregnancy, labour, or delivery, care can also be sought from private practitioners

Participants
Women of reproductive age. Total of 44,916 live births from intervention and control areas 
Ronsmans 1997 (Continued)

\begin{tabular}{|c|c|c|}
\hline Interventions & \multicolumn{2}{|c|}{$\begin{array}{l}\text { Intervention arm } \\
\text { Health are provided by } 80 \text { female community health workers who deliver services during } \\
\text { twice-monthly home visits. Tetanus immunisation was introduced in half the MCH-FP } \\
\text { area in } 1979 \text {, and traditional birth attendants were trained in } 1982 \text {. The maternity-care } \\
\text { programme entailed, primarily, the establishment of a maternity-care clinic in Matlab, } \\
\text { the posting of four trained midwives in two health centres in the northern part of the } \\
\text { MCHFP area, and provision of } 24 \text {-hour access to a speedboat. The midwives were asked } \\
\text { to attend pregnant women antenatally or during delivery, to provide minimum obstetric } \\
\text { care, and to accompany the patients to Matlab when required } \\
\text { Control arm } \\
\text { Control areas were not intervened with such intensive health inputs }\end{array}$} \\
\hline Outcomes & \multicolumn{2}{|l|}{ Maternal mortality. } \\
\hline \multicolumn{3}{|l|}{ Notes } \\
\hline \multicolumn{3}{|l|}{ Risk of bias } \\
\hline Item & Authors' judgement & Description \\
\hline Adequate sequence generation? & No & $\begin{array}{l}\text { MCH-FP areas were compared with non } \\
\text { MCH-FP areas. }\end{array}$ \\
\hline Allocation concealment? & No & This is a quasi-experimental study. \\
\hline $\begin{array}{l}\text { Blinding? } \\
\text { All outcomes }\end{array}$ & Unclear & $\begin{array}{l}\text { Insufficient information to permit judge- } \\
\text { ment. }\end{array}$ \\
\hline $\begin{array}{l}\text { Incomplete outcome data addressed? } \\
\text { All outcomes }\end{array}$ & Unclear & $\begin{array}{l}\text { Insufficient information to permit judge- } \\
\text { ment. }\end{array}$ \\
\hline Free of selective reporting? & Unclear & $\begin{array}{l}\text { Insufficient information to permit judge- } \\
\text { ment. }\end{array}$ \\
\hline
\end{tabular}

Srinivasan 1995

Methods

This RCT was conducted in Karur health district in Tamil Nadu from July 1987 to July 1990. 4 PHC centres were selected within $100 \mathrm{~km}$ radius of Karur; 3 sub-centres were selected at random from among those beyond $10 \mathrm{~km}$ pf PHC. 1 each was randomly allocated to high-risk package, Tamil Nadu government package and control. All packages were implemented by trained female ancillary nurse midwives (ANMs). Baseline characteristics of all groups were comparable

Participants

Total of 45,154 newly diagnosed pregnant women was covered; analyses were performed on 1623 pregnant women 
Srinivasan 1995 (Continued)

\begin{tabular}{|c|c|c|}
\hline Interventions & \multicolumn{2}{|c|}{$\begin{array}{l}\text { High-risk (HR) package: assessment of women's general condition, abdominal exami- } \\
\text { nation, blood pressure monitoring, measurement of height, weight and haemoglobin, } \\
\text { urine analysis for analysis of albumin and sugar, history taking for other associated ill- } \\
\text { nesses. Screening was done at the time of registration and at } 20,28,34 \text { and } 38 \text { weeks of } \\
\text { gestation. Visits included clinical examination to check height of uterus, presentation of } \\
\text { fetus. Supplementation of folic acid ( } 1 \text { tablet if } \mathrm{Hb}>11 \mathrm{~g} / \mathrm{dl}, 2 \text { tablets if } \mathrm{Hb}<11 \mathrm{~g} / \mathrm{dl} \\
\text { till delivery) and } 700-1000 \mathrm{mg} \text { of parenteral iron if } \mathrm{Hb}<8 \mathrm{mg} / \mathrm{dl} \text {. Two doses of tetanus } \\
\text { toxoid. } 3 \text { postnatal visits on } 3,10,40 \text { postnatal days. ANM were responsible to detect } \\
\text { maternal and neonatal illness and refer if required. ANM were trained for } 6 \text { weeks by } \\
\text { special training program and for } 6 \text { weeks by general training program. } \\
\text { Tamil Nadu Government (TNG) package: screening was done at the time of registration } \\
\text { and at } 20,28,34 \text { and } 38 \text { weeks of gestation. } 5 \text { postnatal visits on } 1,3 \text {, } 7 \text {, } 15 \text { and } \\
30 \text { postnatal days. Clinical examination by ANM for serious morbidity, haemoglobin } \\
\text { estimation and tetanus toxoid immunisation. A total dosage of } 100 \text { tablets of iron and } \\
\text { folic acid were provided uniformly to all women from } 20 \text { weeks of gestation. ANMs } \\
\text { were given } 6 \text { weeks of training. } \\
\text { Control arm } \\
\text { The implementation of TNG services were the responsibility of the general health services }\end{array}$} \\
\hline Outcomes & \multicolumn{2}{|c|}{$\begin{array}{l}\text { Maternal infections, anaemia }(\mathrm{Hb}<8 \mathrm{~g} / \mathrm{dl}) \text {, eclampsia, delayed labour, maternal distress, } \\
\text { puerperal sepsis, perinatal infection, birth weight, birth injuries, birth asphyxia, neonatal } \\
\text { sepsis, diarrhoea, acute respiratory infection, umbilical sepsis, other infections. }\end{array}$} \\
\hline Notes & \multicolumn{2}{|c|}{$\begin{array}{l}\text { High-risk mothers were referred to project medical officer. In TNG package one exam- } \\
\text { ination by medical officer anytime after registration was also stipulated. Women with } \\
\text { severe morbidity in TNG package were referred to Taluk hospital directly. Data were } \\
\text { recorded at } 14 \text { and } 34 \text { weeks of pregnancy }\end{array}$} \\
\hline \multicolumn{3}{|l|}{ Risk of bias } \\
\hline Item & Authors' judgement & Description \\
\hline Adequate sequence generation? & No & $\begin{array}{l}\text { Quote: "Each PHC was randomly allo- } \\
\text { cated to intervention and control groups" } \\
\text { Comment: probably not done. }\end{array}$ \\
\hline Allocation concealment? & Yes & $\begin{array}{l}\text { Comment: since it is a cluster-randomised } \\
\text { trial, allocation concealment should not be } \\
\text { an issue as in this design all clusters are ran- } \\
\text { domised at once }\end{array}$ \\
\hline $\begin{array}{l}\text { Blinding? } \\
\text { All outcomes }\end{array}$ & Unclear & $\begin{array}{l}\text { Insufficient information to permit judge- } \\
\text { ment. }\end{array}$ \\
\hline $\begin{array}{l}\text { Incomplete outcome data addressed? } \\
\text { All outcomes }\end{array}$ & Unclear & $\begin{array}{l}\text { Insufficient information to permit judge- } \\
\text { ment. }\end{array}$ \\
\hline
\end{tabular}

Community-based intervention packages for reducing maternal and neonatal morbidity and mortality and improving neonatal 
Srinivasan 1995 (Continued)

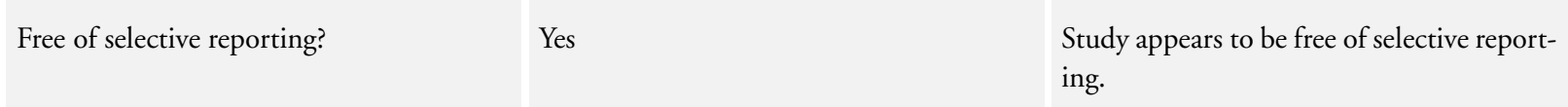

\begin{tabular}{ll} 
Syed 2006 \\
\hline Methods
\end{tabular} \begin{tabular}{l}
$\begin{array}{l}\text { A rural upazila is divided into unions and then into mauzas. An urban upazila is divided } \\
\text { into wards and then mahallas. Thirty mauzas/mahallas were selected from each of the } \\
\text { survey domains with probability proportionate to size (PPS) using the census frame of } \\
\text { the respective upazila. A randomly-selected segment of approximately } 120 \text { households } \\
\text { of a selected mauza/mahalla constituted a cluster. From each cluster, } 12 \text { mothers with } \\
\text { children aged less than } 1 \text { year were selected using the systematic random procedure with } \\
\text { the expectation that at least } 10 \text { respondents would be available for interview successfully } \\
\text { from a cluster. Only } 1 \text { mother from a household was selected for interview. In total, } 3325 \\
\text { mothers in the baseline and } 3110 \text { mothers in the end line survey from } 10 \text { upazilas were } \\
\text { successfully interviewed }\end{array}$ \\
\hline
\end{tabular}

Participants

Pregnant women and mothers of children less than $1 \mathrm{yr}$ of age. Data was gathered from 6435 women in intervention and control clusters

Interventions

\section{Intervention arm}

Increased coverage of CHWs , trained healthcare providers and TBA, use of clean delivery kit, antenatal and postnatal visits

Control arm

No such interventions were delivered in control areas.

Outcomes

Newborn care outcomes, initiation of early breastfeeding.

Notes

Risk of bias

\begin{tabular}{l|l|l}
\hline Item & Authors' judgement & Description \\
\hline Adequate sequence generation? & No & $\begin{array}{l}\text { Quote: "From each cluster, } 12 \text { mothers } \\
\text { with children aged less than one year were } \\
\text { selected using the systematic random pro- } \\
\text { cedure" } \\
\text { Comment: this is not a true RCT. }\end{array}$ \\
\hline $\begin{array}{l}\text { Allocation concealment? } \\
\begin{array}{l}\text { Blinding? } \\
\text { All outcomes }\end{array}\end{array}$ No & This is a quasi-experimental study. \\
\hline $\begin{array}{l}\text { Incomplete outcome data addressed? } \\
\text { All outcomes }\end{array}$ & Unclear & $\begin{array}{l}\text { Insufficient information to permit judg- } \\
\text { ment. }\end{array}$ \\
\hline
\end{tabular}

Community-based intervention packages for reducing maternal and neonatal morbidity and mortality and improving neonatal 
Syed 2006 (Continued)

Free of selective reporting?

Yes

Study appears to be free of selective report-

ing.

Tripathy 2010

$\begin{array}{ll}\text { Methods } & \text { This is a cluster-randomised controlled trial. From } 36 \text { clusters in Jharkhand and Orissa } \\ \text { (mean cluster population: 6338), } 18 \text { clusters were randomly assigned to either interven- } \\ \text { tion or control using stratified allocation. Analysis was by intention to treat }\end{array}$

Participants

Pregnant women. Total number of 19030 births in intervention and control clusters were reported during the trial period

\begin{tabular}{|c|c|c|}
\hline Interventions & \multicolumn{2}{|c|}{$\begin{array}{l}\text { Intervention arm } \\
\text { In intervention clusters a woman facilitator convened } 13 \text { groups every month to sup- } \\
\text { port participatory action and learning for women, and facilitated the development and } \\
\text { implementation of strategies to address maternal and newborn health problems } \\
\text { Implemented a participatory learning cycle, through developing women's groups where } \\
\text { they identify and prioritise maternal and newborn health problems in their commu- } \\
\text { nity, collectively selected relevant strategies to address those problems, implemented the } \\
\text { strategies, and evaluated the results } \\
\text { Control arm } \\
\text { Participatroy activities were not conducted in control areas }\end{array}$} \\
\hline Outcomes & \multicolumn{2}{|c|}{ Miscarriages, stillbirths, neonatal mortality and maternal depression scores } \\
\hline \multicolumn{3}{|l|}{ Notes } \\
\hline \multicolumn{3}{|l|}{ Risk of bias } \\
\hline Item & Authors' judgement & Description \\
\hline Adequate sequence generation? & Unclear & $\begin{array}{l}\text { Quote: "Used stratified randomisation to } \\
\text { allocate clusters to intervention and control } \\
\text { using a two-step process" } \\
\text { Comment: insufficient information to per- } \\
\text { mit judgement. }\end{array}$ \\
\hline Allocation concealment? & Yes & $\begin{array}{l}\text { Comment: since it was cluster-randomised } \\
\text { trial, allocation concealment should not be } \\
\text { an issue in this design as all clusters are ran- } \\
\text { domised at once }\end{array}$ \\
\hline $\begin{array}{l}\text { Blinding? } \\
\text { All outcomes }\end{array}$ & No & $\begin{array}{l}\text { Quote: "Due to the nature of the interven- } \\
\text { tion, neither the intervention team nor the } \\
\text { participants were blinded to group assign- } \\
\text { ment" }\end{array}$ \\
\hline
\end{tabular}

Community-based intervention packages for reducing maternal and neonatal morbidity and mortality and improving neonatal 
Tripathy 2010 (Continued)

\begin{tabular}{lll}
\hline $\begin{array}{l}\text { Incomplete outcome data addressed? } \\
\text { All outcomes }\end{array}$ & Yes & $\begin{array}{l}\text { Attrition (19\%) was reported along with its } \\
\text { reasons. }\end{array}$ \\
\hline $\begin{array}{l}\text { Free of selective reporting? } \\
\text { Yes }\end{array}$ & Study seems to be free from selective re- \\
\hline
\end{tabular}

ANM: assistant nurse midwife

ASMR: asphyxia-specific mortality rate

ARIP acute respiratory infection

BCC: behaviour change communication

BNCP: birth and newborn care preparedness

CF: case fatality

CHW: community health worker

CC: community care

ENC: essential newborn care

GHW: government health worker

HC: home care

HR: high risk

LBW: low birthweight

LHW: lady health worker

MCH-FP: maternal, child health and family planning

MWRA: married women of reproductive age

PHC: primary Health Care

$\mathrm{RBC}$ : routine birth care

TBA: traditional birth attendant

VDC: village development committee

VHW: village health worker

Characteristics of excluded studies [ordered by study ID]

\begin{tabular}{ll}
\hline Study & Reason for exclusion \\
\hline Baqui 2009 & $\begin{array}{l}\text { Not in the scope of this review. It was a validation study. In this study newborns were assessed independently by } \\
\text { a community health worker and a study physician to validate trained community health workers recognition } \\
\text { of signs and symptoms of newborn illnesses and classification of illnesses using a clinical algorithm during } \\
\text { routine home visits in rural Bangladesh }\end{array}$ \\
\hline Bashour 2008 & $\begin{array}{l}\text { Not in the scope of this review. In this study, home visits were made by registered midwives during the } \\
\text { postpartum period }\end{array}$ \\
\hline Bhandari 2003 & $\begin{array}{l}\text { In this study, nutrition workers provided mothers with promotion of exclusive breastfeeding teaching and } \\
\text { then afterwards impact of exclusive breastfeeding practices was observed on the development of diarrhoeal } \\
\text { illnesses and growth of a child }\end{array}$
\end{tabular}

Community-based intervention packages for reducing maternal and neonatal morbidity and mortality and improving neonatal 
(Continued)

Bhandari $2004 \quad \begin{aligned} & \text { Not in the scope of this review. In this study, health and nutrition workers in the intervention communities } \\ & \text { were trained to counsel mothers at multiple contacts on breastfeeding exclusively for } 6 \text { months and on } \\ & \text { appropriate complementary feeding practices thereafter }\end{aligned}$

Bolam 1998 In this study, the impact of health education of mothers were observed on infant care and postnatal family planning practices

Borghi 2005 It was a cost-effectiveness analysis of a participatory intervention with women's groups to improve birth outcomes in rural Nepal.

Cooper 2002 Not in the scope of this review. Interventions to mothers were given related to infant management that includes sleep regimen, crying, feeding

Dongre $2009 \quad$ Not a RCT or quasi RCT.

El-Mohandes 2003 Intervention is related to parenting education program.

El-Mohandes 2005 The Interventions are related to decreasing the intimate partner violence during pregnancy

El-Mohandes 2008 Not in the scope of this review. In this study, interventions addressing psychosocial and behavioral risks were delivered mainly during pregnancy

Gokcay 1993 In this study, the performance of midwives were compared with that of lady home visitors

Haider $2000 \quad$ In this study, education on exclusive breastfeeding was only provided to mothers though peer counsellors

Johnson $1993 \quad$ Not in the scope of this review. Study was about parenting intervention in the first year of child's life and their impact on child development

Joseph $2005 \quad$ Not in the scope of this review. Mothers were provided with behavioural interventions

\begin{tabular}{l|l}
\hline Joseph 2006 & Not in the scope of this review. Mothers were provided with behavioural interventions \\
\hline Joseph 2009 & Not in the scope of this review. Mothers were given psychosocial and behavioural interventions \\
\hline
\end{tabular}

Katz $2001 \quad$ In this study, the strategies of retention efforts were employed and compares the population that completed the study versus those that terminated prior to study completion. Comparison was made of those mothers terminating before study completion versus those retained, and of those terminating early in the study period versus later

Kawuwa $2007 \quad$ Not a RCT or quasi RCT.

Kiely $2007 \quad$ Not in the scope of this review. In this abstract behavioral interventions were delivered to reduce depression and smoking during pregnancy

Koniak-Griffin 1991 Not in the scope of this review. The purpose of this study was to evaluate the effects of a nursing intervention program on affective and behavioral dimensions of maternal role attainment 
(Continued)

\begin{tabular}{ll} 
Koniak-Griffin 2000 & Interventions were given to adolescent mothers only and impact was observed in first year of infant life \\
\hline Le 2009 & Not a RCT or quasi RCT. \\
\hline Lumley 2006 & $\begin{array}{l}\text { Not in the scope of this review. Interventions were given to decrease depression and improve physical health } \\
\text { of mothers }\end{array}$ \\
\hline
\end{tabular}

\begin{tabular}{l|l}
\hline MacArthur 2003 & $\begin{array}{l}\text { Not in the scope of this review. In this study, midwives used symptom checklists and the Edinburgh postnatal } \\
\text { depression scale (EPDS) to identify health needs and guidelines for the management of these needs }\end{array}$ \\
\hline Mannan 2008 & None of the outcomes reported are of interest to this review \\
\hline
\end{tabular}

\begin{tabular}{ll}
\hline Mclnnes 2000 & $\begin{array}{l}\text { It is not a intervention packaged study. In this study, only intervention related to promotion of breastfeeding } \\
\text { was employed }\end{array}$ \\
\hline McPherson 2006 & Not a RCT or quasi RCT. \\
\hline McPherson 2007 & Not a RCT or quasi RCT. \\
\hline Moran 2006 & Not a RCT or quasi RCT. \\
\hline More 2008 & It is a published protocol. \\
\hline Morrell 2000 & Cost-effectiveness analysis of postnatal interventions for mothers and newborns \\
\hline Mullany 2007 & $\begin{array}{l}\text { In this study, women who received education alone was compared with no education and those attended with } \\
\text { their husbands. Antenatal education was given in the hospital }\end{array}$ \\
\hline O'Rourke 1998 & Not a RCT or quasi RCT. \\
\hline
\end{tabular}

Omer $2008 \quad$ Not a community intervention package. In this study, The embroidery depicted maternal practices like attending and not attending antenatal check-ups, giving colostrum after birth and not doing heavy work

Purdin $2009 \quad$ Intervention was implemented in healthcare facility level.

\begin{tabular}{l|l}
\hline Rahman 2008 & In this study, impact of behaviour education was observed on mothers' depression status \\
\hline Shaheen 2003 & Assessed the effectiveness of second visit of CHWs. \\
\hline Subramanian 2005 & $\begin{array}{l}\text { Not in the scope of this review. It was only a published abstract, and in this trial impact of psychosocial risks } \\
\text { were observed on pregnancy and infant outcomes }\end{array}$ \\
\hline Turan 2003 & Interventions were delivered to first time expectant women at healthcare facility level \\
\hline Wiggins 2004 & $\begin{array}{l}\text { None of the outcomes reported are of interest to this review. In this study Investigattor measured the impact } \\
\text { of postnatal social support on occurrence of child injury, maternal smoking or maternal depression }\end{array}$
\end{tabular}


(Continued)

Xu 1995

Not a RCT or quasi RCT.

RCT: randomised controlled trial

CHW: community health worker

Copyright $\Subset 2010$ The Cochrane Collaboration. Published by John Wiley \& Sons, Ltd. 
DATA AND ANALYSES

\section{Comparison 1. Community-based intervention versus control}

\begin{tabular}{|c|c|c|c|c|}
\hline Outcome or subgroup title & $\begin{array}{l}\text { No. of } \\
\text { studies }\end{array}$ & $\begin{array}{c}\text { No. of } \\
\text { participants }\end{array}$ & Statistical method & Effect size \\
\hline 1 Maternal mortality & 10 & 144956 & Risk Ratio (Random, 95\% CI) & $0.77[0.59,1.02]$ \\
\hline $\begin{array}{l}1.1 \text { Intervention package } \\
\text { mainly consisted of building } \\
\text { community-support } \\
\text { groups/women groups }\end{array}$ & 3 & 54789 & Risk Ratio (Random, 95\% CI) & $0.84[0.36,1.95]$ \\
\hline $\begin{array}{l}1.2 \text { Intervention package } \\
\text { mainly consisted of community } \\
\text { mobilisation and antenatal \& } \\
\text { postnatal home visitation }\end{array}$ & 3 & 43233 & Risk Ratio (Random, 95\% CI) & $0.72[0.49,1.05]$ \\
\hline $\begin{array}{l}1.3 \text { Intervention package } \\
\text { mainly consisted of training } \\
\text { TBAs and antenatal \& during } \\
\text { delivery home visitation }\end{array}$ & 4 & 46934 & Risk Ratio (Random, 95\% CI) & $0.70[0.51,0.96]$ \\
\hline 2 Neonatal mortality & 13 & 136425 & Risk Ratio (Random, 95\% CI) & $0.76[0.68,0.84]$ \\
\hline $\begin{array}{l}2.1 \text { Intervention package } \\
\text { mainly consisted of building } \\
\text { community-support } \\
\text { groups/women groups }\end{array}$ & 4 & 59984 & Risk Ratio (Random, 95\% CI) & $0.79[0.68,0.92]$ \\
\hline $\begin{array}{l}2.2 \text { Intervention package } \\
\text { mainly consisted of community } \\
\text { mobilisation and antenatal \& } \\
\text { postnatal home visitation }\end{array}$ & 4 & 44520 & Risk Ratio (Random, 95\% CI) & $0.77[0.61,0.96]$ \\
\hline $\begin{array}{l}2.3 \text { Intervention package } \\
\text { mainly consisted of community } \\
\text { mobilisation and home based } \\
\text { neonatal treatment }\end{array}$ & 1 & 4248 & Risk Ratio (Random, 95\% CI) & $0.66[0.47,0.93]$ \\
\hline $\begin{array}{l}2.4 \text { Intervention package } \\
\text { mainly consisted of training } \\
\text { TBAs and antenatal and during } \\
\text { delivery home visitation }\end{array}$ & 2 & 25067 & Risk Ratio (Random, 95\% CI) & $0.79[0.63,1.01]$ \\
\hline $\begin{array}{l}2.5 \text { Intervention package } \\
\text { mainly consisted of home-based } \\
\text { neonatal care } \& \text { treatment }\end{array}$ & 1 & 2087 & Risk Ratio (Random, 95\% CI) & $0.43[0.27,0.69]$ \\
\hline $\begin{array}{l}2.6 \text { Intervention package } \\
\text { mainly consisted of mother's } \\
\text { education and antenatal } \& \\
\text { postnatal home visitation }\end{array}$ & 1 & 519 & Risk Ratio (Random, 95\% CI) & $0.67[0.46,0.98]$ \\
\hline 3 Early neonatal mortality & 8 & 88836 & Risk Ratio (Random, 95\% CI) & $0.74[0.64,0.86]$ \\
\hline $\begin{array}{l}\text { 3.1 Intervention package } \\
\text { mainly consisted of community } \\
\text { support groups/women groups }\end{array}$ & 3 & 54221 & Risk Ratio (Random, 95\% CI) & $0.76[0.58,0.98]$ \\
\hline
\end{tabular}

Community-based intervention packages for reducing maternal and neonatal morbidity and mortality and improving neonatal 
3.2 Intervention package

3

mainly consisted of community

mobilisation and antenatal \&

postnatal home visitation

3.3 Intervention package

mainly consisted of training

TBAs and antenatal \& during

delivery home visitation

3.4 Intervention package

mainly consisted of home-based

neonatal care

4 Late neonatal mortality

4.1 Intervention package

mainly consisted of community support groups/women groups

4.2 Intervention package

mainly consisted of community

mobilisation and antenatal \&

postnatal home visitation

4.3 Intervention package

mainly consisted of training

TBAs and antenatal \& during delivery home visitation

4.4 Intervention package

mainly consisted of home-based

neonatal care

5 Perinatal mortality

5.1 Intervention package

mainly consisted of community

support groups/women groups

5.2 Intervention package

mainly consisted of community

mobilisation and antenatal and postnatal home visitation

5.3 Intervention package mainly consisted of training

TBAs and antenatal \& during delivery home visitation

5.4 Intervention package

mainly consisted of home-based

neonatal care

6 Stillbirths

6.1 Intervention package

mainly consisted of community support groups/women groups

6.2 Intervention package

mainly consisted of community

mobilisation and antenatal $\&$

postnatal home visitation

1

1834

54221

2

$11-11382$

32152
Risk Ratio (Random, 95\% CI)

$0.81[0.69,0.94]$

Risk Ratio (Random, 95\% CI)

$0.85[0.52,1.39]$

$0.45[0.28,0.72]$

$0.72[0.65,0.80]$

$0.82[0.65,1.03]$

Risk Ratio (Fixed, 95\% CI)

Risk Ratio (Fixed, 95\% CI)

$0.74[0.60,0.93]$

30694 Risk Ratio (Fixed, 95\% CI)

$0.70[0.61,0.79]$

20533 Risk Ratio (Fixed, 95\% CI)

$0.31[0.09,1.07]$

Risk Ratio (Fixed, 95\% CI)

$0.80[0.71,0.91]$

$0.88[0.72,1.06]$

Risk Ratio (Random, 95\% CI)

$0.72[0.59,0.88]$

32152 Risk Ratio (Random, 95\% CI)

$0.97[0.70,1.33]$

26248 Risk Ratio (Random, 95\% CI)

$0.52[0.38,0.71]$

2164 Risk Ratio (Random, 95\% CI)

113821 Risk Ratio (Random, 95\% CI)

$0.84[0.74,0.97]$

Risk Ratio (Random, 95\% CI)

$1.02[0.90,1.15]$

Risk Ratio (Random, 95\% CI)

$0.75[0.67,0.85]$

Community-based intervention packages for reducing maternal and neonatal morbidity and mortality and improving neonatal 
6.3 Intervention package mainly consisted of training TBAs and antenatal \& during delivery home visitation

6.4 Intervention package mainly consisted of home-based neonatal care

6.5 Intervention package mainly consisted of mother's education and antenatal \& postnatal home visitation

\section{Mean birthweight}

8 Maternal morbidity

9 Complication of pregnancy: haemorrhage

10 Complication of pregnancy: obstructed labour

11 Complication of pregnancy: puerperal sepsis

12 Complication of pregnancy: eclampsia

13 Complication of pregnancy: spontaneous abortion

14 Referal to health facility for any complication during pregnancy

15 Institutional deliveries

16 Birth attended by healthcare provider

17 Initiation of breastfeeding within 1 hour of birth

18 Healthcare seeking for maternal morbidities

19 Healthcare seeking for neonatal morbidities

20 Maternal mortality: low risk of bias studies

21 Neonatal mortality: low risk of bias studies

22 Perinatal mortality: low risk of bias studies

23 Stillbirths: low risk of bias studies
Risk Ratio (Random, 95\% CI)

$0.57[0.26,1.27]$

1

19525

Risk Ratio (Fixed, 95\% CI)

$0.74[0.43,1.27]$

1

19525

Risk Ratio (Fixed, 95\% CI)

$0.81[0.55,1.18]$

222800

Risk Ratio (Fixed, 95\% CI)

$1.40[1.19,1.65]$

Risk Ratio (Random, 95\% CI)

$1.28[0.98,1.67]$ 


\section{Analysis I.I. Comparison I Community-based intervention versus control, Outcome I Maternal mortality.}

Review: Community-based intervention packages for reducing maternal and neonatal morbidity and mortality and improving neonatal outcomes

Comparison: I Community-based intervention versus control

Outcome: I Maternal mortality

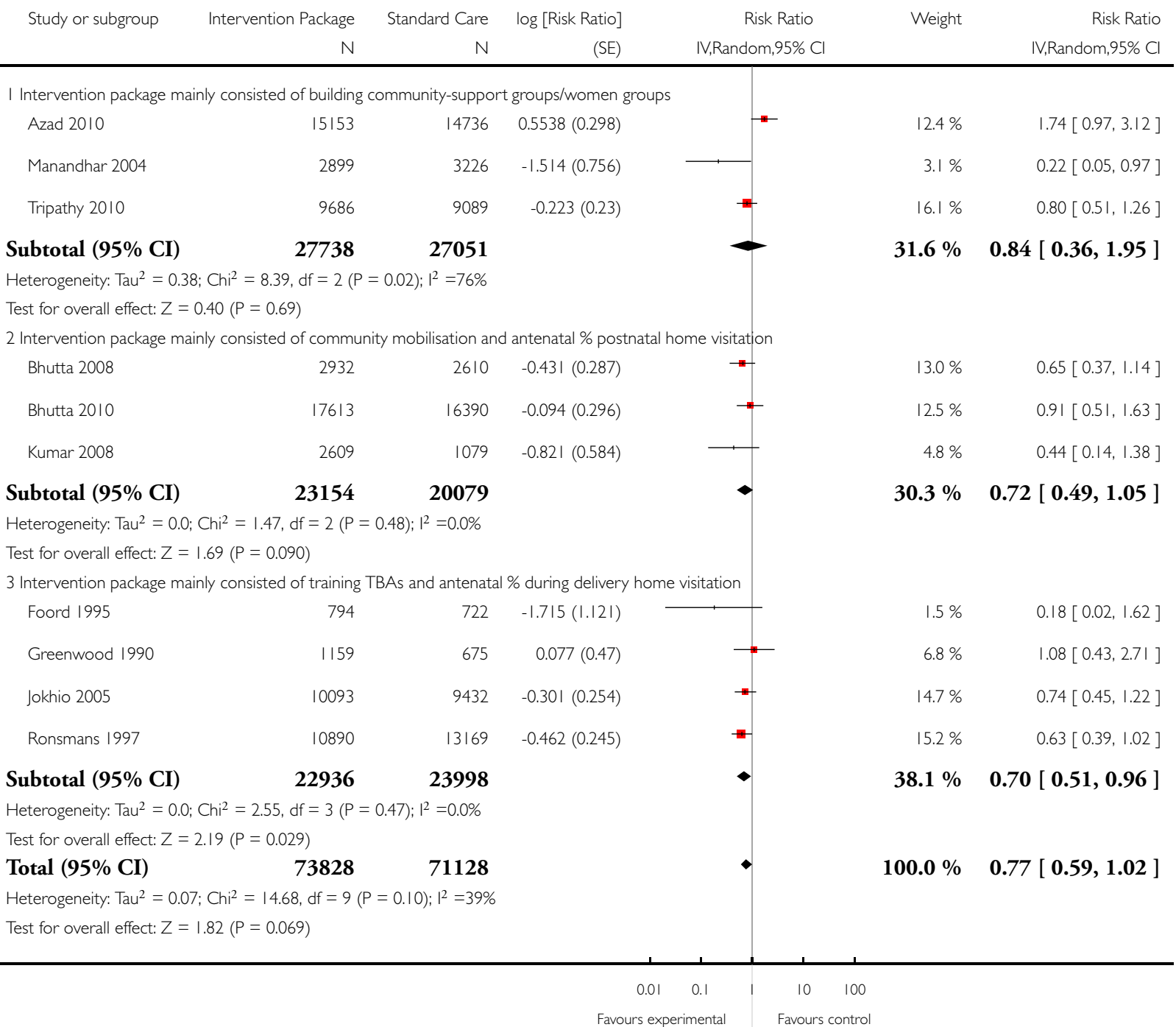




\section{Analysis I.2. Comparison I Community-based intervention versus control, Outcome 2 Neonatal mortality.}

Review: Community-based intervention packages for reducing maternal and neonatal morbidity and mortality and improving neonatal outcomes

Comparison: I Community-based intervention versus control

Outcome: 2 Neonatal mortality

Study or subgroup Intervention Package Standard Care log [Risk Ratio] Risk Ratio Reight $\quad$ Ratio $\begin{array}{llll}\mathrm{N} & \mathrm{N} & \text { (SE) IV,Random,95\% Cl } \quad \text { IV,Random,95\% Cl }\end{array}$

I Intervention package mainly consisted of building community-support groups/women groups

$\begin{array}{llll}\text { Azad } 2010 & 15153 & 14736 & -0.105(0.107)\end{array}$

$\begin{array}{llll}\text { Baqui-com care (a) } 2008 & 3009 & 1436 & -0.051(0.16)\end{array}$

$\begin{array}{llll}\text { Manandhar } 2004 & 2899 & 3226 & -0.357\end{array}(0.142)$

Tripathy 2010

10093

$9432-0.342(0.077)$

$31154 \quad 28830$

Subtotal $(95 \% \mathrm{CI})$

Heterogeneity: Tau $^{2}=0.01 ; \mathrm{Chi}^{2}=5.38, \mathrm{df}=3(\mathrm{P}=0.15) ; \mathrm{I}^{2}=44 \%$

Test for overall effect: $Z=3.00(P=0.0027)$

2 Intervention package mainly consisted of community mobilisation and antenatal \% postnatal home visitation

\begin{tabular}{|c|c|c|c|c|c|c|}
\hline Baqui-CARE INDIA 2008 & 7812 & 6014 & $0.0099(0.076)$ & P & $10.2 \%$ & $1.01[0.87,1.17]$ \\
\hline Bhutta 2008 & 2932 & 2610 & $-0.37 \mid(0.116)$ & $\#$ & $8.1 \%$ & $0.69[0.55,0.87]$ \\
\hline Bhutta 2010 & 12028 & 11005 & $-0.163(0.057)$ & * & $11.2 \%$ & $0.85[0.76,0.95]$ \\
\hline Kumar 2008 & 1065 & 1054 & $-0.693(0.168)$ & $\Psi$ & $5.7 \%$ & $0.50[0.36,0.70]$ \\
\hline
\end{tabular}

Subtotal (95\% CI) $23837 \quad 20683$

Heterogeneity: $\mathrm{Tau}^{2}=0.04 ; \mathrm{Chi}^{2}=18.31, \mathrm{df}=3(\mathrm{P}=0.00038) ; \mathrm{I}^{2}=84 \%$

Test for overall effect: $Z=2.31(P=0.021)$

3 Intervention package mainly consisted of community mobilisation and home based neonatal treatment

$\begin{array}{lllll}\text { Baqui -home care (a) } 2008 & 2812 & 1436 & -0.415(0.173) & \mathbf{*}\end{array}$

$35.3 \% \quad 0.77[0.61,0.96]$

Subtotal $(95 \% \mathrm{CI})$

$2812 \quad 1436$

1436

$5.5 \% \quad 0.66[0.47,0.93]$

Heterogeneity: not applicable

Test for overall effect: $Z=2.40(P=0.016)$

4 Intervention package mainly consisted of training TBAs and antenatal and during delivery home visitation

\begin{tabular}{|c|c|c|c|c|c|}
\hline Greenwood 1990 & 2932 & 2610 & $-0.371(0.116)$ & $8.1 \%$ & $0.69[0.55,0.87]$ \\
\hline Jokhio 2005 & 10093 & 9432 & $-0.128(0.061)$ & $11.0 \%$ & $0.88[0.78,0.99]$ \\
\hline
\end{tabular}

Subtotal $(95 \% \mathrm{CI}) \quad \mathbf{1 3 0 2 5} \quad \mathbf{1 2 0 4 2}$

Heterogeneity: Tau $^{2}=0.02 ; \mathrm{Chi}^{2}=3.44, \mathrm{df}=\mathrm{I}(\mathrm{P}=0.06) ; \mathrm{I}^{2}=71 \%$

Test for overall effect: $Z=1.91(P=0.056)$

5 Intervention package mainly consisted of home-based neonatal care \% treatment
Bang 1999
979
I $108-0.844(0.238)$

$19.1 \%$

$0.79[0.63,1.01]$

Subtotal (95\% CI)

979

1108

Heterogeneity: not applicable 


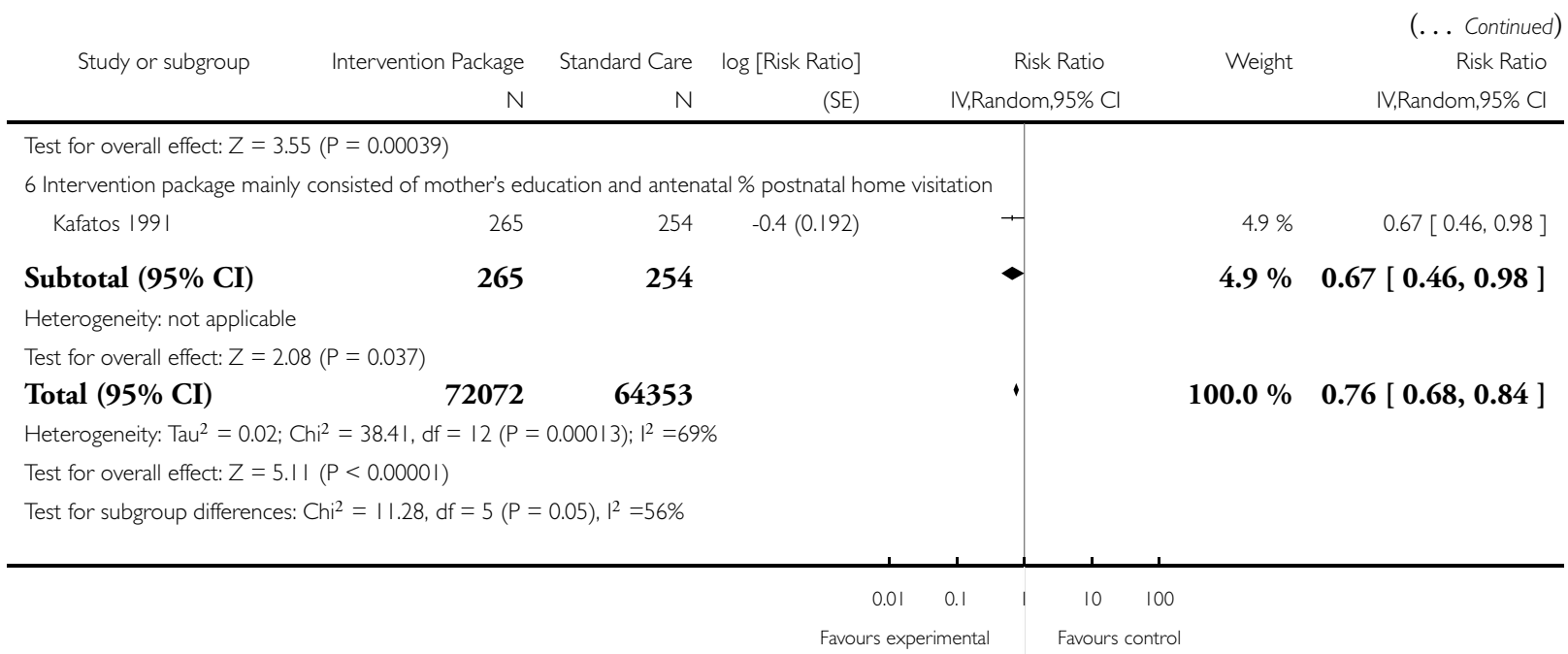

\section{Analysis I.3. Comparison I Community-based intervention versus control, Outcome 3 Early neonatal} mortality.

Review: Community-based intervention packages for reducing maternal and neonatal morbidity and mortality and improving neonatal outcomes

Comparison: I Community-based intervention versus control

Outcome: 3 Early neonatal mortality

Study or subgroup Intervention Package Standard Care log [Risk Ratio] Risk Ratio Risk Ratio

$\mathrm{N} \quad \mathrm{N} \quad(\mathrm{SE})$

E)

I Intervention package mainly consisted of community support groups/women groups

$\begin{array}{lrrr}\text { Azad 2010 } & 15153 & 14736 & -0.0943(0.112) \\ \text { Manandhar 2004 } & 2899 & 3226 & -0.236(0.188) \\ \text { Tripathy 2010 } & 9388 & 8819 & -0.462(0.079) \\ \text { Subtotal (95\% CI) } & \mathbf{2 7 4 4 0} & \mathbf{2 6 7 8 1} & \end{array}$

IV,Random,95\% Cl IV,Random,95\% Cl

Heterogeneity: $\mathrm{Tau}^{2}=0.04 ; \mathrm{Chi}^{2}=7.47, \mathrm{df}=2(\mathrm{P}=0.02) ; \mathrm{I}^{2}=73 \%$

Test for overall effect: $Z=2.09(P=0.037)$

2 Intervention package mainly consisted of community mobilisation and antenatal \% postnatal home visitation

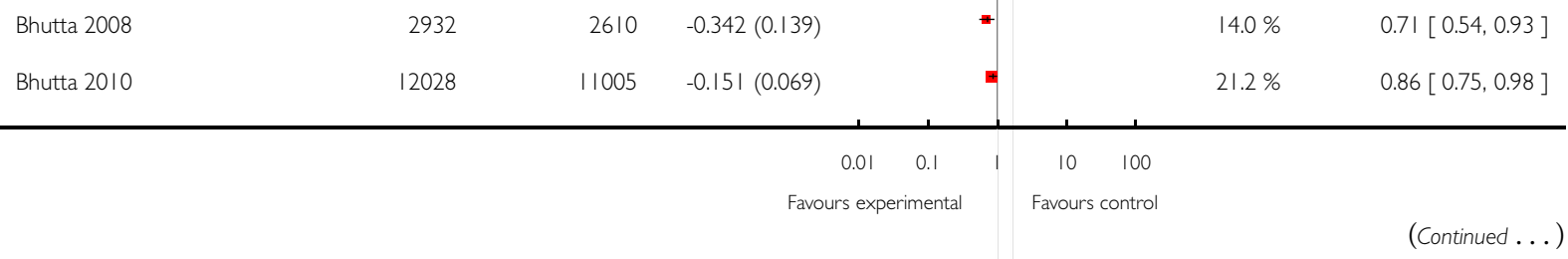

Community-based intervention packages for reducing maternal and neonatal morbidity and mortality and improving neonatal 


\begin{tabular}{|c|c|c|c|c|c|c|}
\hline \multirow[t]{2}{*}{ Study or subgroup } & Intervention Package & Standard Care & log [Risk Ratio] & Risk Ratio & \multirow[t]{2}{*}{ Weight } & $\begin{array}{c}\text { (... Continued) } \\
\text { Risk Ratio }\end{array}$ \\
\hline & $\mathrm{N}$ & N & $(\mathrm{SE})$ & IV,Random,95\% Cl & & IV,Random,95\% Cl \\
\hline Kumar 2008 & 1065 & 1054 & $-0.528(0.364)$ & 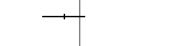 & $3.8 \%$ & $0.59[0.29,1.20]$ \\
\hline Subtotal $(95 \% \mathrm{CI})$ & 16025 & 14669 & & - & $38.9 \%$ & $0.81[0.69,0.94]$ \\
\hline \multicolumn{7}{|c|}{ Heterogeneity: $\operatorname{Tau}^{2}=0.00 ; \mathrm{Chi}^{2}=2.36, \mathrm{df}=2(P=0.31) ; \mathrm{I}^{2}=15 \%$} \\
\hline \multicolumn{7}{|c|}{ Test for overall effect: $Z=2.81(P=0.0050)$} \\
\hline \multicolumn{7}{|c|}{3 Intervention package mainly consisted of training TBAs and antenatal \% during delivery home visitation } \\
\hline Greenwood 1990 & 1159 & 675 & $-0.163(0.25)$ & $\rightarrow$ & $6.9 \%$ & $0.85[0.52,1.39]$ \\
\hline Subtotal $(95 \% \mathrm{CI})$ & 1159 & 675 & & 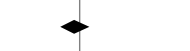 & $6.9 \%$ & $0.85[0.52,1.39]$ \\
\hline \multicolumn{7}{|c|}{ Heterogeneity: not applicable } \\
\hline \multicolumn{7}{|c|}{ Test for overall effect: $Z=0.65(P=0.5 \mathrm{I})$} \\
\hline \multicolumn{7}{|c|}{4 Intervention package mainly consisted of home-based neonatal care } \\
\hline Bang 1999 & 979 & 1108 & $-0.799(0.242)$ & $\rightarrow$ & $7.3 \%$ & $0.45[0.28,0.72]$ \\
\hline Subtotal $(95 \% \mathrm{CI})$ & 979 & 1108 & & 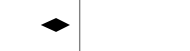 & $7.3 \%$ & $0.45[0.28,0.72]$ \\
\hline \multicolumn{7}{|c|}{ Heterogeneity: not applicable } \\
\hline \multicolumn{7}{|c|}{ Test for overall effect: $Z=3.30(P=0.00096)$} \\
\hline Total $(95 \% \mathrm{CI})$ & 45603 & 43233 & & - & $100.0 \%$ & $0.74[0.64,0.86]$ \\
\hline \multicolumn{7}{|c|}{ Heterogeneity: $\operatorname{Tau}^{2}=0.02 ; \mathrm{Chi}^{2}=17.08, \mathrm{df}=7(\mathrm{P}=0.02) ; 1^{2}=59 \%$} \\
\hline \multicolumn{7}{|c|}{ Test for overall effect: $Z=3.91 \quad(P=0.000093)$} \\
\hline & & & & 10 & 100 & \\
\hline & & & Favo & Favour & & \\
\hline
\end{tabular}




\section{Analysis I.4. Comparison I Community-based intervention versus control, Outcome 4 Late neonatal}

mortality.

\begin{tabular}{|c|c|c|c|c|c|c|}
\hline \multicolumn{7}{|c|}{ Comparison: I Community-based intervention versus control } \\
\hline \multicolumn{7}{|c|}{ Outcome: 4 Late neonatal mortality } \\
\hline \multirow[t]{2}{*}{ Study or subgroup } & Intervention Package & Standard Care & $\log [$ Risk Ratio] & \multirow{2}{*}{$\begin{array}{r}\text { Risk Ratio } \\
\text { IV,Fixed,95\% Cl }\end{array}$} & \multirow[t]{2}{*}{ Weight } & \multirow{2}{*}{$\begin{array}{r}\text { Risk Ratic } \\
\text { IV,Fixed,95\% C }\end{array}$} \\
\hline & $\mathrm{N}$ & $\mathrm{N}$ & (SE) & & & \\
\hline \multicolumn{7}{|c|}{ I Intervention package mainly consisted of community support groups/women groups } \\
\hline Azad 2010 & 15153 & 14736 & $-0.139(0.243)$ & $\rightarrow$ & $4.5 \%$ & $0.87[0.54,1.40]$ \\
\hline Manandhar 2004 & 2899 & 3226 & $-0.527(0.238)$ & $一$ & $4.7 \%$ & $0.59[0.37,0.94]$ \\
\hline Tripathy 2010 & 9388 & 8819 & $-0.0834(0.162)$ & $\rightarrow$ & $10.2 \%$ & $0.92[0.67,1.26]$ \\
\hline Subtotal $(95 \% \mathrm{CI})$ & 27440 & 26781 & & $\bullet$ & $19.4 \%$ & $0.82[0.65,1.03]$ \\
\hline \multicolumn{7}{|c|}{ Heterogeneity: Chi ${ }^{2}=2.47, \mathrm{df}=2(\mathrm{P}=0.29) ; \mathrm{I}^{2}=19 \%$} \\
\hline \multicolumn{7}{|c|}{ Test for overall effect: $Z=1.74(P=0.082)$} \\
\hline \multicolumn{7}{|c|}{2 Intervention package mainly consisted of community mobilisation and antenatal \% postnatal home visitation } \\
\hline Bhutta 2008 & 2932 & 2610 & $-0.446(0.227)$ & 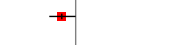 & $5.2 \%$ & $0.64[0.41,1.00]$ \\
\hline Bhutta 2010 & 12028 & 11005 & $-0.186(0.133)$ & $\#$ & $15.1 \%$ & $0.83[0.64,1.08]$ \\
\hline Kumar 2008 & 1065 & 1054 & $-1.139(0.501)$ & $\longrightarrow$ & $1.1 \%$ & $0.32[0.12,0.85]$ \\
\hline Subtotal $(95 \% \mathrm{CI})$ & 16025 & 14669 & & - & $21.4 \%$ & $0.74[0.60,0.93]$ \\
\hline \multicolumn{7}{|c|}{ Heterogeneity: $\mathrm{Chi}^{2}=3.95, \mathrm{df}=2(\mathrm{P}=0.14) ; \mathrm{I}^{2}=49 \%$} \\
\hline \multicolumn{7}{|c|}{ Test for overall effect: $Z=2.65(P=0.0080)$} \\
\hline \multicolumn{7}{|c|}{3 Intervention package mainly consisted of training TBAs and antenatal \% during delivery home visitation } \\
\hline Greenwood 1990 & 1159 & 675 & $-0.821(0.331)$ & + & $2.4 \%$ & $0.44[0.23,0.84]$ \\
\hline Jokhio 2005 & 9710 & 8989 & $-0.342(0.069)$ & + & $56.1 \%$ & $0.71[0.62,0.81]$ \\
\hline Subtotal $(95 \% \mathrm{CI})$ & 10869 & 9664 & & - & $58.6 \%$ & $0.70[0.61,0.79]$ \\
\hline \multicolumn{7}{|c|}{ Heterogeneity: $\mathrm{Chi}^{2}=2.01, \mathrm{df}=1(P=0.16) ; \mathrm{I}^{2}=50 \%$} \\
\hline \multicolumn{7}{|c|}{ Test for overall effect: $Z=5.36(P<0.0000 I)$} \\
\hline \multicolumn{7}{|c|}{4 Intervention package mainly consisted of home-based neonatal care } \\
\hline Bang 1999 & 979 & 1108 & $-1.171(0.631)$ & . & $0.7 \%$ & $0.31[0.09,1.07]$ \\
\hline Subtotal $(95 \% \mathrm{CI})$ & 979 & 1108 & & & $0.7 \%$ & $0.31[0.09,1.07]$ \\
\hline \multicolumn{7}{|c|}{ Heterogeneity: not applicable } \\
\hline \multicolumn{7}{|c|}{ Test for overall effect: $Z=1.86(P=0.063)$} \\
\hline Total $(95 \% \mathrm{CI})$ & 55313 & 52222 & & $\cdot$ & $100.0 \%$ & $0.72[0.65,0.80]$ \\
\hline \multicolumn{7}{|c|}{ Heterogeneity: $\mathrm{Chi}^{2}=|1.65, \mathrm{df}=8(\mathrm{P}=0.17) ;|^{2}=31 \%$} \\
\hline \multicolumn{7}{|c|}{ Test for overall effect: $Z=6.24(P<0.0000 I)$} \\
\hline \multicolumn{7}{|c|}{ Test for subgroup differences: $\mathrm{Chi}^{2}=3.22, \mathrm{df}=3(\mathrm{P}=0.36), \mathrm{I}^{2}=7 \%$} \\
\hline
\end{tabular}




\section{Analysis I.5. Comparison I Community-based intervention versus control, Outcome 5 Perinatal mortality.}

Review: Community-based intervention packages for reducing maternal and neonatal morbidity and mortality and improving neonatal outcomes

Comparison: I Community-based intervention versus control

Outcome: 5 Perinatal mortality

Study or subgroup Intervention Package Standard Care log [Risk Ratio] Risk Ratio Reight $\quad$ Ratio

$\mathrm{N} \quad \mathrm{N} \quad$ (SE) IV,Random,95\% Cl IV,Random,95\% Cl

I Intervention package mainly consisted of community support groups/women groups

$\begin{array}{lll}\text { Azad } 2010 & 15695 & 15257 \quad-0.04(0.043)\end{array}$

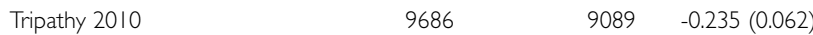

Subtotal (95\% CI) $25381 \quad 24346$

Heterogeneity: Tau $^{2}=0.02 ; \mathrm{Chi}^{2}=6.68, \mathrm{df}=\mathrm{I}(\mathrm{P}=0.0 \mathrm{I}) ; \mathrm{I}^{2}=85 \%$

Test for overall effect: $Z=1.36(P=0.17)$

2 Intervention package mainly consisted of community mobilisation and antenatal and postnatal home visitation

\begin{tabular}{|c|c|c|c|c|}
\hline Bhutta 2008 & 3064 & 2778 & $-0.329(0.084)$ & $0.72[0.61,0.85]$ \\
\hline Bhutta 2010 & 12517 & 11568 & $-0.186(0.059)$ & $0.83[0.74,0.93]$ \\
\hline Kumar 2008 & 1110 & 1115 & $-0.635(0.17)$ & $0.53[0.38,0.74]$ \\
\hline
\end{tabular}

Subtotal (95\% CI) $\quad 16691 \quad 15461$

Heterogeneity: $\operatorname{Tau}^{2}=0.02 ; \mathrm{Chi}^{2}=7.1 \mathrm{I}, \mathrm{df}=2(\mathrm{P}=0.03) ; \mathrm{I}^{2}=72 \%$

Test for overall effect: $Z=3.25(P=0.0012)$

3 Intervention package mainly consisted of training TBAs and antenatal \% during delivery home visitation

$\begin{array}{lccc}\text { Alisjahbana 1995 } & 2275 & 1000 & 0.166(0.192) \\ \text { Foord 1995 } & 794 & 722 & 0.322(0.235) \\ \text { Greenwood 1990 } & 1220 & 712 & -0.083(0.154) \\ \text { Jokhio 2005 } & 10093 & 9432 & -0.343(0.045)\end{array}$

Subtotal (95\% CI) $14382 \quad 11866$

Heterogeneity: $\mathrm{Tau}^{2}=0.08 ; \mathrm{Chi}^{2}=15.55, \mathrm{df}=3(\mathrm{P}=0.00 \mathrm{I}) ; \mathrm{I}^{2}=8 \mathrm{I} \%$

Test for overall effect: $Z=0.19(P=0.85)$

4 Intervention package mainly consisted of home-based neonatal care

$\begin{array}{llll}\text { Bang } 1999 & 1005 & 1159 & -0.654\end{array}$

$1005 \quad 1159$

Subtotal (95\% CI)

Heterogeneity: not applicable

Test for overall effect: $Z=4.1$ I ( $(P=0.000039)$

Total (95\% CI)

57459

52832

Heterogeneity: $\mathrm{Tau}^{2}=0.03 ; \mathrm{Chi}^{2}=50.38, \mathrm{df}=9(\mathrm{P}<0.0000 \mathrm{I}) ; \mathrm{I}^{2}=82 \%$

Test for overall effect: $Z=3.50(P=0.00046)$

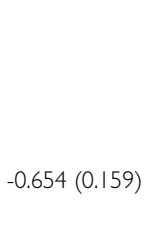

$\begin{array}{ll}6.3 \% & 1.18[0.81,1.72] \\ 4.9 \% & 1.38[0.87,2.19] \\ 8.0 \% & 0.92[0.68,1.24] \\ 13.8 \% & 0.71[0.65,0.78]\end{array}$

$33.1 \% \quad 0.97[0.70,1.33$ ]

$7.7 \%$

$0.52[0.38,0.71]$

$7.7 \%$

$0.52[0.38,0.71]$

$100.0 \%$

$0.80[0.71,0.91]$ 


\section{Analysis I.6. Comparison I Community-based intervention versus control, Outcome 6 Stillbirths.}

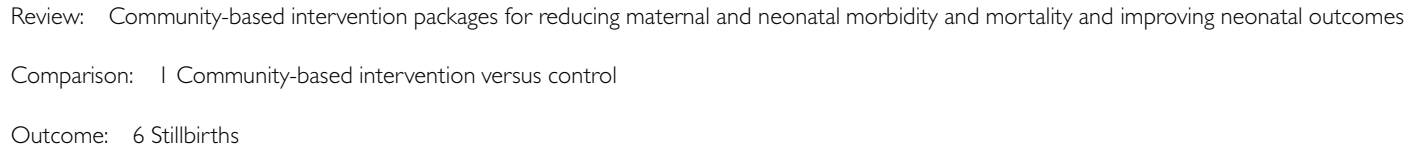

$90890.0198(0.093)$

ubtotal $(95 \% \mathrm{CI})$

28353

27649

Heterogeneity: $\mathrm{Tau}^{2}=0.0 ; \mathrm{Chi}^{2}=0.09, \mathrm{df}=2(\mathrm{P}=0.96) ; \mathrm{I}^{2}=0.0 \%$

Test for overall effect: $Z=0.28(P=0.78)$

2 Intervention package mainly consisted of community mobilisation and antenatal \% postnatal home visitation

$\begin{array}{lccc}\text { Bhutta } 2008 & 3064 & 2778 & -0.342(0.112) \\ \text { Bhutta 2010 } & 12517 & 11568 & -0.236(0.076) \\ \text { Kumar 2008 } & 1110 & 1115 & -0.431(0.199)\end{array}$

Subtotal $(\mathbf{9 5 \%} \mathrm{CI})$

$16691 \quad 15461$

Heterogeneity: $\mathrm{Tau}^{2}=0.0 ; \mathrm{Chi}^{2}=1.21, \mathrm{df}=2(\mathrm{P}=0.55) ; \mathrm{I}^{2}=0.0 \%$

Test for overall effect: $Z=4.74(P<0.00001)$

3 Intervention package mainly consisted of training TBAs and antenatal \% during delivery home visitation

$\begin{array}{lrrr}\text { Foord 1995 } & 794 & 722 & 0.482(0.288) \\ \text { Greenwood 1990 } & 1220 & 712 & -0.041(0.198) \\ \text { Jokhio 2005 } & 10093 & 9432 & -0.3567(0.069) \\ \text { Subtotal }(\mathbf{9 5 \%} \mathbf{C I}) & \mathbf{1 2 1 0 7} & \mathbf{1 0 8 6 6} & \end{array}$

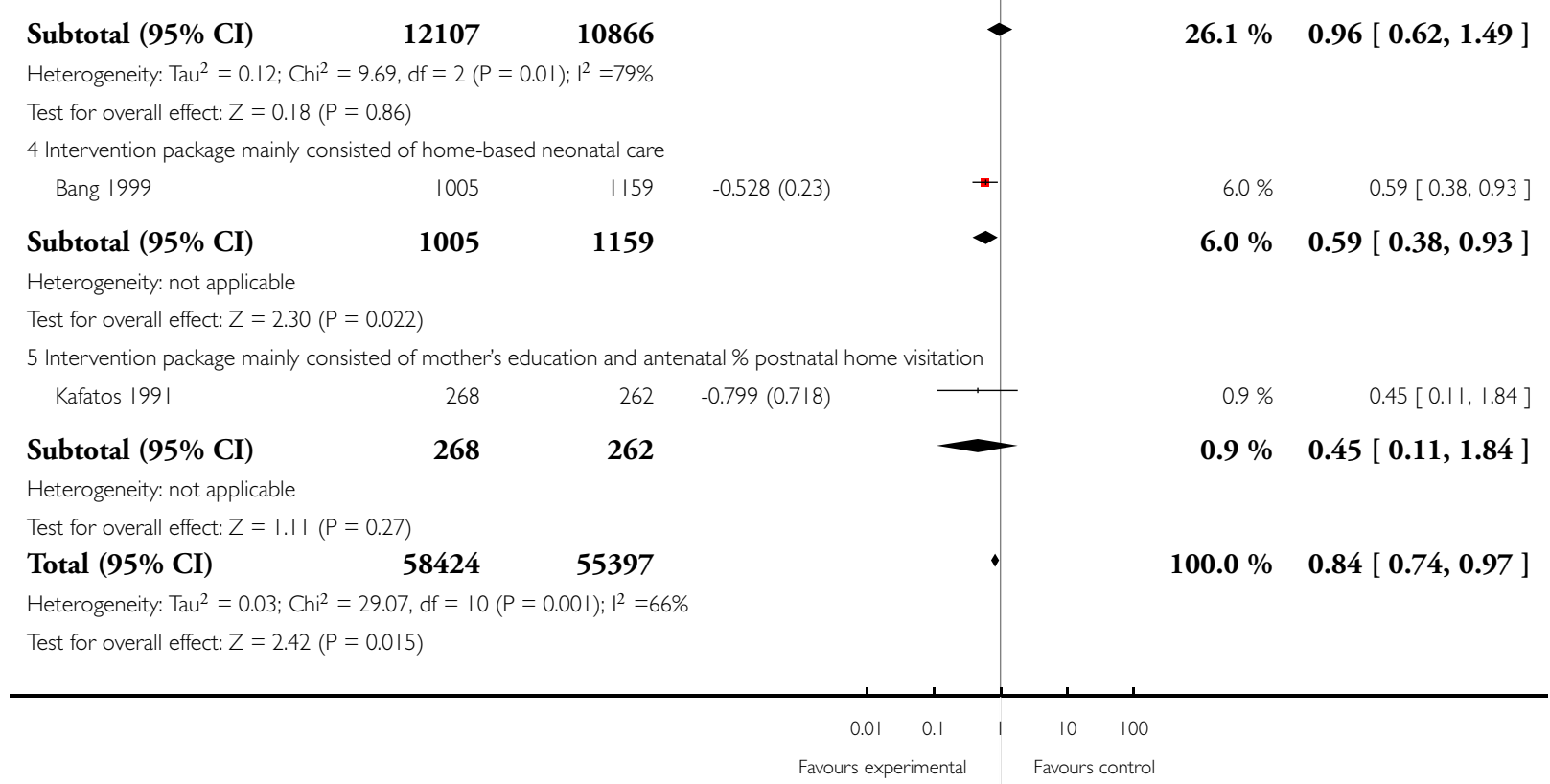

Community-based intervention packages for reducing maternal and neonatal morbidity and mortality and improving neonatal 


\section{Analysis I.7. Comparison I Community-based intervention versus control, Outcome 7 Mean birthweight.}

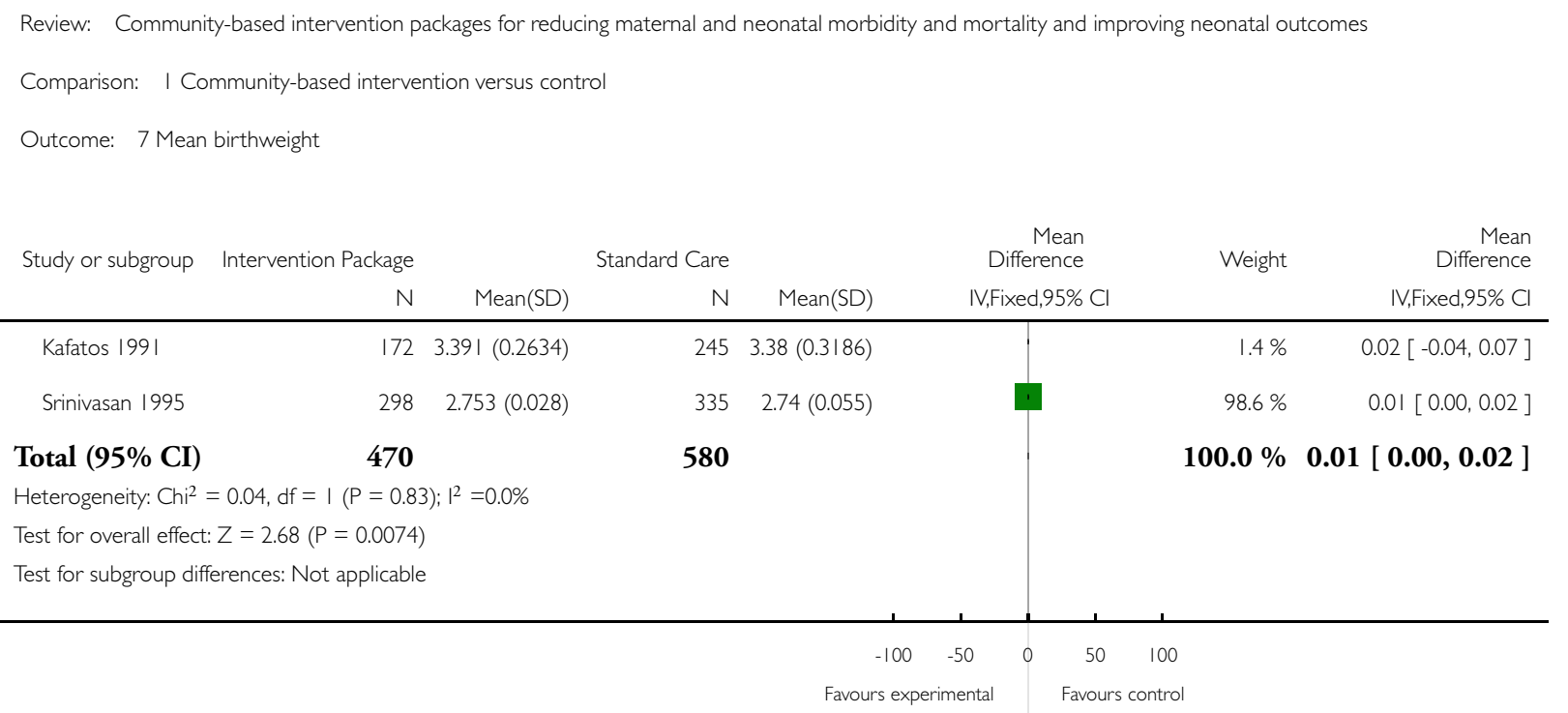




\section{Analysis I.8. Comparison I Community-based intervention versus control, Outcome 8 Maternal morbidity.}

Review: Community-based intervention packages for reducing maternal and neonatal morbidity and mortality and improving neonatal outcomes

Comparison: I Community-based intervention versus control

Outcome: 8 Maternal morbidity

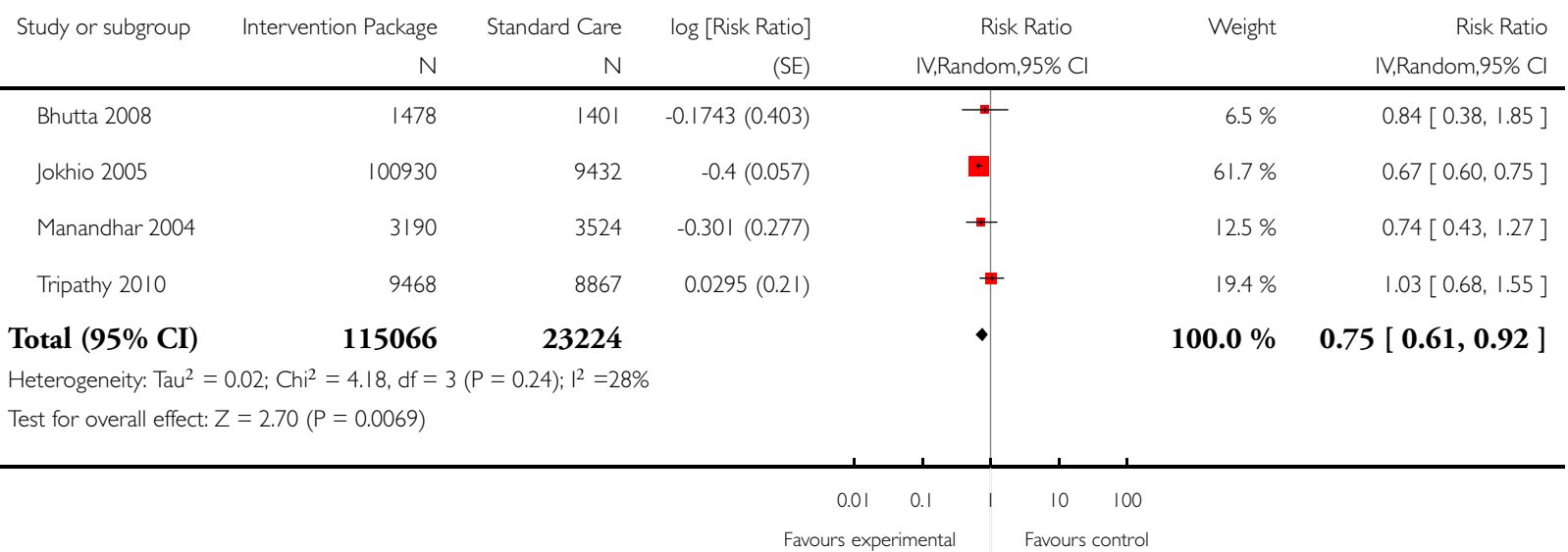

Analysis I.9. Comparison I Community-based intervention versus control, Outcome 9 Complication of pregnancy: haemorrhage.

Review: Community-based intervention packages for reducing maternal and neonatal morbidity and mortality and improving neonatal outcomes

Comparison: I Community-based intervention versus control

Outcome: 9 Complication of pregnancy: haemorrhage

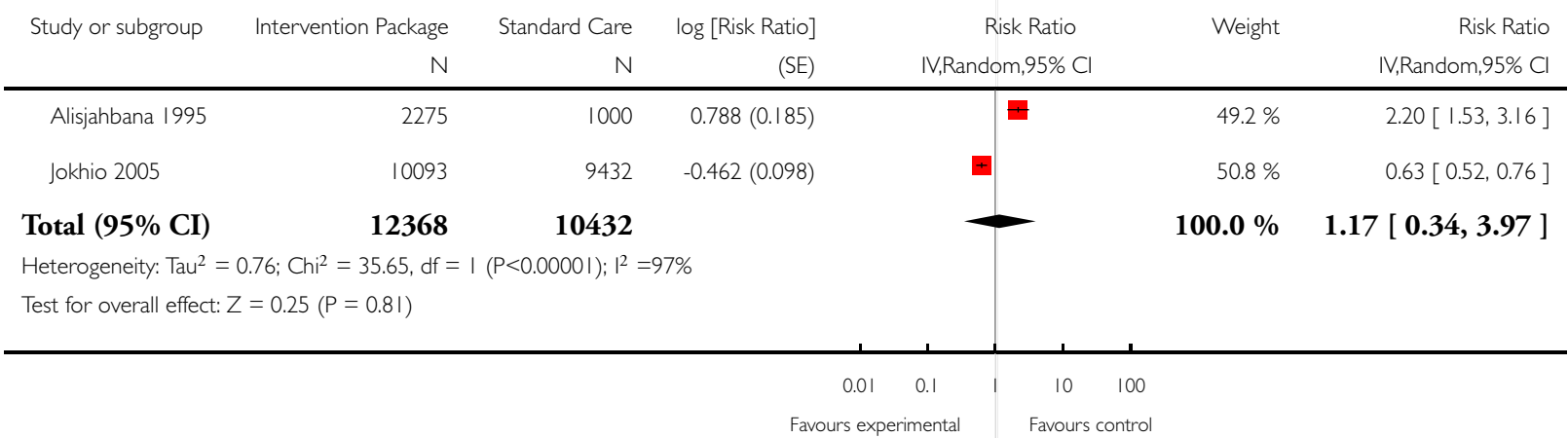

Community-based intervention packages for reducing maternal and neonatal morbidity and mortality and improving neonatal 
Analysis I.I0. Comparison I Community-based intervention versus control, Outcome 10 Complication of pregnancy: obstructed labour.

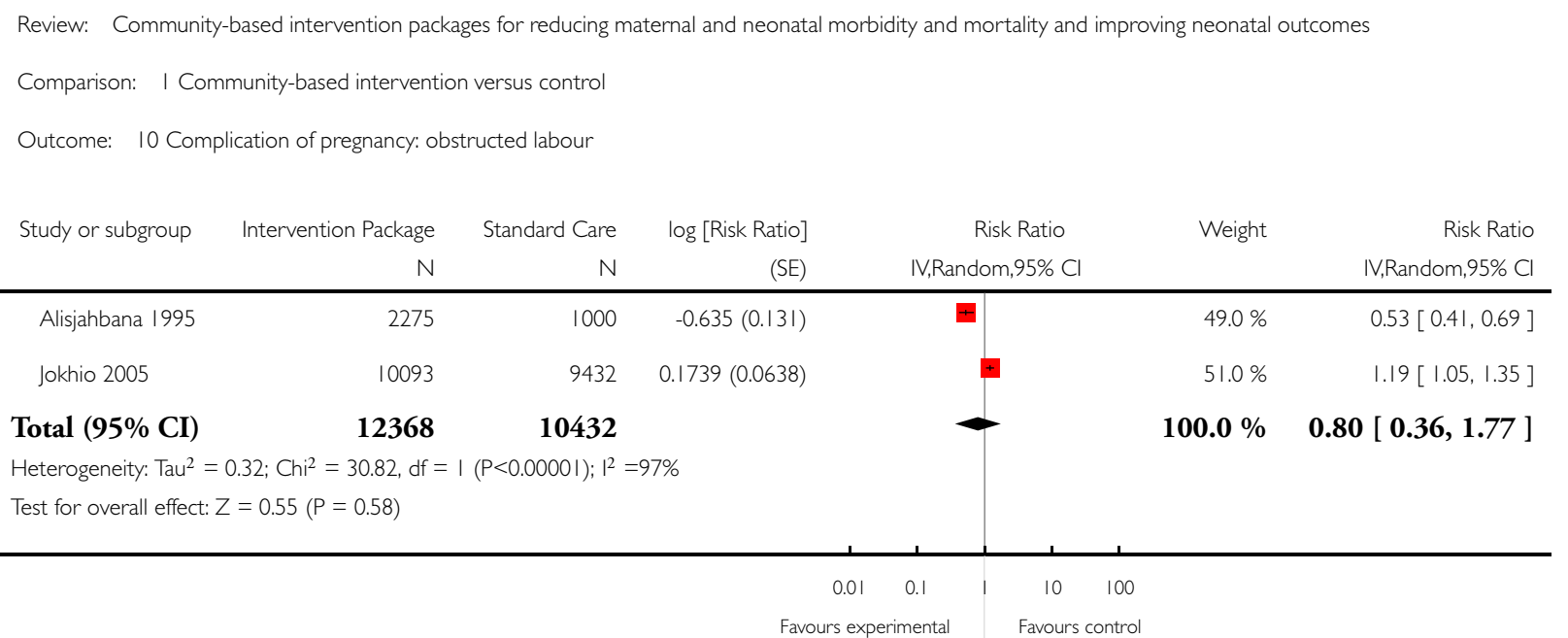

\section{Analysis I.I I. Comparison I Community-based intervention versus control, Outcome I I Complication of pregnancy: puerperal sepsis.}

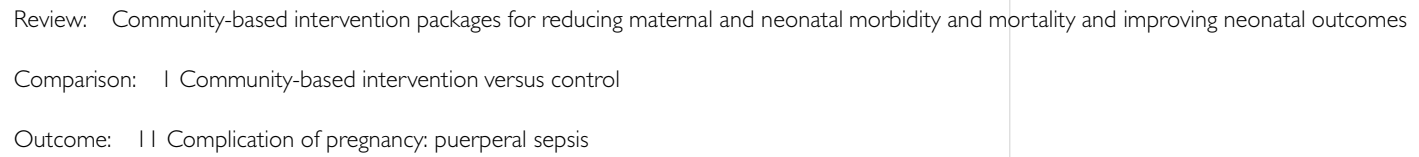

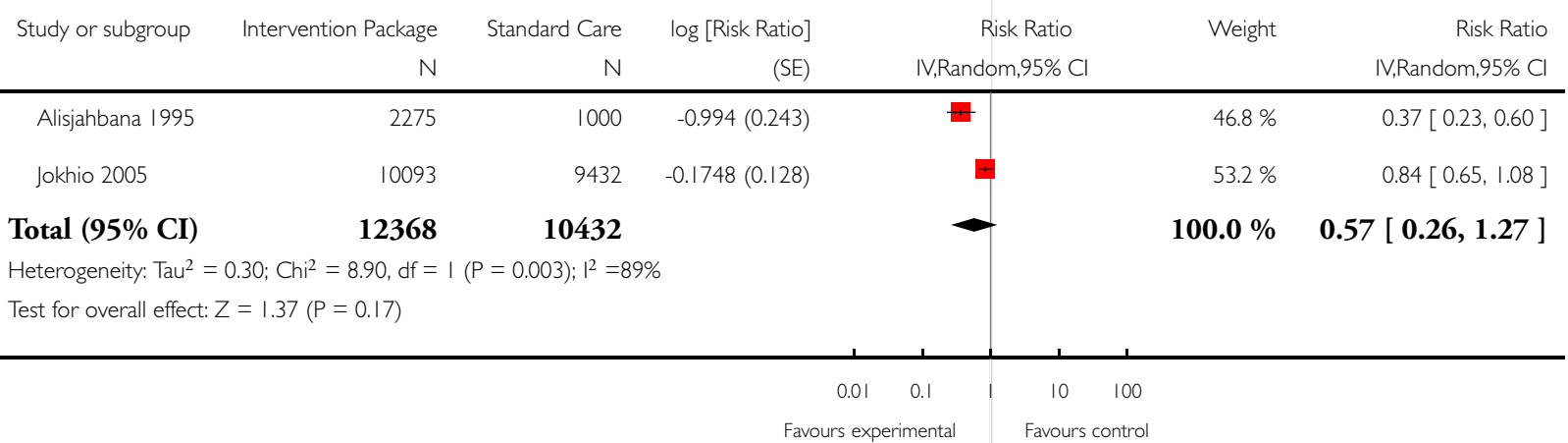


Analysis I.12. Comparison I Community-based intervention versus control, Outcome 12 Complication of pregnancy: eclampsia.

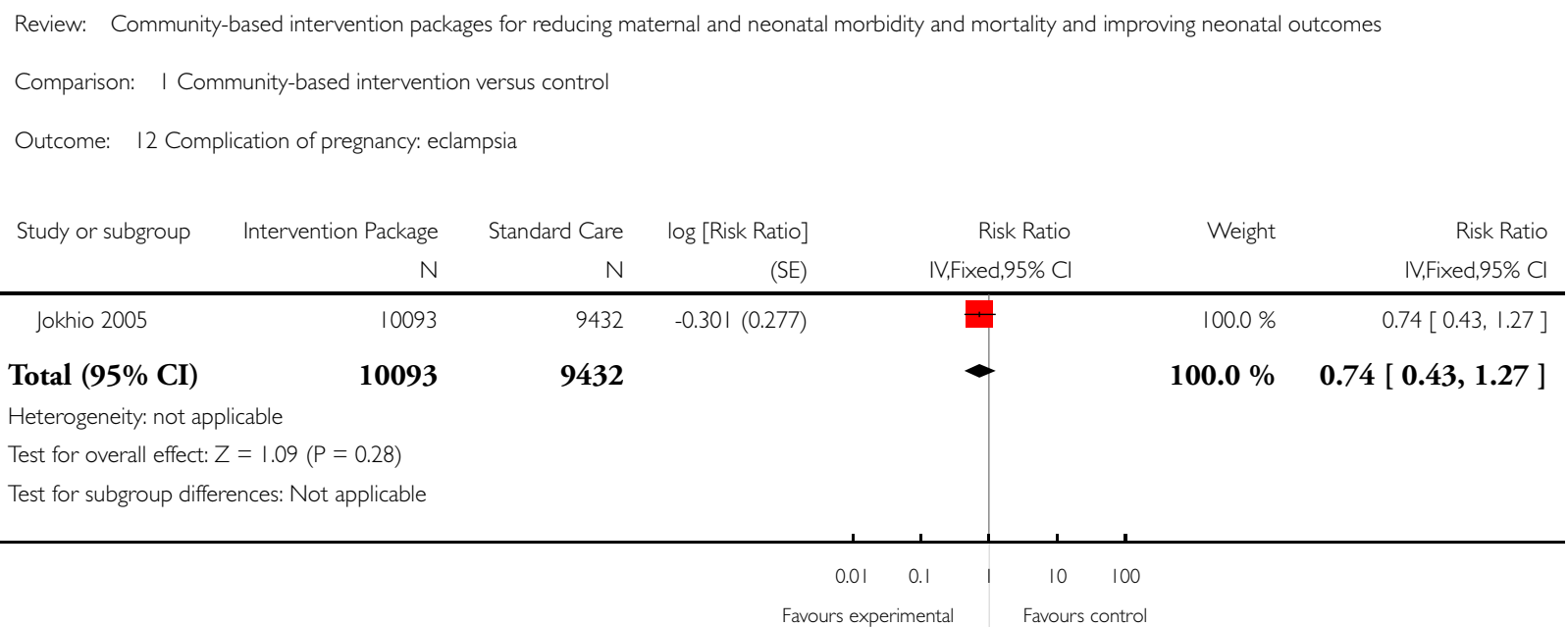

\section{Analysis I.13. Comparison I Community-based intervention versus control, Outcome 13 Complication of} pregnancy: spontaneous abortion.

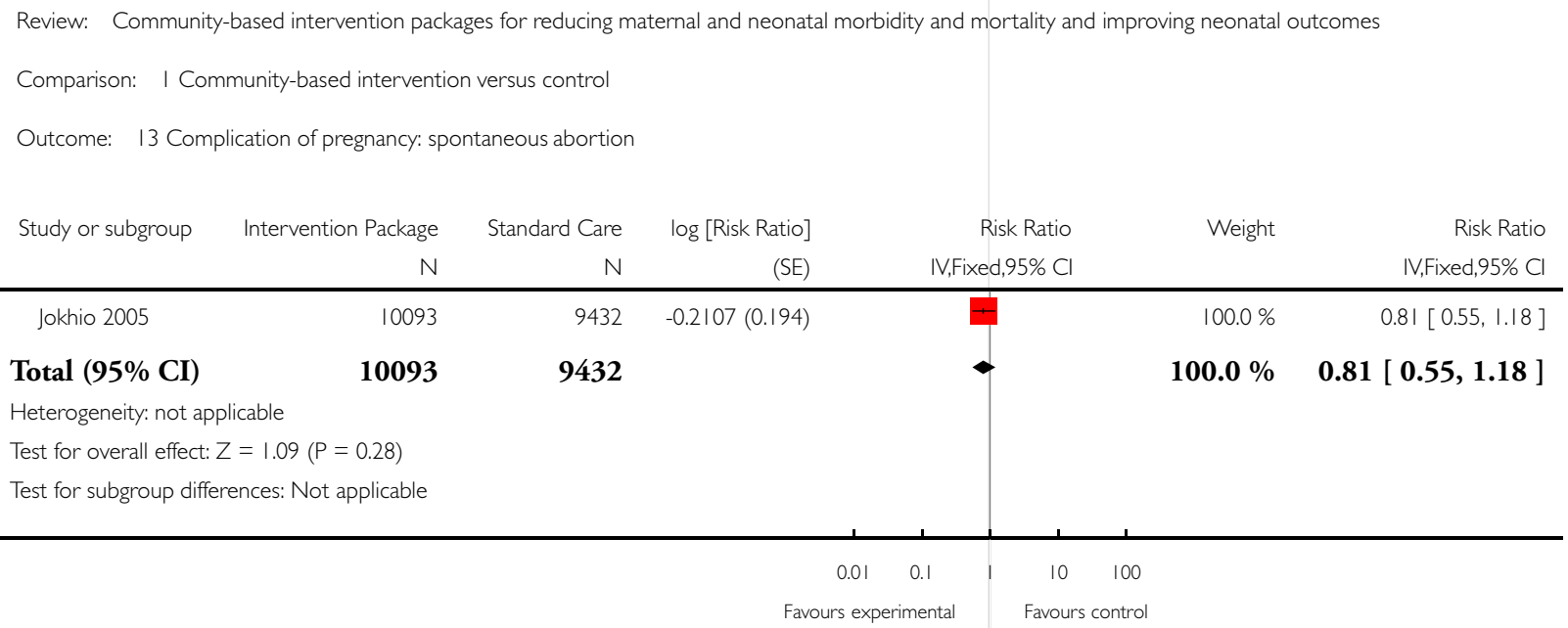


Analysis I.I4. Comparison I Community-based intervention versus control, Outcome I4 Referal to health facility for any complication during pregnancy.

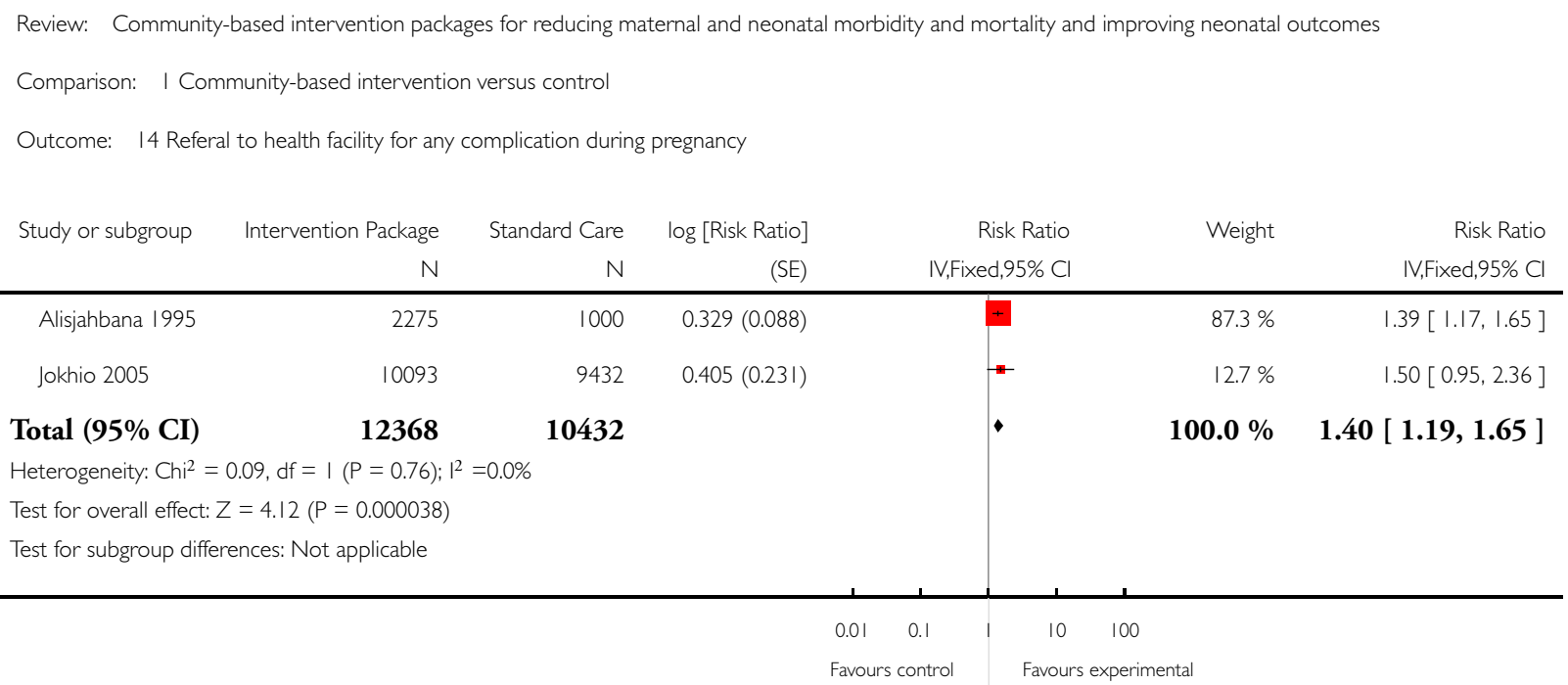


Analysis I.I5. Comparison I Community-based intervention versus control, Outcome I5 Institutional deliveries.

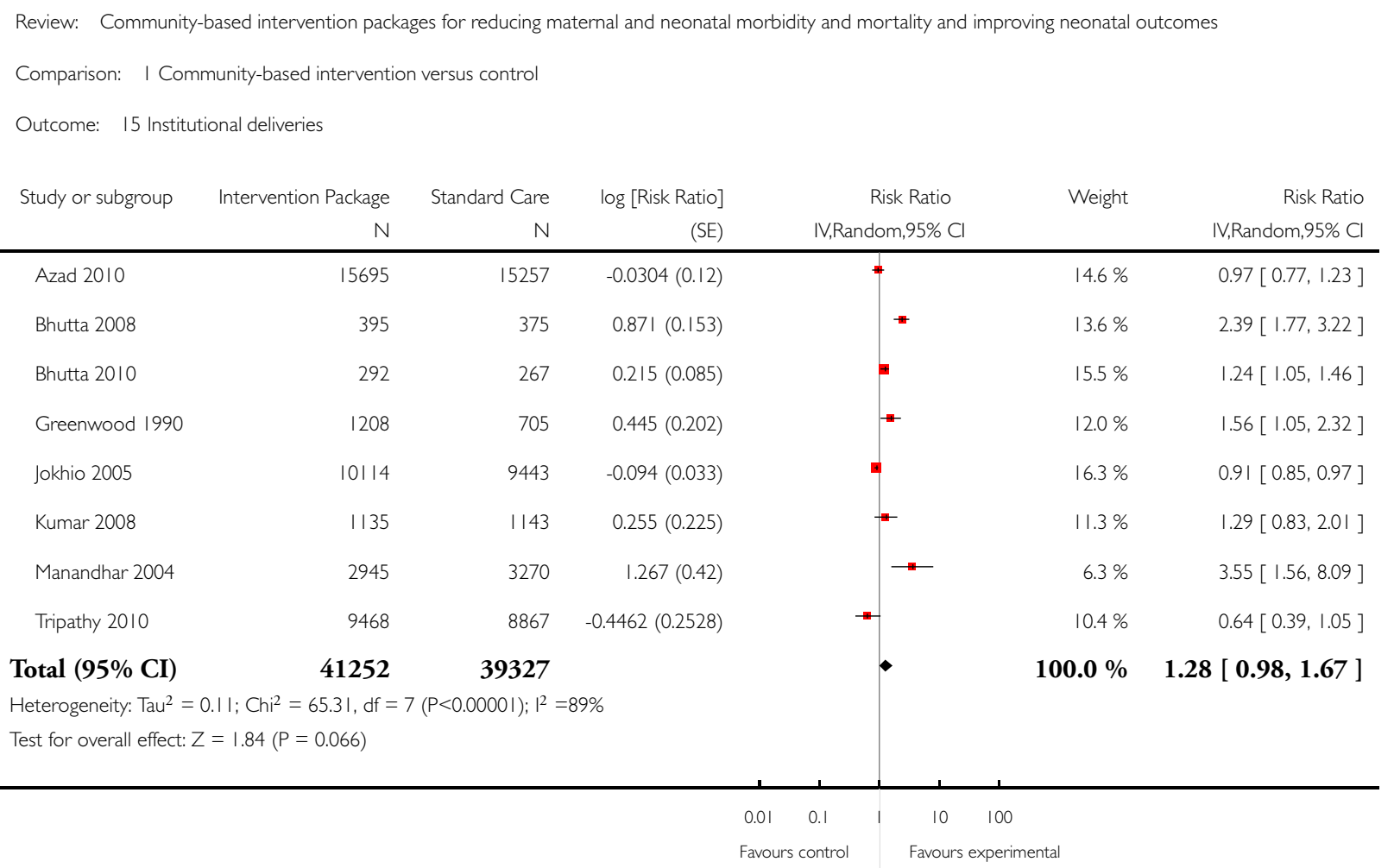


Analysis I.16. Comparison I Community-based intervention versus control, Outcome 16 Birth attended by healthcare provider.

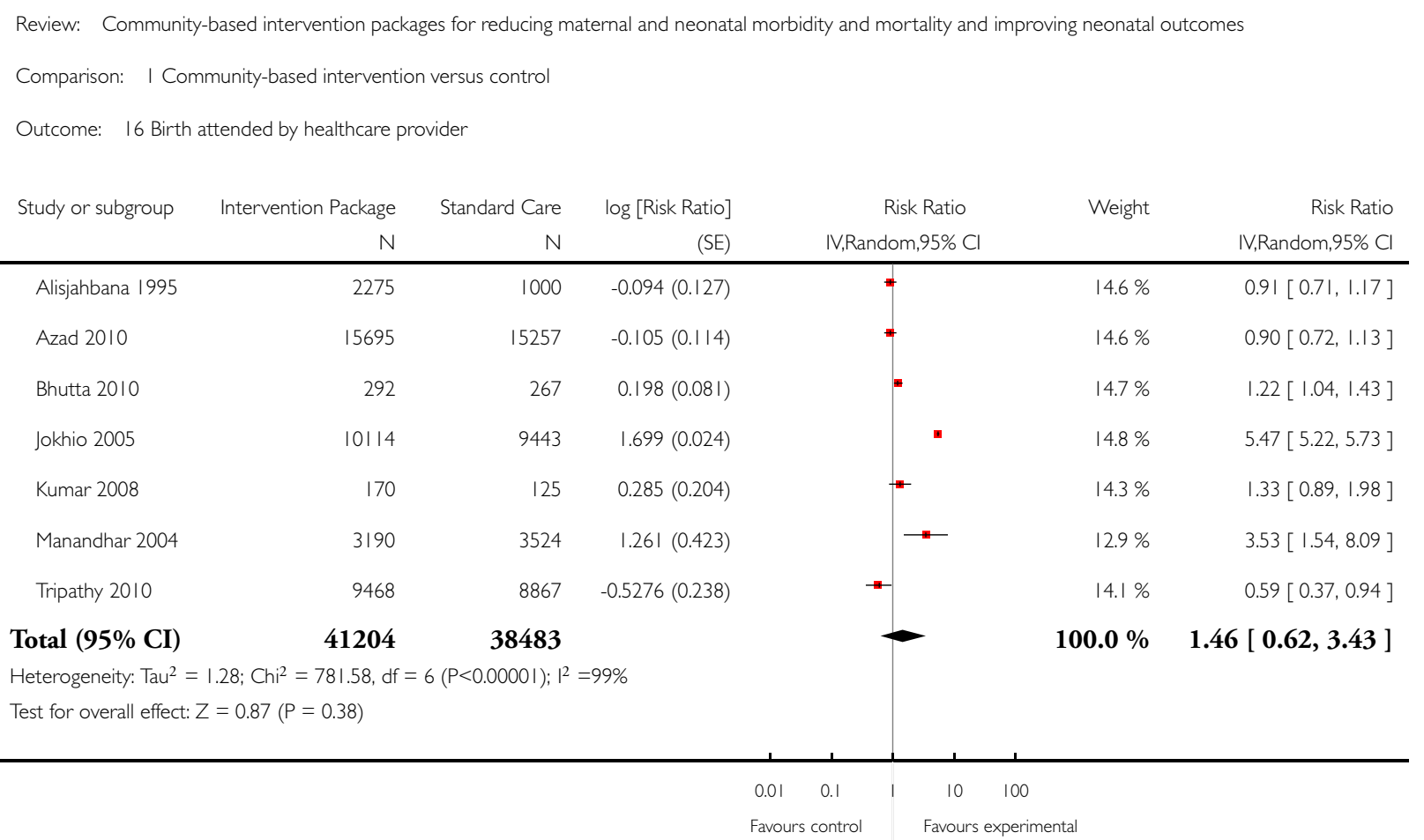




\section{Analysis I.I7. Comparison I Community-based intervention versus control, Outcome I7 Initiation of} breastfeeding within I hour of birth.

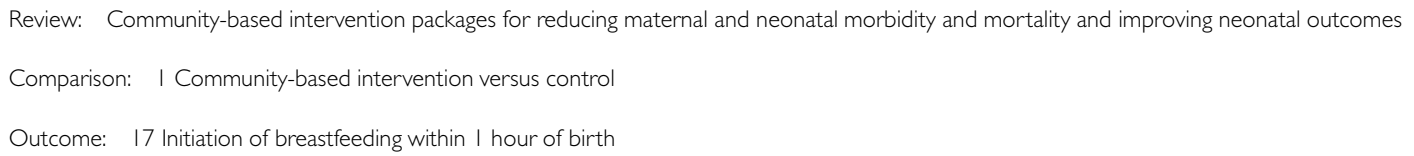

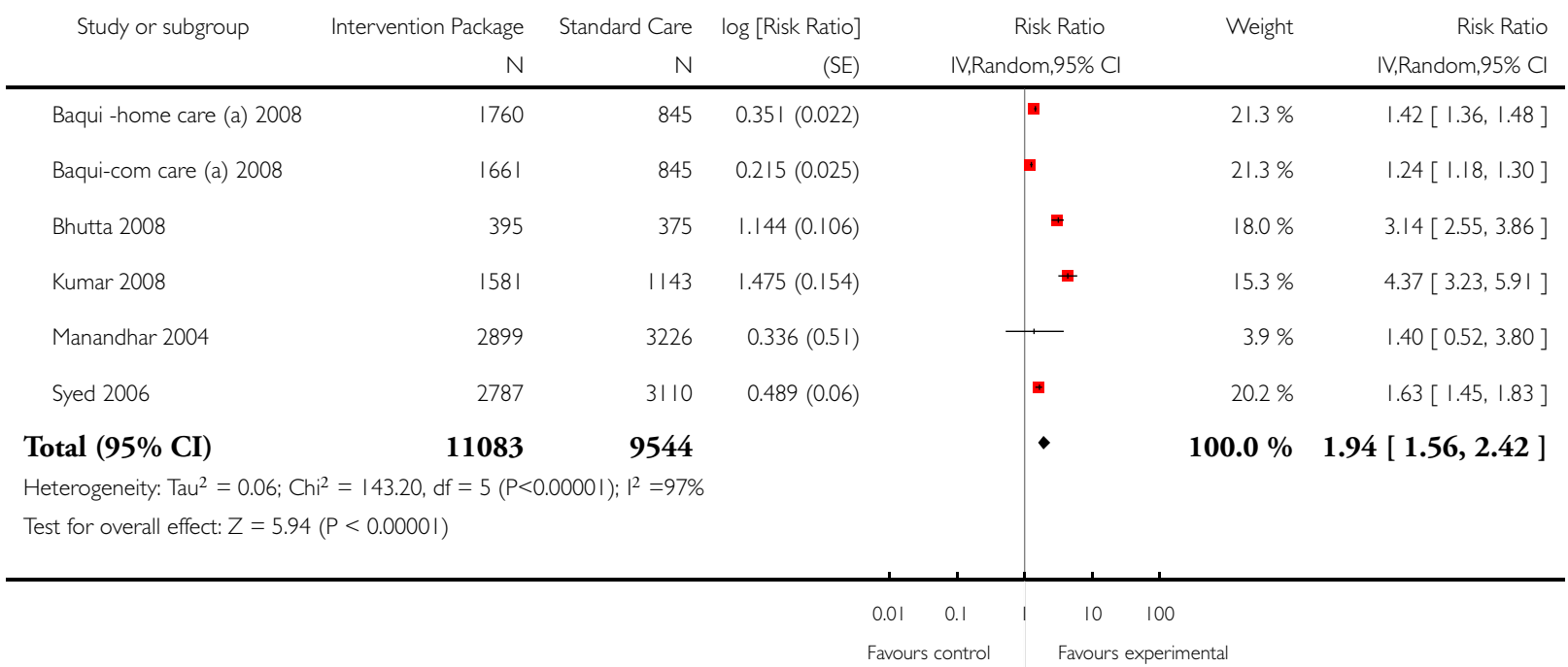




\section{Analysis I.18. Comparison I Community-based intervention versus control, Outcome 18 Healthcare seeking for maternal morbidities.}

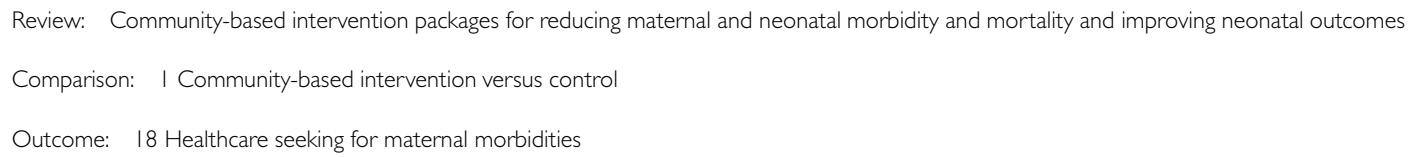

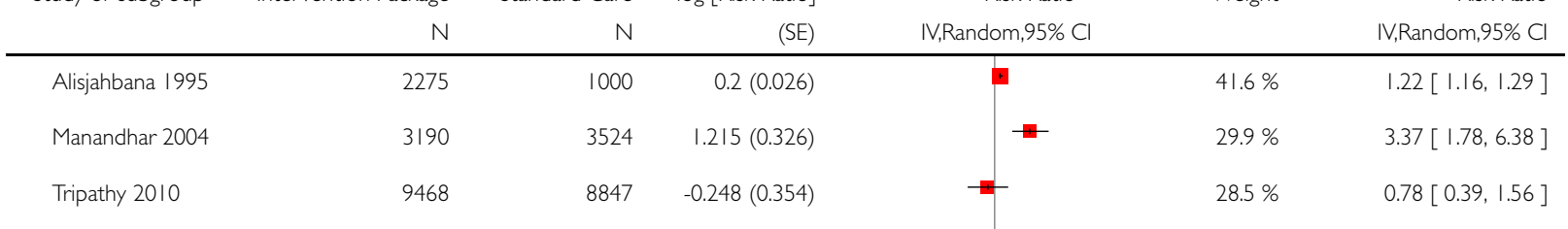

Total $(95 \% \mathrm{CI}) \quad \mathbf{1 4 9 3 3} \quad 13371$

Heterogeneity: $\mathrm{Tau}^{2}=0.27 ; \mathrm{Chi}^{2}=11.27, \mathrm{df}=2(\mathrm{P}=0.004) ;\left.\right|^{2}=82 \%$

Test for overall effect: $Z=1.12(P=0.26)$

$\begin{array}{cccc}0.01 \quad 0.1 & 1 & 10 & 100 \\ \text { Favours control } & & \text { Favours experimental }\end{array}$

\section{Analysis I.19. Comparison I Community-based intervention versus control, Outcome 19 Healthcare seeking for neonatal morbidities.}

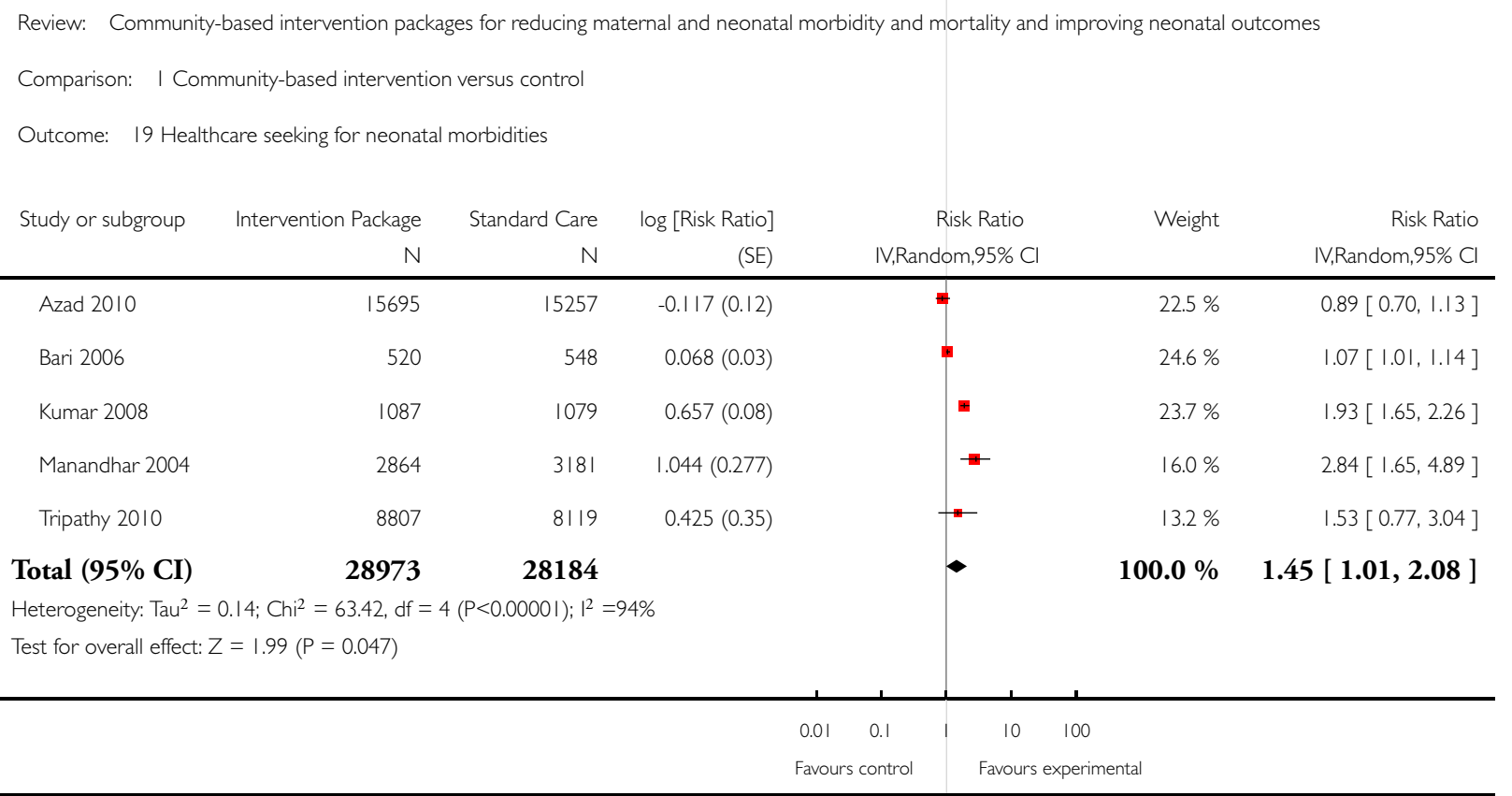

Community-based intervention packages for reducing maternal and neonatal morbidity and mortality and improving neonatal 


\section{Analysis I.20. Comparison I Community-based intervention versus control, Outcome 20 Maternal mortality: low risk of bias studies.}

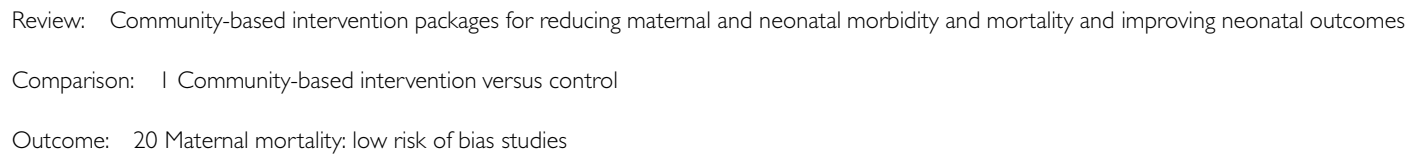

\begin{tabular}{|c|c|c|c|c|c|c|}
\hline \multirow[t]{2}{*}{ Study or subgroup } & Intervention Package & Standard Care & log [Risk Ratio] & Risk Ratio & Weight & Risk Ratio \\
\hline & $N$ & $\mathrm{~N}$ & $(\mathrm{SE})$ & IV,Fixed,95\% Cl & & IV,Fixed,95\% Cl \\
\hline Bhutta 2010 & 17613 & 16390 & $-0.094(0.296)$ & & $38.2 \%$ & $0.91[0.51,1.63]$ \\
\hline Jokhio 2005 & 10093 & 9432 & $-0.301(0.254)$ & + & $51.9 \%$ & $0.74[0.45,1.22]$ \\
\hline Kumar 2008 & 2609 & 1079 & $-0.821(0.584)$ & $\longrightarrow$ & $9.8 \%$ & $0.44[0.14,1.38]$ \\
\hline Total $(95 \% \mathrm{CI})$ & 30315 & 26901 & & 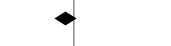 & $100.0 \%$ & $0.76[0.53,1.09]$ \\
\hline \multicolumn{7}{|c|}{ Heterogeneity: $\mathrm{Chi}^{2}=1.26, \mathrm{df}=2(\mathrm{P}=0.53) ; \mathrm{I}^{2}=0.0 \%$} \\
\hline \multicolumn{7}{|c|}{ Test for overall effect: $Z=1.49(P=0.14)$} \\
\hline \multicolumn{7}{|c|}{ Test for subgroup differences: Not applicable } \\
\hline
\end{tabular}

Favours experimental Favours control 


\section{Analysis I.2I. Comparison I Community-based intervention versus control, Outcome 2I Neonatal}

mortality: low risk of bias studies.

Review: Community-based intervention packages for reducing maternal and neonatal morbidity and mortality and improving neonatal outcomes

Comparison: I Community-based intervention versus control

Outcome: 21 Neonatal mortality: low risk of bias studies

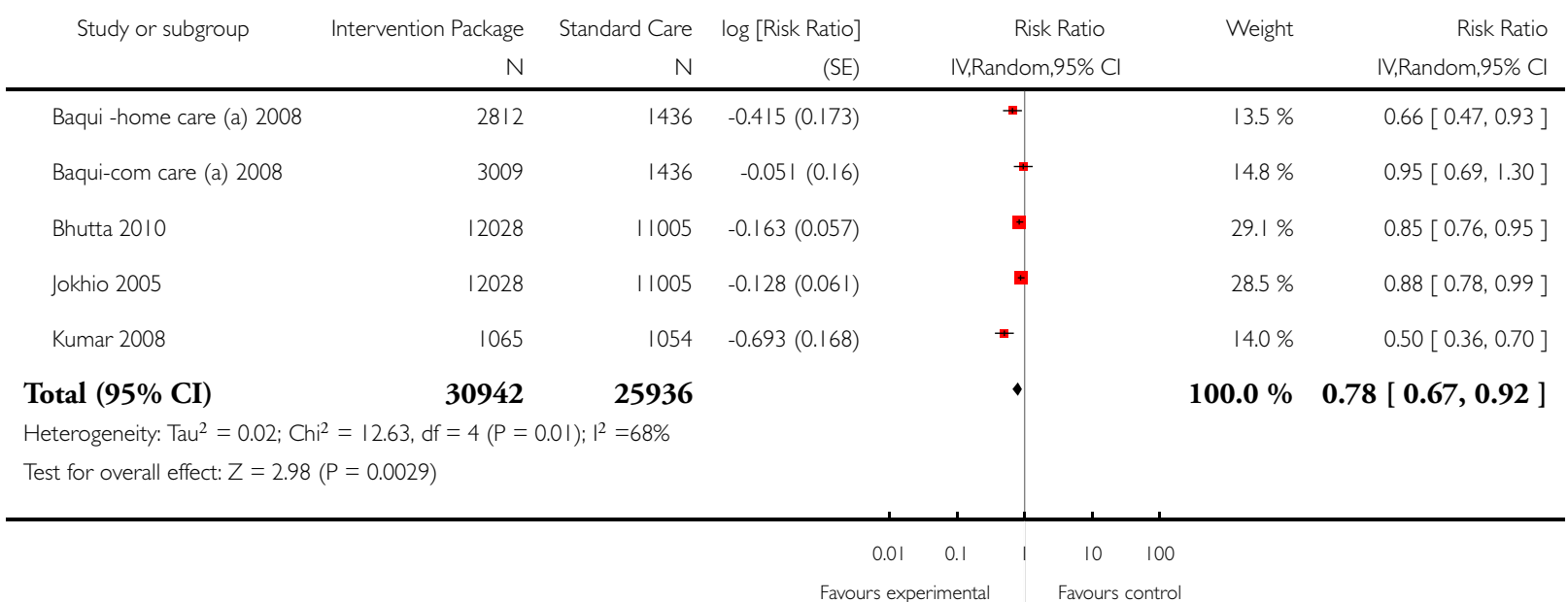




\section{Analysis I.22. Comparison I Community-based intervention versus control, Outcome 22 Perinatal} mortality: low risk of bias studies.

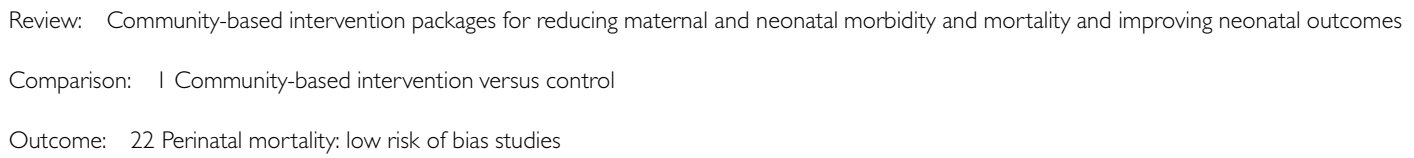

$\begin{array}{ccccc}0.01 & 0.1 & 1 & 10 & 100 \\ \text { Favours experimental } & & \text { Favours control }\end{array}$

Analysis I.23. Comparison I Community-based intervention versus control, Outcome 23 Stillbirths: low risk of bias studies.

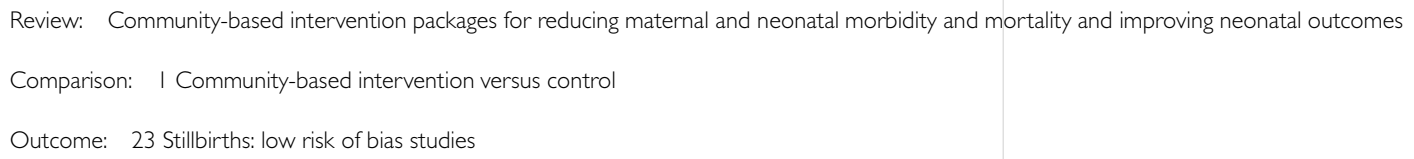

\begin{tabular}{|c|c|c|c|c|c|c|}
\hline \multirow[t]{2}{*}{ Study or subgroup } & Intervention Package & Standard Care & $\log$ [Risk Ratio] & Risk Ratio & Weight & Risk Ratio \\
\hline & $\mathrm{N}$ & $\mathrm{N}$ & (SE) & IV,Fixed,95\% Cl & & IV,Fixed,95\% Cl \\
\hline Bhutta 2010 & 12517 & 11568 & $-0.236(0.076)$ & + & $42.4 \%$ & $0.79[0.68,0.92]$ \\
\hline Jokhio 2005 & 10093 & 9432 & $-0.3567(0.069)$ & + & $51.4 \%$ & $0.70[0.61,0.80]$ \\
\hline Kumar 2008 & 1110 & 1115 & $-0.431(0.199)$ & $\rightleftarrows$ & $6.2 \%$ & $0.65[0.44,0.96]$ \\
\hline
\end{tabular}

Total (95\% CI) $23720 \quad 22115$

Heterogeneity: Chi $^{2}=1.78, d f=2(P=0.41) ;\left.\right|^{2}=0.0 \%$

Test for overall effect: $Z=6.27(P<0.00001)$

Test for subgroup differences: Not applicable

$100.0 \% \quad 0.73[0.67,0.81]$

Community-based intervention packages for reducing maternal and neonatal morbidity and mortality and improving neonatal 


\section{ADDITIONAL TABLES}

Table 1. Predominant community-based intervention package in included studies

\begin{tabular}{|c|c|c|c|c|c|c|c|c|}
\hline \multirow[b]{2}{*}{ Studies } & \multicolumn{5}{|c|}{ Predominant intervention factor in package } & \multicolumn{2}{|c|}{$\begin{array}{l}\text { Health worker characteris- } \\
\text { tics }\end{array}$} & \multirow{2}{*}{$\begin{array}{l}\text { Coverage in } \\
\text { experimen- } \\
\text { tal group (n) }\end{array}$} \\
\hline & $\begin{array}{l}\text { Commu- } \\
\text { nity support } \\
\text { groups/ } \\
\text { com- } \\
\text { munity mo- } \\
\text { bilisation) }\end{array}$ & $\begin{array}{l}\text { TBA train- } \\
\text { ing }\end{array}$ & $\begin{array}{l}\text { Home visi- } \\
\text { tation }\end{array}$ & $\begin{array}{l}\text { Home based } \\
\text { neonatal } \\
\text { care } \\
\text { and } \\
\text { treatment }\end{array}$ & $\begin{array}{l}\text { Health edu- } \\
\text { cation } \\
\text { to mothers } \\
\text { (one-to-one } \\
\text { counselling) }\end{array}$ & $\begin{array}{l}\text { Type of } \\
\text { health } \\
\text { worker } \\
\text { involved }\end{array}$ & $\begin{array}{l}\text { Training du- } \\
\text { ration }\end{array}$ & \\
\hline $\begin{array}{l}\text { Alisjahbana } \\
1995\end{array}$ & & Yes & $\begin{array}{l}\text { Yes } \\
(\mathrm{AN}+\mathrm{IP})\end{array}$ & & & TBA & & $\begin{array}{l}2275 \\
\text { women }\end{array}$ \\
\hline Azad 2010 & Yes & & & & & CHW TBA & 5 sessions & $\begin{array}{l}15,695 \\
\text { births } \\
\text { and } 15,153 \\
\text { live births }\end{array}$ \\
\hline Bang 1999 & & & $\begin{array}{l}\text { Yes } \\
(\mathrm{AN}+\mathrm{PN})\end{array}$ & Yes & Yes & $\begin{array}{l}\text { CHW } \\
\text { TBA }\end{array}$ & 3 days & $\begin{array}{l}1108 \text { live } \\
\text { births }\end{array}$ \\
\hline $\begin{array}{l}\text { Baqui- } \\
\text { CARE } \\
\text { INDIA } \\
2008\end{array}$ & Yes & & $\begin{array}{l}\text { Yes } \\
(\mathrm{AN}+\mathrm{PN})\end{array}$ & & & $\begin{array}{l}\text { CHW } \\
\text { ANM }\end{array}$ & 6 days & $\begin{array}{l}7812 \\
\text { women }\end{array}$ \\
\hline $\begin{array}{l}\text { Baqui } \\
\text {-home care } \\
\text { (a) } 2008\end{array}$ & Yes & & $\begin{array}{l}\text { Yes } \\
(\mathrm{AN}+\mathrm{PN})\end{array}$ & Yes & & CHW & 6 weeks & $\begin{array}{l}1760 \text { total } \\
\text { births }\end{array}$ \\
\hline $\begin{array}{l}\text { Baqui- } \\
\text { com care (a) } \\
2008\end{array}$ & Yes & & $\begin{array}{l}\text { Yes } \\
(\mathrm{AN}+\mathrm{PN})\end{array}$ & & & CHW & 6 weeks & $\begin{array}{l}1661 \text { total } \\
\text { births }\end{array}$ \\
\hline Bari 2006 & & & $\begin{array}{l}\text { Yes } \\
(\mathrm{AN}+\mathrm{PN})\end{array}$ & & & CHW & & $\begin{array}{l}794 \text { sick } \\
\text { newborns }\end{array}$ \\
\hline Bhutta 2008 & Yes & & $\begin{array}{l}\text { Yes } \\
(\mathrm{AN}+\mathrm{PN})\end{array}$ & & & $\begin{array}{l}\text { CHW } \\
\text { TBA }\end{array}$ & $\begin{array}{l}6 \text { days } \\
3 \text { days }\end{array}$ & $\begin{array}{l}2672 \\
\text { total births } \\
\text { and } 2496 \\
\text { live births }\end{array}$ \\
\hline
\end{tabular}

Community-based intervention packages for reducing maternal and neonatal morbidity and mortality and improving neonatal 
Table 1. Predominant community-based intervention package in included studies (Continued)

\begin{tabular}{|c|c|c|c|c|c|c|c|}
\hline Bhutta 2010 & Yes & & $\begin{array}{l}\text { Yes } \\
(\mathrm{AN}+\mathrm{PN})\end{array}$ & & $\begin{array}{l}\text { CHW } \\
\text { TBA }\end{array}$ & $\begin{array}{l}6 \text { days } \\
3 \text { days }\end{array}$ & $\begin{array}{l}12,517 \text { total } \\
\text { births } \\
\text { and } 12,028 \\
\text { live births }\end{array}$ \\
\hline Foord 1995 & & Yes & $\begin{array}{l}\text { Yes } \\
(\mathrm{AN}+\mathrm{IP})\end{array}$ & & TBA & 4 weeks & $\begin{array}{l}794 \text { preg- } \\
\text { nant women }\end{array}$ \\
\hline $\begin{array}{l}\text { Greenwood } \\
1990\end{array}$ & & Yes & $\begin{array}{l}\text { Yes } \\
(\mathrm{AN}+\mathrm{IP})\end{array}$ & & TBA & 6 weeks & $\begin{array}{l}1208 \text { preg- } \\
\text { nant women }\end{array}$ \\
\hline Jokhio 2005 & & Yes & $\begin{array}{l}\text { Yes } \\
(\mathrm{AN}+\mathrm{IP})\end{array}$ & & TBA & 3 days & $\begin{array}{l}10,093 \\
\text { women }\end{array}$ \\
\hline $\begin{array}{l}\text { Kafatos } \\
1991\end{array}$ & & & $\begin{array}{l}\text { Yes }(\mathrm{AN}+ \\
\mathrm{PN})\end{array}$ & Yes & $\mathrm{CHN}$ & & 300 women \\
\hline Kumar 2008 & Yes & & $\begin{array}{l}\text { Yes }(\mathrm{AN}+ \\
\mathrm{PN})\end{array}$ & & CHW & 7 days & $\begin{array}{l}1110 \text { births } \\
\text { and } 1065 \\
\text { live births } \\
\text { (thermospot } \\
\text { arm) }\end{array}$ \\
\hline $\begin{array}{l}\text { Manandhar } \\
2004\end{array}$ & Yes & & & & CHW & & $\begin{array}{l}3190 \text { preg- } \\
\text { nancies, } \\
2972 \text { births } \\
\text { and } 2899 \\
\text { live births }\end{array}$ \\
\hline $\begin{array}{l}\text { Ronsmans } \\
1997\end{array}$ & & Yes & $\begin{array}{l}\text { Yes } \\
(\mathrm{AN}+\mathrm{IP})\end{array}$ & & CHW & & $\begin{array}{l}20,360 \text { live } \\
\text { births }\end{array}$ \\
\hline $\begin{array}{l}\text { Srinivasan } \\
1995\end{array}$ & & & $\begin{array}{l}\text { Yes } \\
(\mathrm{AN})\end{array}$ & & $\mathrm{CHN}$ & & $\begin{array}{l}573 \\
\text { pregnancies }\end{array}$ \\
\hline Syed 2006 & & & & & CHW & 6 days & $\begin{array}{l}3110 \\
\text { women }\end{array}$ \\
\hline $\begin{array}{l}\text { Tripathy } \\
2010\end{array}$ & Yes & & & & $\mathrm{CHW}$ & 7 days & $\begin{array}{l}9770 \text { births } \\
\text { and } 9469 \\
\text { live births }\end{array}$ \\
\hline
\end{tabular}

AN: antenatal

ANM: ancillary nurse midwife

CHW: cComunity health worker (we used this term for all kinds of CHWs that include lady health worker, female health volunteer, maternal and child health worker, anganwadi worker, etc.)

$\mathrm{CHN}$ : community health nurse

IP: intrapartum

PN: postnatal 


\section{A P P E N D I C E S}

\section{Appendix I. Search Strategies and Search Results}

\section{Last Search Date: 12 January 2010}

\section{Google Scholar}

["community-based nutrition program" OR "community-based primary health care" OR "community-based program" OR "community-based perinatal care" OR "community-based neonatal care" OR "community health" OR "health worker" OR "community involvement" OR "community participation” OR “community program” OR package OR "behaviour change"] AND [pregnancy OR women OR infant OR neonate OR perinatal OR newborn]

Search results: 16,800

Google

"community-based nutrition programs" OR "community -based primary health care" OR "community-based programs" OR "community health" OR "community health workers" OR "village health workers" OR "community involvement" OR "community participation" OR "community programs"

Search results: 16,100

FOR IDEAS, BLDS and World Bank JOLIS, the individual keywords were added into the search engines and search results were screened. We cumulatively added hits for each searched keyword and added into our total number of hits.

\section{H I S T O R Y}

Protocol first published: Issue 2, 2009

Review first published: Issue 11, 2010

Date Event Description

9 May 2009 Amended The Background section has been expanded and additional secondary outcomes identified. The name of funding agency for the review has been added. Additional databases to be searched have also been added

\section{CONTRIBUTIONS OFAUTHORS}

The review was conducted by Zohra Lassi (ZSL) under the guidance of Dr Zulfiqar A Bhutta (ZAB). The draft protocol was written by Dr Batool A Haider, who also designed the eligibility and the data extraction forms. Dr Batool A Haider also took part in initial stages of review and assisted in data extraction.

\section{DECLARATIONSOF INTEREST}

Dr Zulfiqar A Bhutta is the principal investigator of two included studies evaluating community care perinatal care package in Pakistan (Bhutta 2008; Bhutta 2010) but he was not involved in assessing these trials for inclusion in this review, assessing trial quality, or data extraction. These tasks were carried out by other members of the review team who were not involved with the original studies (Zohra Lassi and Batool Haider). 


\section{SOURCES OF SUPPORT}

\section{Internal sources}

- The Aga Khan University, Pakistan.

\section{External sources}

- International Initiative for Impact Evaluation (3ie), Global Development Network, India.

Funding for this review was provided by a grant from the International Initiative for Impact Evaluation

\section{DIFFERENCES BETWEEN PROTOCOLANDREVIEW}

We added neonatal mortality under primary outcomes of the review, as neonatal outcomes seemed unclear.

\section{NDEX TERMS}

\section{Medical Subject Headings (MeSH)}

*Infant Mortality; *Maternal Mortality; *Perinatal Mortality; Cause of Death; Community Health Services [ ${ }^{*}$ organization \& administration; statistics \& numerical data]; Infant, Newborn; Maternal Health Services [organization \& administration; statistics \& numerical data]; Morbidity; Randomized Controlled Trials as Topic

\section{MeSH check words}

Female; Humans; Pregnancy 